\title{
The Effects of Composition on Properties in an 11-Component Nuclear Waste Glass System
}

\author{
L. A. Chick \\ G. F. Piepel \\ G. B. Mellinger \\ R. P. May \\ W. J. Gray \\ C. Q. Buckwalter
}

September 1981

Prepared for the U.S. Department of Energy under Contract DE-AC06-76RLO 1830

Pacific Northwest Laboratory Operated for the U.S. Department of Energy by Battelle Memorial Institute 
NOTICE

This report was prepared as an account of work sponsored by the United States Government. Neither the United States nor the Department of Energy. nor any of their employees, nor any of their contractors, subcontractors. or their employees, makes any warranty. express or implied. or assumes any legal liability or responsibility for the accuracy. completeness or usefulness of any information, apparatus, product or process disclosed, or represents that its use would not infringe privately owned rights.

The views. opinions and conclusions contained in this report are those of the contractor and do not necessarily represent those of the United States Government or the United States Department of Energy.

\author{
PACIFIC NORTHWEST LABORATORY \\ operated by \\ BATTELLE \\ for the \\ UNITED STATES DEPARTMENT OF ENERGY \\ Under Contract DE-AC06-76RLO 1830
}
Printed in the United States of America
Available from
National Technical Information Service
United States Department of Commerce
5285 Port Royal Road
Springfield. Virginia 22151

Price: Printed Copy $\$$

$\therefore$ Microfiche $\$ 3.00$

NTIS

-Pages Selling Price

$\begin{array}{ll}001-025 & \$ 4.00 \\ 026-050 & \$ 4.50 \\ 051-075 & \$ 5.25 \\ 076-100 & \$ 6.00 \\ 101-125 & \$ 6.50 \\ 126-150 & \$ 7.25 \\ 151-175 & \$ 8.00 \\ 176-200 & \$ 9.00 \\ 201-225 & \$ 9.25 \\ 226-250 & \$ 9.50 \\ 251-275 & \$ 10.75 \\ 276-300 & \$ 11.00\end{array}$


THE EFFECTS OF COMPOSITION ON PROPERTIES

IN AN 11-COMPONENT NUCLEAR WASTE GLASS SYSTEM
L. A. Chick
G. F. Piepe]
G. B. Mellinger
R. P. May
W. J. Gray
C. Q. Buckwalter

September 1981

Prepared for the U.S. Department of Energy under Contract DE-AC06-76RLO 1830

Pacific Northwest Laboratory

Richland, Washington 99352 
4
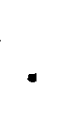

$\ddots$

.

.

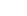




\section{ACKNOWLEDGMENTS}

Many capable people were indispensable in conducting this study and preparing the report. The authors are grateful to them for their fine efforts.

J. N. Diven and C. A. Lopresti assisted in writing the computer codes for the experimental design and data analysis. F. T. Hara coordinated the chemical analys is of glass samples and leach solutions. B. 0 . Barnes and F. D. Hobbs conducted the volatility measurements. C. A. Church, K. D. Richardson, and J. W. MacPherson prepared the glass samples and performed the weight loss leaching and viscosity measurements. K. R. Welsch assisted with the static leach testing. G. D. Maupin helped with the x-ray diffraction. Professor M. Tomozawa of Rensselaer Polytechic Institute conducted the studies of phase separation. S. K. Edler provided text editing and production coordination. 
4
.

.

$\ddots$

.

.

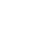

• 


\section{ABSTRACT}

Ninety simplified nuclear waste glass compositions within an 11-component oxide composition matrix were tested for crystallinity, viscosity, volatility, and chemical durability. Empirical models of property response as a function of glass composition were developed using statistical experimental design and modeling techniques.

A new statistical technique was developed to calculate the effects of oxide components on each property. Independent melts were used to check the prediction accuracy of the models. 


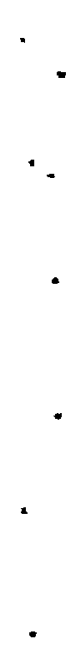




\section{SUMMARY AND CONCLUSIONS}

Empirical prediction models were developed to investigate the effect of composition on the properties of glass-like nuclear waste immobilization materials. These materials are more chemically complex and variable than glass systems normally studied in industry and the scientific literature. The statistical methods used to produce the empirical property models are described, and a new statistical technique to investigate the effect of composition on the properties is also presented in this report. The objective of this study was to evaluate and refine these study methods by applying them to a somewhat restricted glass composition matrix.

Sixty-seven extreme compositions and the "overall average" (centroid) composition comprised the test melts used for modeling, and 22 less extreme compositions were used to test the predictive capabilities of the models. Replicates were included to determine experimental error. Quadratic polynomial approximation models were fit to the property data to yield equations expressing the property response as a function of melt composition. These prediction equations were used to produce plots that show the effects of the composition changes on the properties tested.

Useful models were developed for predicting crystallinity, viscosity, volatility, and weight loss-type chemical durability of compositions falling within the studied region. Figure 1 presents a qualitative summary of the major component effects on the successfully modeled properties.

Modeling results for heat of vaporization and static (solution analysistype) chemical durability were less than satisfactory. Problems with these models were related to large experimental errors produced by performing the tests over a long time period and to overly restrictive limits placed on compositional variability in the experimental design. Suggestions for improvement are presented.

Investigations of crystallinity revealed that chromium, iron, zinc, and nickel tend to produce spinel crystals in rapidly cooled melts; but increasing the levels of sodium, calcium, boron, or silicon tends to reduce spinel formation. Spinel crystals form at high temperature and were found to increase 


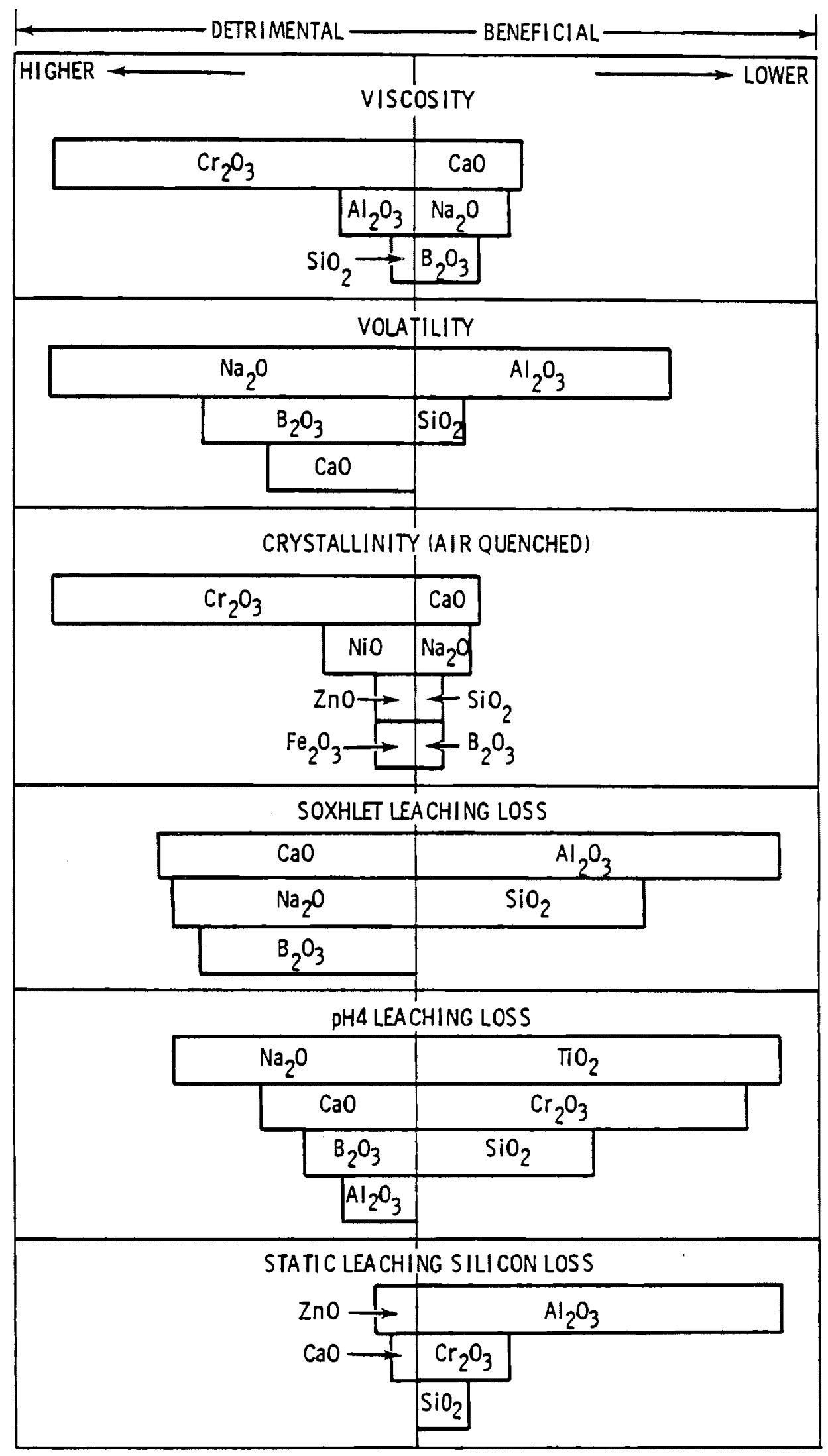

FIGURE 1. Qualitative Summary of Major Component Effects 
viscosity and decrease volatility. Deliberate slow cooling of the melts of ten produced silicates, aluminates, titanates, and some chrome spinels. Boron and silicon act to inhibit formation of these crystalline species.

Limited study of glass-in-glass phase separation showed that probabiy all materials within the study region were phase separated. The continuous matrix phase is the less chemically durable, indicating probable enrichment of silica in the dispersed droplet phase.

Chromium, aluminum, and silicon were found to increase viscosity. The surprisingly strong effect of chromium is probably due to its tendency to cause crystal formation even at high temperatures in the melt. Boron, calcium, and sodium were found to reduce viscosity.

$\mathrm{Na}_{2} \mathrm{O}$ and $\mathrm{B}_{2} \mathrm{O}_{3}$ were found to volatilize in equimolar quantities from melts containing them in a range of ratios, which indicates formation of a volatile compound of composition $\left(\mathrm{NaBO}_{2}\right)_{x}$. Chromium, in minor quantity, was the only other component found to volatilize from the melts.

Three separate tests were used to investigate chemical durability. Aluminum was found to have a very strong beneficial effect in the static solution analysis test. Its effect was so large that it obscured the effects of other components. Silicon had a less beneficial effect, and calcium and sodium had detrimental effects. Boron had a small positive effect in the static test and detrimental effects in weight loss tests. Under acid conditions, the effect of aluminum was detrimental to glass durability; but in the same test, the effects of chromium, titanium, and silicon were beneficial.

Several interesting correlations were found to exist between properties. For instance, a strong positive correlation was found between volatility and Soxhlet leach rate; and viscosity and volatility were found to be negatively correlated.

A strong positive correlation was found between resulting solution $\mathrm{pH}$ and elemental release in the static leaching test. This result supports the conclusion that the glasses studied here corrode by the two-stage process (ion exchange and hydroxyl attack) established in the literature for corrosion of simpler soda-lime-silica glasses. 
. 


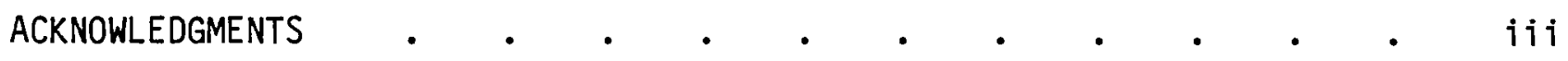

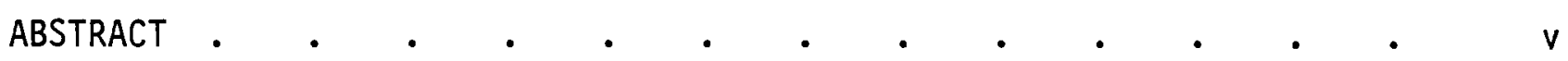

SUMMARY AND CONCLUSIONS

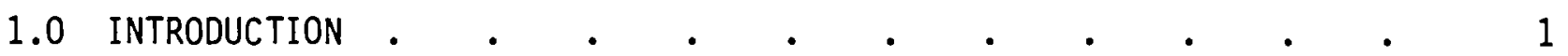

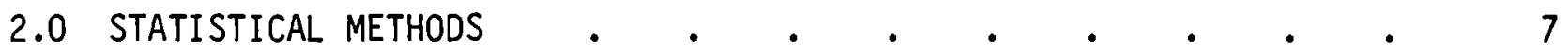

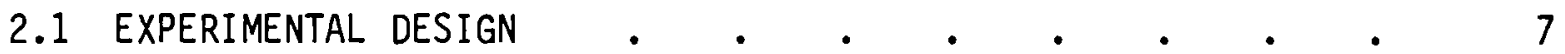

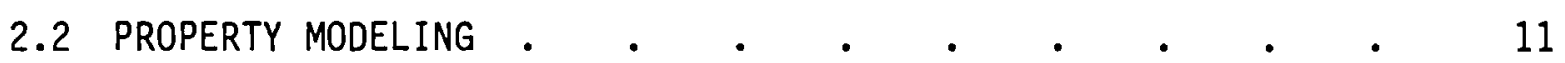

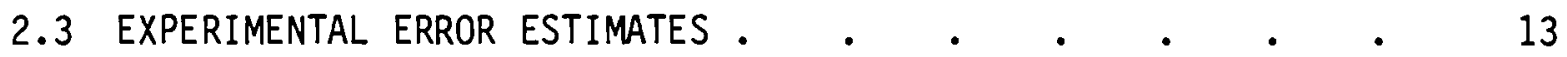

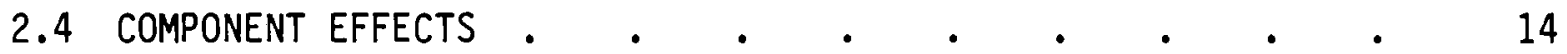

2.5 COMPARISON OF OBSERVED VERSUS PREDICTED
COMPONENT TOTAL EFFECTS . $. . \quad . \quad . \quad . \quad . \quad . \quad 18$

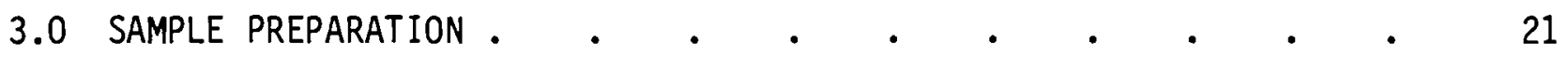

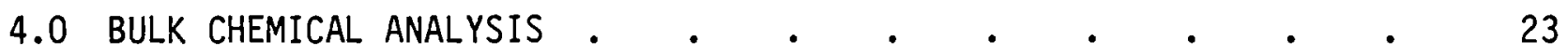

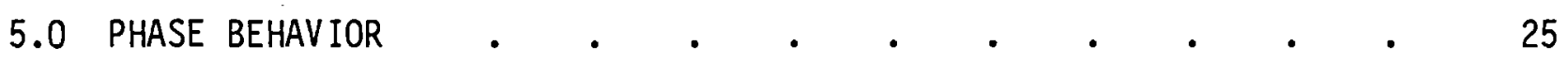

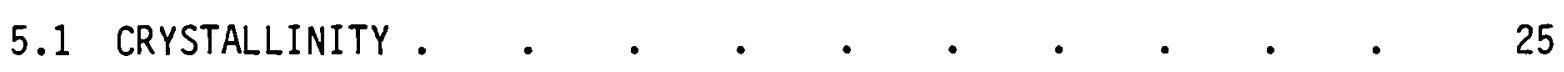

5.1.1 X-Ray Diffraction Procedure . $\quad . \quad$ - $\quad . \quad$. $\quad 25$

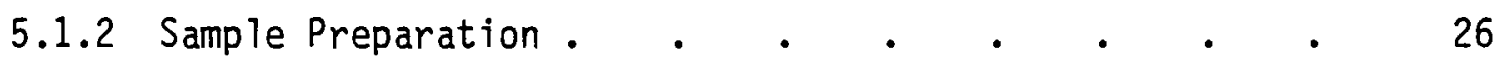

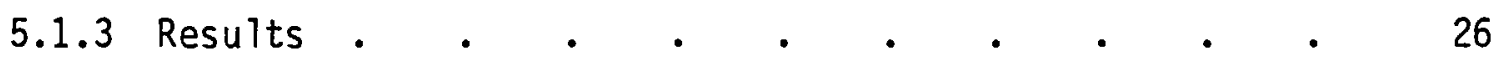

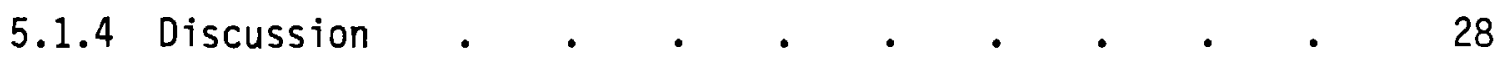

5.2 GLASS-IN-GLASS PHASE SEPARATION $\quad$. $\quad . \quad$. $\quad . \quad$. $\quad 30$

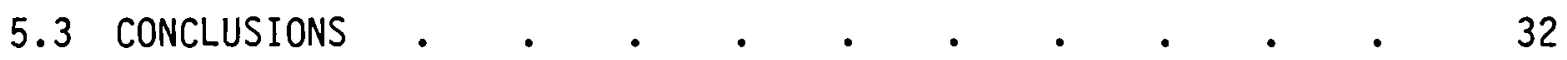

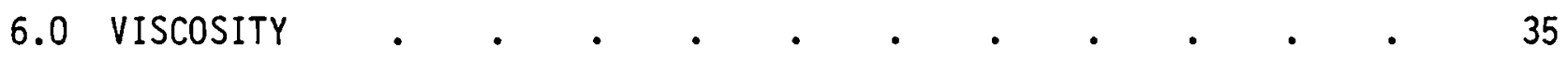

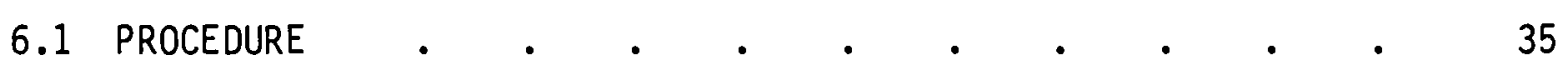

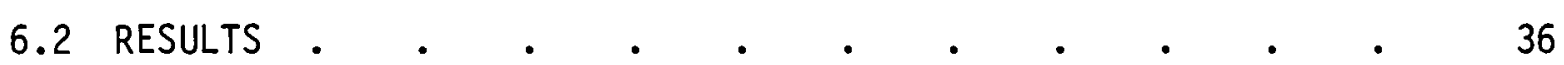




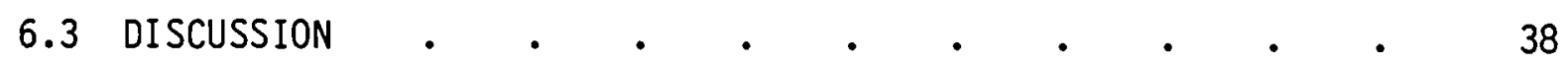

6.4 CONCLUSIONS $\quad . \quad \ldots \quad$.

7.0 VOLATILITY $\quad . \quad$ • $\quad$ •

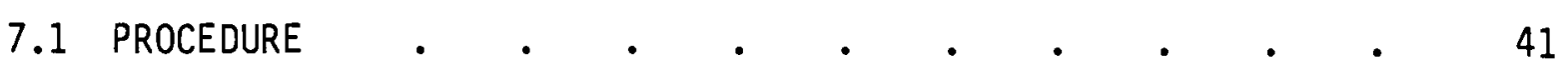

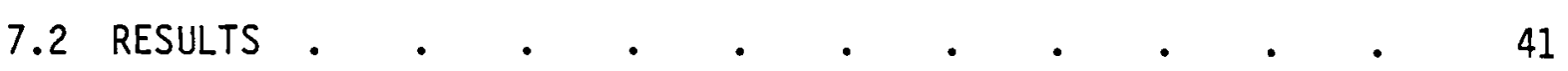

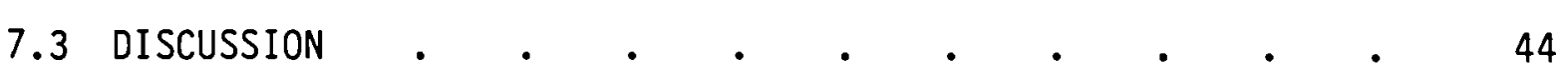

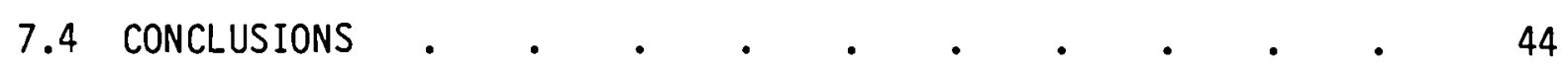

8.0 CHEMICAL DURABILITY

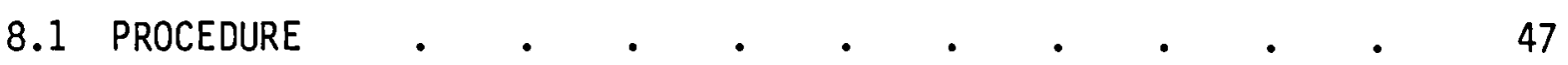

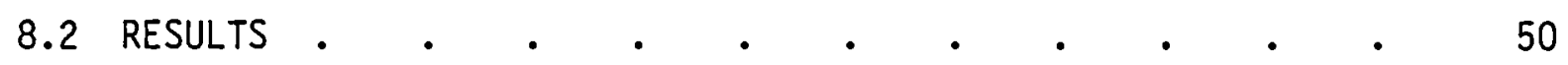

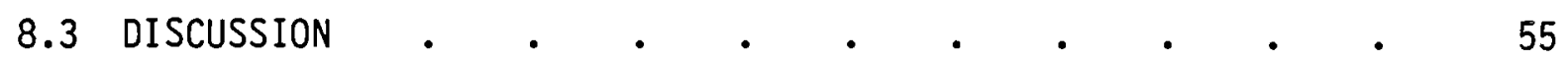

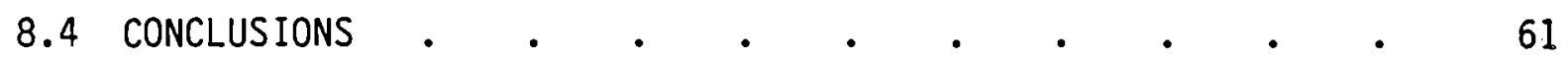

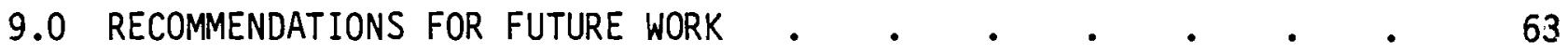

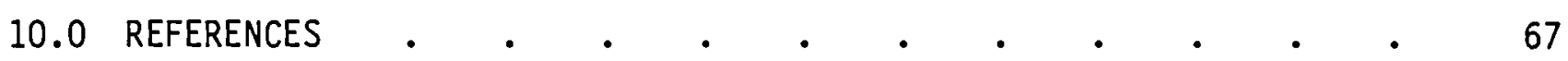

APPENDIX A - DETAILS OF STATISTICAL TECHNIQUES $\quad$ • $\quad$ • $\quad$ • $\quad$ • A.1

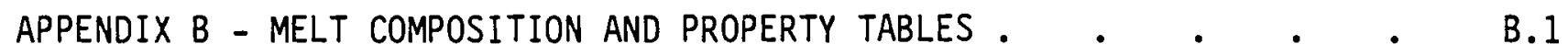

APPENDIX C - ANALYSIS OF VARIANCE TABLES AND PSEUDO-

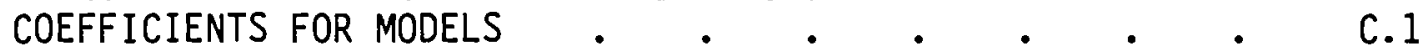




\section{FIGURES}

1 Qualitative Summary of Major Component Effects . . . . viii

2 Elements in High-Level Wastes and Waste Glasses . . . . 2

3 Ternary Diagram of Nuclear Waste Compositions . . . . 3

4 Ternary Diagram of Waste Glass Composition Regions . . . 4

5 Hypothetical Three-Component Example . . • . . . . 9

$6 \quad$ Hypothetical Three-Component Example Showing Directions With in Experimental Region Along Which Component

Effects are Calculated. . . . . . . . . 16

7 Hypothetical Component Effects Plot . . . • . . 17

8 Effects of Components on Air-Quenched Crystallinity . . . 29

9 Effects of Components on Slow-Cooled Crystallinity . . . 30

10 TEM Photographs of Glass-in-Glass Separation
for Samples 29,33 , and 34 . . . . . . . . 31

11 Schematic of Viscosity Measurement Apparatus and Spindle/Crucible Combinations . . . . . . . 36

12 Comparison of Measured Viscosity of Standard Glass

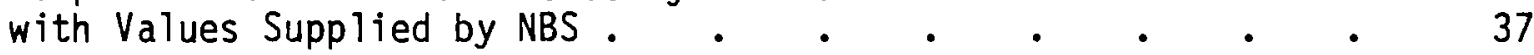

13 Effects of Components on Viscosity at $1250^{\circ} \mathrm{C}$. . . . . 38

14 Effects of Components on Volatility at $1300^{\circ} \mathrm{C}$ for $3 \mathrm{~h} \quad . \quad$. 43

15 Volatility Weight Loss Versus Time . . . • . . . 45

16 Static Leaching Procedure . . . . . . . . . 48

17 Effects of Components on Soxhlet Leaching Weight Loss . $\quad 52$

18 Effects of Components on pH 4 Leaching Weight Loss . . . 54

19 Sample $27-90^{\circ} \mathrm{C}$ Static Leaching . . • . . . 55

20 Sample $56-900^{\circ} \mathrm{C}$ Static Leaching . . . . . . 56

21 Sample $42-90^{\circ} \mathrm{C}$ Static Leaching . . . . . . $\quad$ • 57 
22 Silicon Release Versus Resulting pH for Static Leaching of a Variety of Glass Compositions

23 Mechanisms of Glass Corrosion for a Soda-Silica Glass 


\section{$\underline{\text { TABLES }}$}

1 Experimental Region Constraints . 1 . $\quad$. $\quad$. $\quad$. $\quad$. 8

2 Estimates of Experimental Error . . . . . . . . . 14

3 Oxide Components and Batch Chemicals . . . . . . . 21

4 Comparison of Observed and Predicted Total Effects

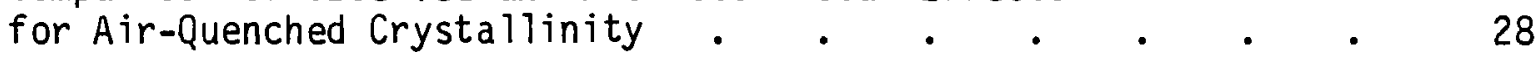

5 Comparison of Observed and Predicted Total Effects

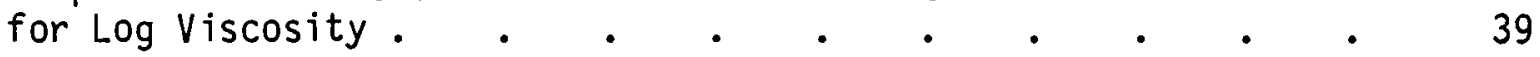

6 Comparison of Observed and Predicted Total Effects

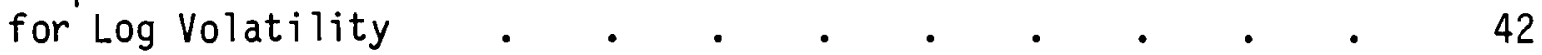

7 Surmary of Weight Loss Leaching Tests . . . . . . . . 47

8 Comparison of Observed and Predicted

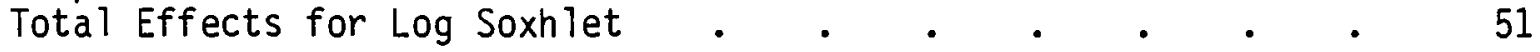

9 Comparison of Observed and Predicted

Total Effects for $\log \mathrm{pH} 4$. $\quad . \quad$. $\quad . \quad . \quad . \quad 53$

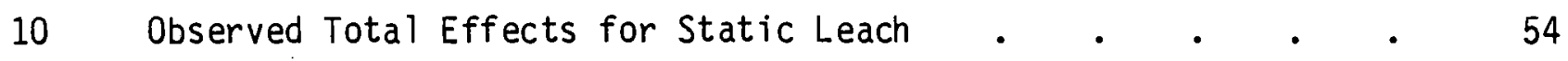

A.1 Analysis of Variance (AOV) Table . . . . . . . . . A.2

A.2 The Student-t Probability Function . . . . . . . A.10

A.3 95th Percentile Values $(0.05$ Levels), Fo.95,
for the F Distribution . $\quad . \quad . \quad . \quad . \quad . \quad$. $\quad$ A.11

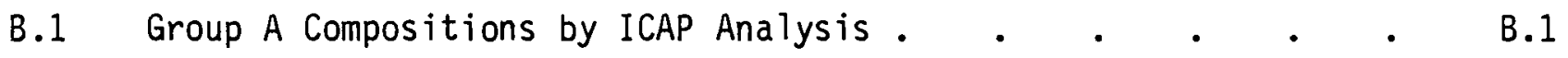

B.2 Group B Compositions by ICAP Analysis . . . . . . . . B.2

B.3 Group C Compositions by ICAP Analysis . . . . . . . . . B.3

B.4 Group D Compositions by ICAP Analysis . . . . . . . . . . B.4

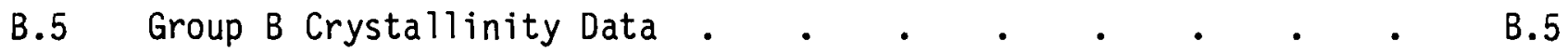

B.6 Group C Crystallinity Data . . . . . . . . . . . B.6

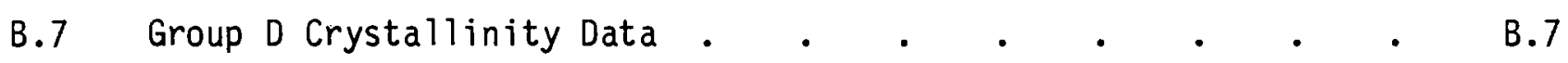

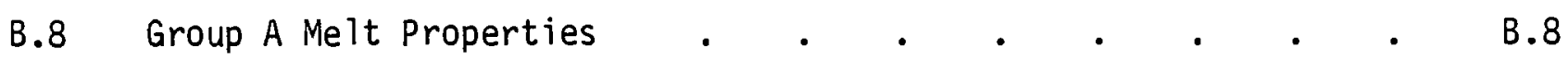




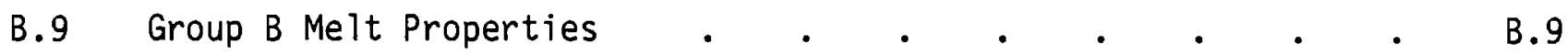

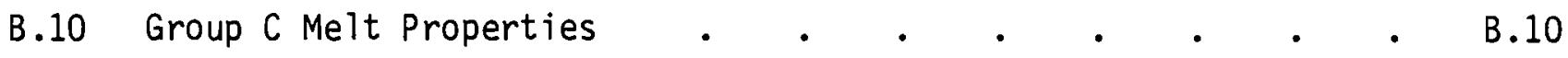

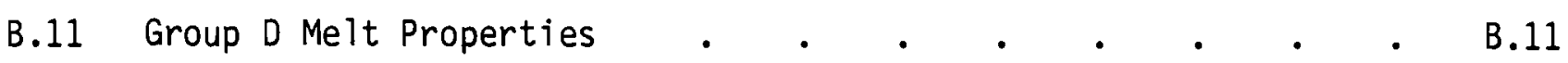

B.12 Group B Weight Loss Leaching Data . • . • • • • • B.12

B.13 Group C Weight Loss Leaching Data . . . . • • • B.13

B.14 Group D Weight Loss Leaching Data . . . . . • • • B.14

B.15 Group B Static Solution Analysis Leaching Data . • • • • B.15

B.16 Group C Static Solution Analys is Leaching Data . • • • • B.16

B.17 Group D Static Solution Analysis Leaching Data . • • • B.17

C.1 Analysis of Variance (AOV) and Pseudo-Coefficients

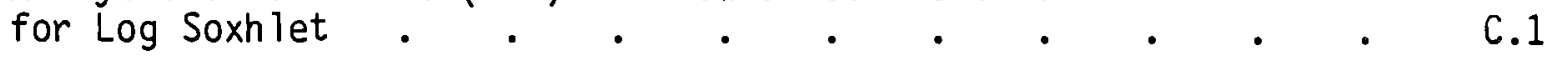

C.2 Analysis of Variance (AOV) and Pseudo-Coefficients

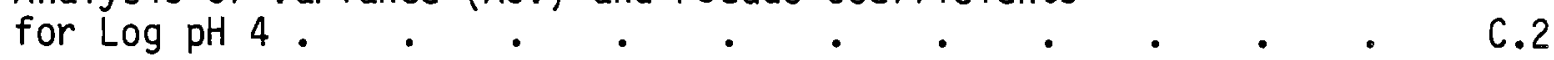

C.3. Analys is of $V$ ariance (AOV) and Pseudo-Coefficients

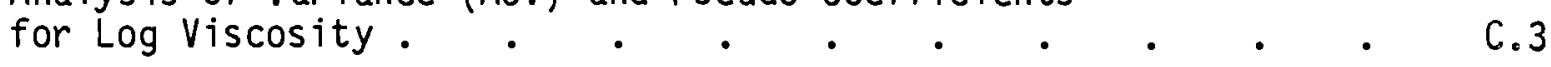

C.4 Analysis of Variance (AOV) and Pseudo-Coefficients for Log Volatility

C.5 Analysis of Variance (AOV) and Pseudo-Coefficients for Air-Quenched Crystallinity . . . C.5 


\subsection{INTRUDUCTION}

A wide variety of nuclear waste compositions are considered candidates for immobilization in glass, including high-level commercial wastes from reprocessing of nuclear fuels, high-level defense wastes from processing of plutonium, and low-level transuranic (TRU) wastes. These wastes are chemically complex, containing up to 55 elements (see Figure 2) and vary widely in composition (see Figure 3 ). Figure 3 is a ternary plot of waste composition, plotted according to the respective content of three types of glass components: network formers, modifiers, and intermediates.

Network formers include $\mathrm{SiO}_{2}, \mathrm{~B}_{2} \mathrm{O}_{3}, \mathrm{Al}_{2} \mathrm{O}_{3}$, and $\mathrm{P}_{2} \mathrm{O}_{5}$ and comprise the basic structural network of glasses. Modifiers, which include alkaline and alkalineearth oxides, tend to weaken the structural network and lower the melt viscosity, thus allowing processing at reasonable temperatures. Intermediates, which include all other oxides, can enter the network as formers or modifiers depending on the overall composition and processing conditions.

Most of these assemblages of nuclear waste oxides will not form glasses by themselves; they must be combined with nonradioactive mixtures of oxides (called frits) and melted to form acceptable glasses. The waste oxides usually comprise 10 to $30 \%$ of the total oxides in the glass, leaving 70 to $90 \%$ of the glass composition to the choice of the glassmaker; thus, the glassmaker can tailor the properties of the final glass product by adjusting the frit composition.

Three laboratories in the United States--Savannah River Laboratory (SRL), Pacific Northwest Laboratory (PNL), ${ }^{(a)}$ and Rockwell Hanford Operations (RHO)-have performed extensive investigations of nuclear waste glass formulation. Each laboratory, while working with a similar variety of nuclear waste compositions, has tended to formulate glasses lying within its own specific compositional region on the ternary plot in Figure 4 . Glasses formulated by RHU lie within a region high in network formers and tend to have moderately high processing temperatures (from 1100 to $1250^{\circ} \mathrm{C}$ ) and relatively good chemical

(a) Operated for the U.S. Department of Energy (DOE) by Battelle Wemorial Institute. 


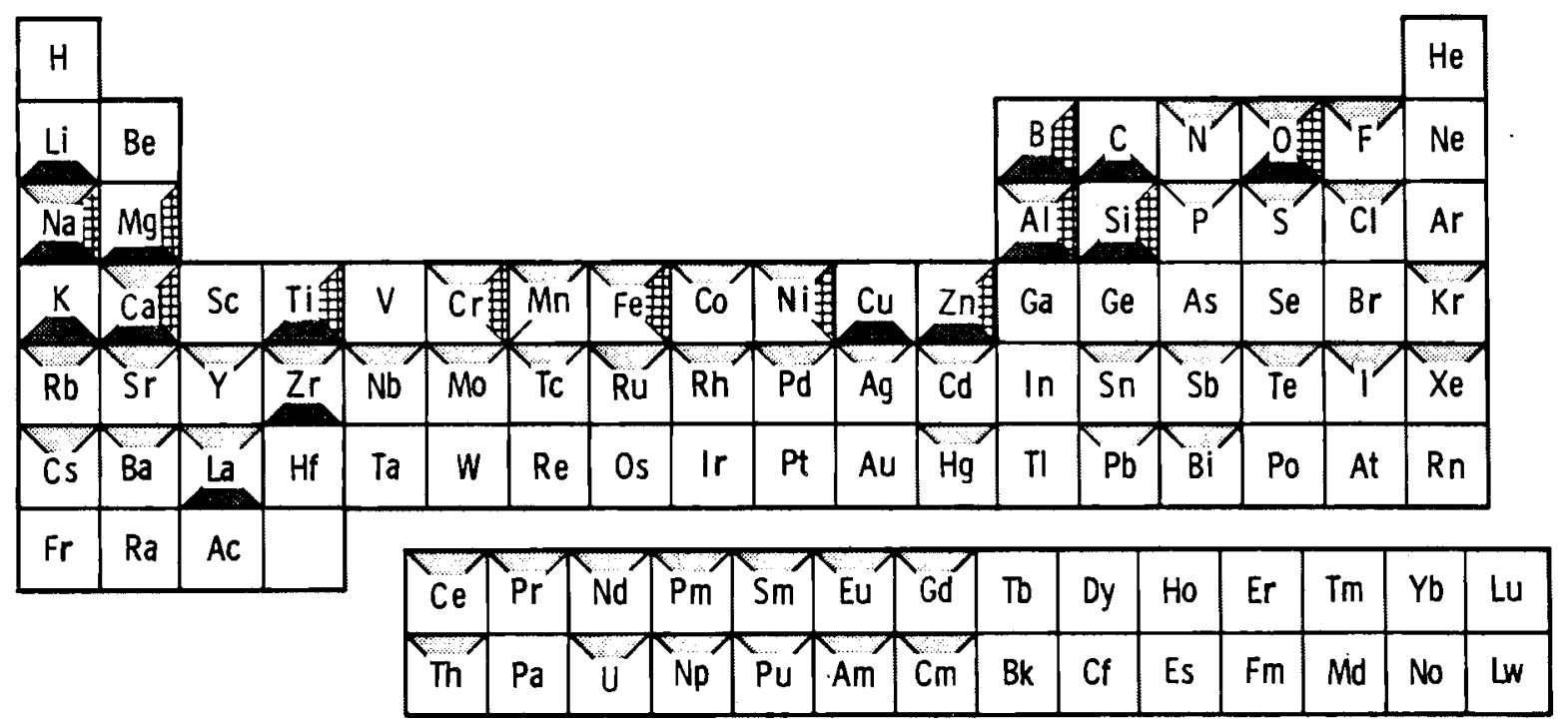

ELEMENTS IN HIGH-LEVEL WASTES

(INCLUDES FISSION PRODUCTS, ACTINIDES AND PROCESSING CHEMICALSI

ELEMENTS INCLUDED IN THIS STUDY

GLASS ADDITIVES

FIGURE 2. Elements in High-Level Wastes and Waste Glasses

durabilities. Glasses formulated by SRL lie in the region lower in glass network formers and higher in modifiers and tend to have lower processing temperatures (1000 to $1150^{\circ} \mathrm{C}$ ) and somewhat lower chemical durabilities. Glasses formulated by PNL contain similar amounts of network formers to SRL glasses but are lower in modifier content and somewhat higher in the content of intermediates. Both processing temperatures and chemical durability of PNL glasses tend to be between those of SRL and RHO glasses. Thus, a large variety of nuclear waste compositions exist; and there is much flexibility for formulating glasses from these wastes. 


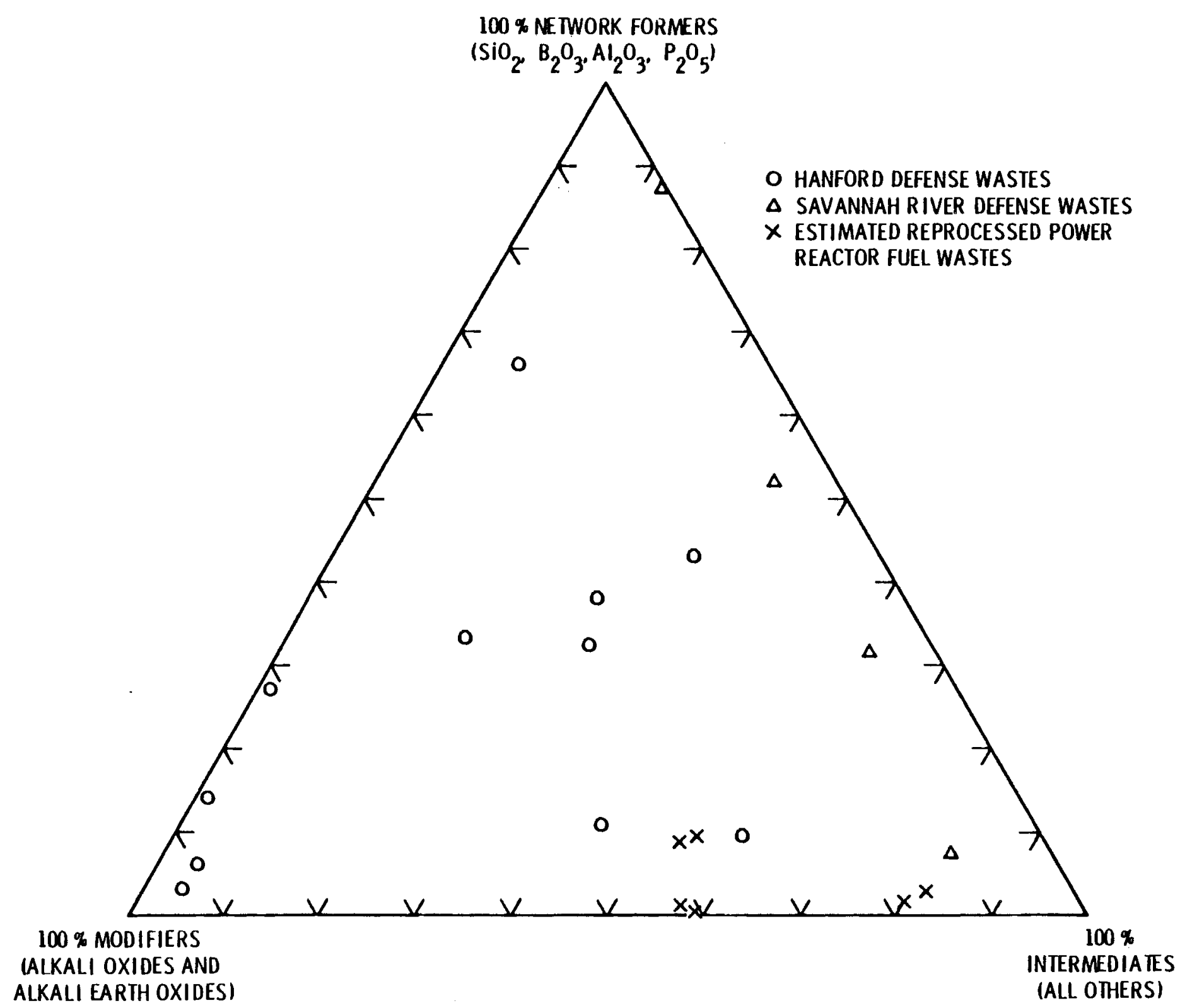

FIGURE 3. Ternary Diagram of Nuclear Waste Compositions 


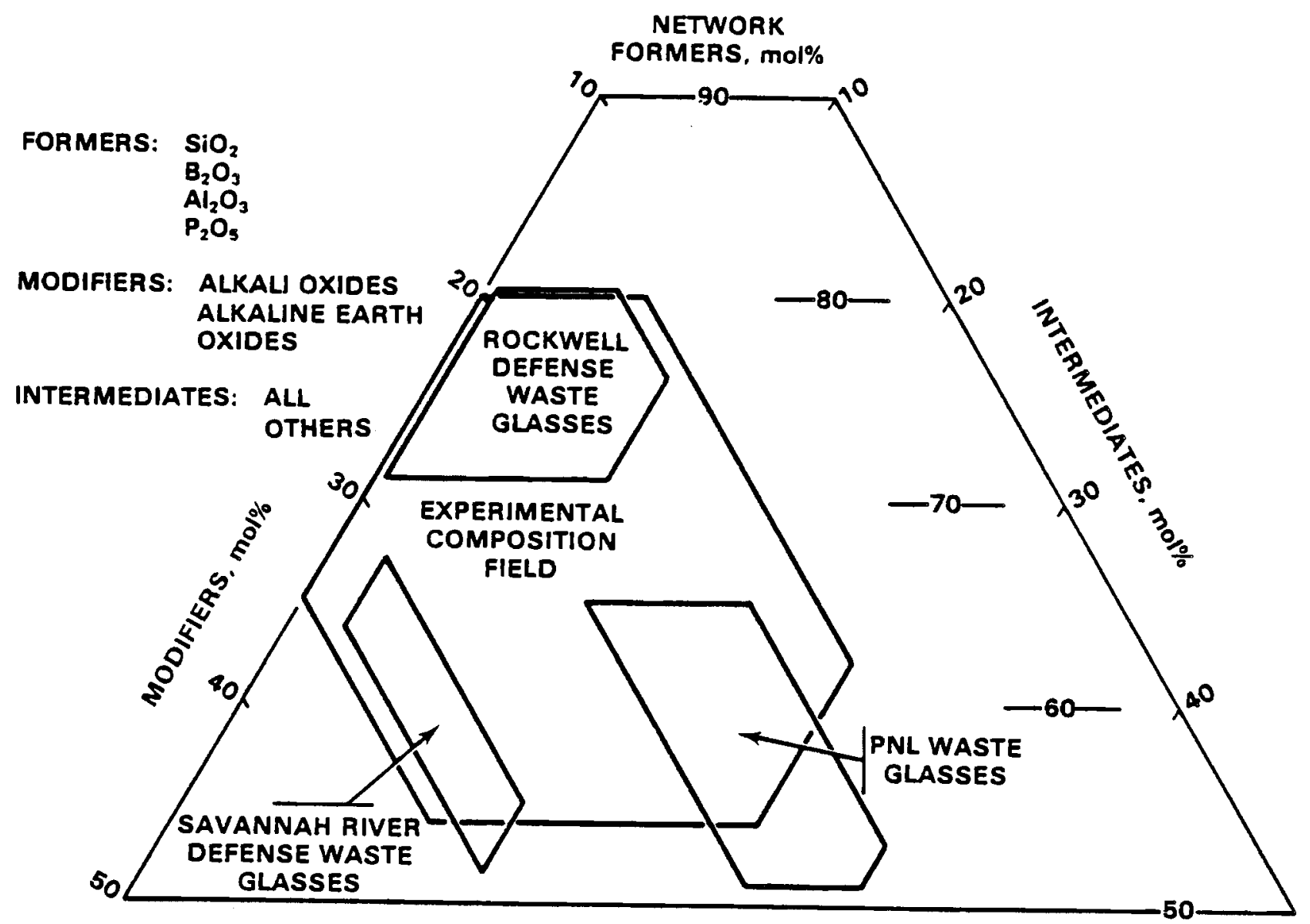

FIGURE 4. Ternary Diagram of Waste Glass Composition Regions

The final choice of glass compositions for the immobilization of the various nuclear wastes must be based on an understanding of the possible compromises between glass processing properties and final product properties. For instance, although glasses containing higher amounts of network formers tend to be more chemically durable, they also require higher processing temperatures. The criteria for product properties such as chemical durability have not been defined nor have the practical processing limits of waste glass melters been established. Thus, because of the uncertainty in product and processing criteria and the large variety of wastes that may be considered for immobilization in glass, it is advantageous to develop a broad, empirical understanding of the relationship between composition and a variety of glass properties over a large compositional region. 
The present work was carried out by PNL to evaluate new methods of producing this information. To test and refine these new study methods, the work reported in this document was performed on a somewhat restricted matrix using 11 oxide components. Section 2 of this report discusses the statistical experimental design, modeling, analysis, and predictive testing methods employed, which are somewhat different from commonly used methods for the study of materials systems. Sections 3 and 4 discuss sample preparation and chemical analysis; and Sections 5 through 8 discuss phase behavior, viscosity, volatility, and chemical durability, respectively. Each property section describes the measurement procedure, results, discussion, and conclusions for the subject property. Recommendations for future work are given in Section 9. 


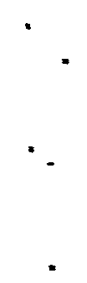




\subsection{STATISTICAL METHODS}

This section describes the statistical methods used to determine the experimental design, property modeling, experimental error, and component effects. A comparison is made between observed and predicted component effects.

\subsection{EXPERIMENTAL DESIGN}

The goal of this study was to predict and understand various glass properties in terms of the mole percent (mol\%) proportions of the components in the glass mixture. Due to the lack of theoretical models for complex systems, approximation models (see Section 2.2) were used. As the number of components and ranges thereof increase, the experimental region also increases in size and the possibility of easily fitting approximation models with a small number of experimental points (melts) is reduced. With this in mind and while wishing to obtain useful preliminary results, the experimental region was defined as shown in Table 1. Both the "as-defined" and "as-melted" ranges are shown. The as-defined range was that which was to be studied according to the experimental design. Often, however, there were significant differences between glass compositions as they were designed and as actually made. Thus, the experimental region actually considered was bounded by the as-melted range.

The 11-component experimental region defined in Table 1 takes the geometric form of a 10-dimensional hyperpolyhedron. Since this cannot be displayed graphically, a hypothetical three-component example corresponding to a two-dimensional geometric form (see Figure 5) will be used to illustrate important concepts. The simplex (triangle) in Figure 5 includes all three component $\left(\mathrm{SiO}_{2}, \mathrm{Na}_{2} \mathrm{O}, \mathrm{B}_{2} \mathrm{O}_{3}\right)$ glasses having a least $50 \% \mathrm{SiO}_{2}$. The experimental region is defined by upper and lower bounds on the components and is shown as the shaded area in Figure 5. Points 1 through 5 are the extreme vertices of the experimental region while point 6 is the overall centroid.

Four groups of glasses (A, B, C, and D) were sequentially prepared and studied so that improvements learned in the early work could be included. The first phase (Group A) produced 25 glasses, including replicate points required 
TABLE 1. Experimental Region Constraints

\begin{tabular}{|c|c|c|c|}
\hline Component & Variable & $\begin{array}{l}\text { "As-Designed" (b) } \\
\text { Range, mol\% } \\
\end{array}$ & $\begin{array}{l}\text { "As-Melted"(c) } \\
\text { Range, mol\% } \\
\end{array}$ \\
\hline \multicolumn{4}{|l|}{ Formers: } \\
\hline $\mathrm{SiO}_{2}$ & $x_{1}$ & 42 to 58 & 41 to 60 \\
\hline $\mathrm{B}_{2} \mathrm{O}_{3}$ & $x_{2}$ & 6 to 12 & 5.5 to 15 \\
\hline $\mathrm{Al}_{2} \mathrm{O}_{3}$ & $x_{3}$ & 0 to 15 & 0 to 16 \\
\hline \multicolumn{4}{|l|}{ Modifiers: } \\
\hline $\mathrm{CaO}$ & $x_{4}$ & 0 to 14 & 0 to 14 \\
\hline MgO & $x_{5}$ & 0 to 8 & 0 to 9 \\
\hline $\mathrm{Na}_{2} \mathrm{O}$ & $x_{6}$ & 11 to 16 & 9 to 17 \\
\hline \multicolumn{4}{|l|}{ Intermediates: } \\
\hline Zno & $x_{7}$ & 0 to 6 & 0 to 6.5 \\
\hline $\mathrm{TiO}_{2}$ & $x_{8}$ & 0 to 7 & 0 to 8 \\
\hline $\mathrm{Cr}_{2} \mathrm{O}_{3}$ & $x_{9}$ & 0 to 3 & 0 to 3.5 \\
\hline $\mathrm{Fe}_{2} \mathrm{O}_{3}$ & $x_{10}$ & 0 to 3 & 0 to 3.5 \\
\hline $\mathrm{NiO}$ & $x_{11}$ & 0 to 3 & 0 to 3.5 \\
\hline Formers ${ }^{(d)}$ & $x_{1}+x_{2}+x_{3}$ & 55 to 75 & 54 to 80 \\
\hline Modifiers $(d)$ & $x_{4}^{1}+x_{5}^{2}+x_{6}$ & 14 to 34 & 13 to 35 \\
\hline
\end{tabular}

(a) $x_{i}(i=1,2, \ldots, 11)$ represents the mo $1 \%$ proportion of the $i$ th component in a glass mixture. Since there are 11 components in the glass, the sum of their proportions must be:

$$
\sum_{i=1}^{11} x_{i}=1
$$

(b) These mol\% ranges define the experimental region originally chosen. The experimental design points were developed using these ranges.

(c) Many glasses in the experimental design had significantly different (paired t-test; $\alpha<0.05$ ) compositions than designed; thus, these mol\% ranges define the actual experimental region considered.

(d) Additional restrictions on sums of components imposed due to prior experimental knowledge. 


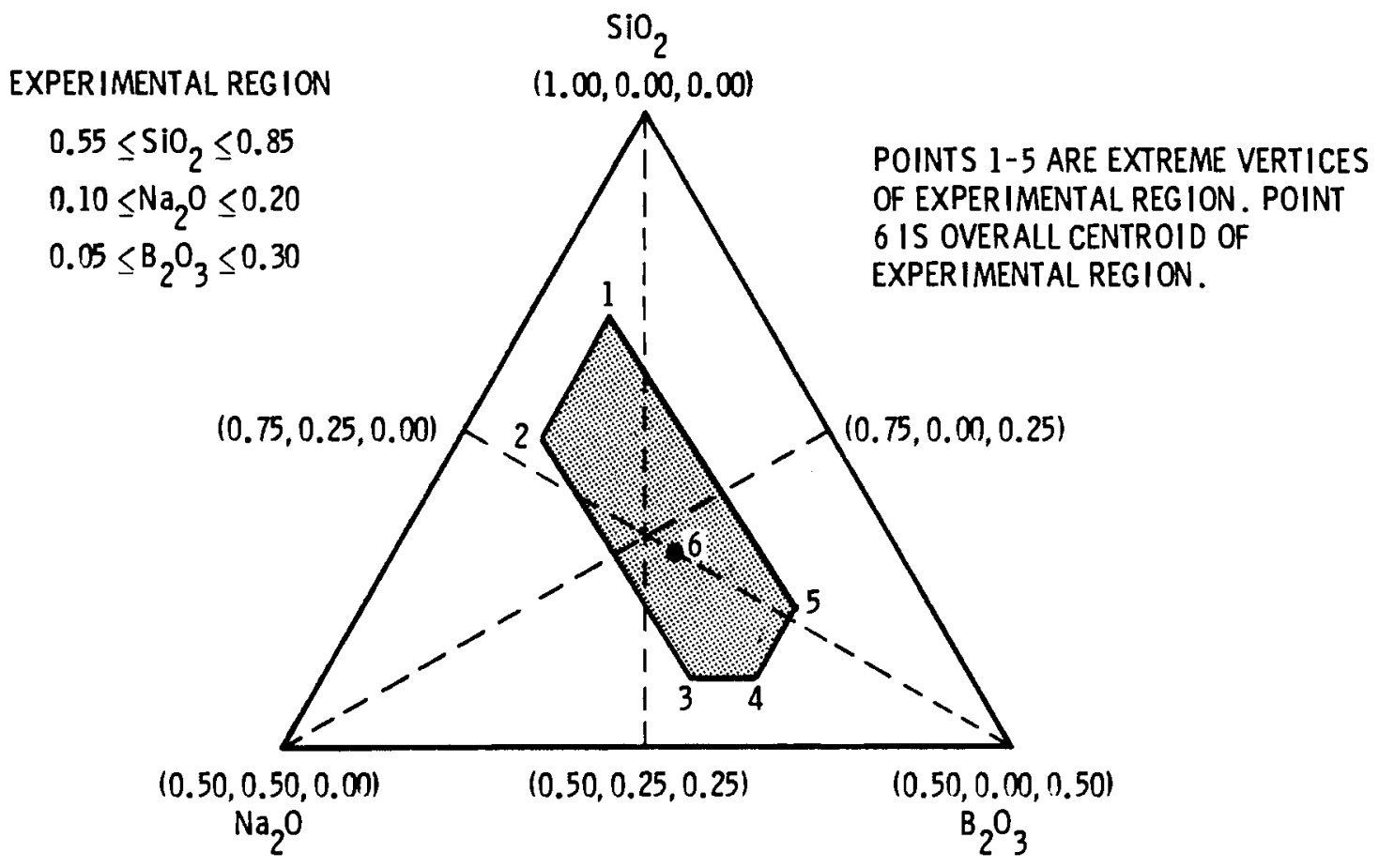

\begin{tabular}{|c|c|}
\hline $\begin{array}{c}\text { POINT } \\
\text { NUMBER }\end{array}$ & $\begin{array}{c}\text { PROPORTIONAL COMPOSITION } \\
\left(\mathrm{SiO}_{2}, \mathrm{Na}_{2} \mathrm{O}_{2} \mathrm{~B}_{2} \mathrm{O}_{3}\right)\end{array}$ \\
\hline 1 & $(0.85,0.10,0.05)$ \\
\hline 2 & $(0.75,0.20,0.05)$ \\
\hline 3 & $(0.55,0.20,0.25)$ \\
\hline 4 & $(0.55,0.15,0.30)$ \\
\hline 5 & $(0.60,0.10,0.30)$ \\
\hline 6 & $(0.66,0.15,0.19)$ \\
\hline
\end{tabular}

FIGURE 5. Hypothetical Three-Component Example (experimental region shaded)

to estimate experimental error. The points were chosen from the set of extreme vertices $^{(a)}$ of the experimental region by a series of computer algorithms $(b)$ designed to minimize variances of property predictions to be made by a firstdegree approximation model:

(a) McLean and Anderson 1966; Snee 1975; Snee and Marquardt 1974.

(b) Wynn 1970; St. John and Draper 1975. 


$$
\hat{y}=\sum_{i=1}^{11} \hat{\beta}_{i} x_{i}
$$

where $\hat{y}=$ property predictions

$\hat{\beta}_{i}=$ fitted regression coefficient of $i^{\text {th }}$ component

$x_{i}=$ proportion of $i^{\text {th }}$ component in glass.

The overall centroid of the experimental region was added to the design to allow inclusion of curvature terms in the prediction equations.

Group A points were used to fit second-degree polynomial approximation models of the form:

$$
y=\sum_{i=1}^{11} \beta_{i} x_{i}+\sum_{i<j} \beta_{i j} x_{i} x_{j}
$$

where $y=$ property observations (or common logarithms thereof)

$\beta_{j}=$ coefficient of $i^{\text {th }}$ component

$x_{i}=$ proportion of $i^{\text {th }}$ component in the glass

$\beta_{i j}=$ coefficients of cross-product terms

to the observed properties (see Section 2.2 for more details). Acceptable model fits were obtained for several properties, and these fits were used to help select 44 additional glasses that were melted in the second phase of the experimental design. Twenty of the $44 \mathrm{glasses}$ (Group B) were chosen to complement the Group $A$ points. Finally, 24 additional design points (Group $C$ ) were selected to complement Group $A$ and $B$ points by improving the estimation of cross-product terms $\left(x_{i} x_{j}\right)$ in property models. Both Group $B$ and $C$ experimental points were chosen from the set of extreme vertices by the previously mentioned computer selection algorithms.

An additional set of 33 points (Group D) was chosen to provide an independent set of data with which to test the accuracy of the predictive models. These points were not used in the model-fitting process. The as-melted compositions of Groups A, B, C, and D are given in Appendix B. Corresponding property measurements are given in Tables B.5 through B.16. 


\subsection{PROPERTY MODELING}

Several properties are of interest in this study, including chemical durability, viscosity, crystallinity, and volatility. Since composition-dependent theoretical models are not available for these properties even for simple glasses, polynomial approximation models were chosen to fit the properties. These are of the general form:

$$
\hat{y}=\sum_{i=1}^{11} \hat{\beta}_{i} x_{i}+\sum_{i<j} \sum_{i j} \hat{\beta}_{i} x_{j}
$$

Some consideration was given to models with ratio terms; however, they did not perform as well as polynomial models.

It should be noted that Equation (3) does represent a general quadratic polynomial for this type of problem. The restriction that $\sum x_{j}=1$ allows the constant $\left(\hat{\beta}_{0}\right)$ and pure quadratic $\left(\hat{\beta}_{i j} x_{i}{ }^{2}\right)$ terms to be replaced with linear terms and second-degree cross-product terms as displayed in Equation (3).

Before discussing the process of property modeling, note that a model of the form of Equation (3), which fits property "responses" to several variables, is often called a response surface. This terminology is derived from the graphical analogy in three dimensions where a graph of a property versus two variables is a surface in the third dimension. If all coefficients $\hat{\beta}_{i j}$ in Equation (3) are zero, the property response surface is a hyperplane. Seconddegree cross-product terms add curvature to the response surface. This terminology will be useful in the component effects discussion in Section 2.3.

The property modeling process is the same for each property although the process may terminate at different points for different properties. The process begins by fitting the simple model:

$$
\hat{y}=\sum_{i=1}^{11} \hat{B}_{i}^{\prime} x_{i}^{\prime}
$$


where the prime notation $x_{j}$ indicates a pseudo-component variable transformation (defined in Appendix $A$ ). If this first-degree model does not adequately explain the property, second-degree cross-product terms $\left(\hat{\beta}_{i j} x_{i} x_{j}\right)$ are added one at a time to improve the model's ability to explain the data. Seconddegree cross-product terms are no longer added when a) the model adequately explains the data, b) further additions do not improve the model, or c) the number of terms in the model equals the number of observations for that property.

In the above explanation of the modeling process, the question arises as to whether a specific model adequately explains the property data. Since the experimental property data are fit to a specific model, we ask if the model has a significant lack of fit (LOF). This question is resolved as follows. A set of data has a certain amount of variability, and an attempt is made to explain this variability with a predictive model. If a large enough proportion of the variability is explained so that the remaining variability is essentially experimental error, then the model fits well. The proportion of the variability explained by the fit of the model (regression) is denoted $R^{2}$. Since adding terms to a model always increases $R^{2}, R_{A}{ }^{2}$ is considered instead where the $A$ implies adjustment for the number of terms in the approximation model. $R_{A}{ }^{2}$ is between 0 and 1 , and values above 0.85 are generally required to indicate a good fit. However, $R_{A}{ }^{2}$ does not take into account the estimate of experimental error. Even if the regression explains a large proportion of the variability, the model still has a significant LOF if the remaining variability is much larger than the experimental error. The LOF-F test is the ratio:

$$
\frac{v_{1}-v_{2}}{v_{2}}
$$

where $v_{1}=$ variability after regression

$V_{2}=$ variability explained by experimental error.

If this ratio is larger than the appropriate F-distribution table value, the proposed model is said to have a significant LOF. Care must be taken when considering the LOF-F test since it is strongly influenced by the estimate of 
experimental error obtained from replicating several melts. If the experimental error estimate is large (indicates that the data are not reproducible), the LOF will be statistically insignificant and $R_{A}{ }^{2}$ will be lower. However, if the estimate of experimental error is very small (due possibly to replicates of melts with zero property values), the LOF-F test may indicate a significant LOF when none exists. Hence, $R_{A}{ }^{2}$ and the LOF $-F$ test must be considered along with replicated data in assessing the fit of the model. Formulas for calculating $R_{A}{ }^{2}$ and LOF-F use analysis of variance (AOV) tables--a standard part of the output in statistical modeling. Formulas for calculating $A 0 V$ entries, $R_{A}{ }^{2}$, and LOF-F are given in Appendix A.

Final modeling results for several properties are given in Appendix $C$. The model fit to each property will be defined by the pseudo-coefficients for the terms selected for the model. The results also include an AuV table and values of $R_{A}{ }^{2}$ as well as the LOF-F test and its associated F-distribution critical value. The $R_{A}{ }^{2}$ and LOF-F values indicate the goodness or lack of fit of the model.

It should be noted that because of cross-product terms and pseudocomponent transformations, little sense can be made of the effect of a component on a property response by observing the magnitude of coefficients derived in the model-fitting routine. The method for understanding component effects is discussed in Section 2.4 .

\subsection{EXPERIMENTAL ERROR ESTIMATES}

The estimates of experimental error that are used in this work are summarized in Table 2. One estimate for each property was developed using the near-replicate points of Groups $B$ and $C$. These estimates are required to perform a precise LOF test for the property models developed; however, they appear to be too small for several reasons. Some properties had replicate observations that were either "equal" or deleted as outliers, both of which lead to possible underestimation of the experimental error in Groups $B$ and $C$. In addition, other data (including that of Groups $A$ and $D$ ) were used to produce estimates of experimental error. Better experimental reproducibility (smaller standard deviations) was obtained within each data group than between 


\section{TABLE 2. Est imates of Experimental Error}

\begin{tabular}{|c|c|c|}
\hline \multirow[b]{2}{*}{ Property } & \multicolumn{2}{|c|}{ Standard Deviation } \\
\hline & $\begin{array}{l}\text { Group } \mathrm{B} \text { and } \mathrm{C} \\
\text { Est imate } \\
\end{array}$ & $\begin{array}{l}\text { Revised } \\
\text { Estimate }\end{array}$ \\
\hline Soxhlet Leach, log wt\% loss & 0.025 & 0.045 \\
\hline pH 4 Leach, $\log$ wt\% loss & 0.09 & 0.12 \\
\hline Viscosity, $\log$ poise & 0.08 & 0.20 \\
\hline Volatility, log mg loss & 0.05 & 0.05 \\
\hline Air-Quenched Crystallinity, wt\% & 0.60 & 0.85 \\
\hline
\end{tabular}

groups. There were significant differences between property measurements of the first group ( $A$ ) and those of the later groups ( $B$ and $C$ ), for example. Groups $B$ and $C$ were similar to each other and produced the best modeling fits. Data from Group D appear to be significantly different from those of Groups B and $C$. Experimental error estimates using Group $A$ and $D$ data were significantly larger than Group $B$ and $C$ estimates for most properties. The revised experimental error estimates in Table 2 were obtained by combining Group $B$ and $C$ estimates with those derived from the other data.

While these revised estimates could be used to test model LOF, they can produce nonsensical LOF test results; hence, Group $B$ and $C$ estimates have been used to test the LOF in the property modeling. However, the revised estimates are more appropriate when considering data outside Groups $B$ and $C$. For example, predicted component effects developed from Group $B$ and $C$ models will later be compared to effects observed in Group $D$ (see Section 2.5). The revised estimates of experimental error are more appropriate for this statistical comparison of observed versus predicted values.

\subsection{COMPONENT EFFECTS}

The effect on property response of varying the proportions of each chemical component in a melt is of great interest. Glass properties are modeled to understand and predict the effect of chemical components on melt properties. The fitted model, often referred to as a prediction equation, will be used to provide a meaningful and easily understandable display of the effects of each component. 
In some applications, the effect of a variable is found by changing the variable of interest while holding all other variables in the problem at fixed levels; however, this is impossible in this case due to the restriction that the sum of the proportions of the components in the melt must equal one. When one component is changed, the others cannot remain fixed. A new technique for estimating component effects in this type of problem is discussed in detail by Piepel (1980 and 1981) and is briefly explained below.

Component effects are defined to be the change in predicted values when the proportion of a component is changed. Since the property models have cross-product terms that introduce curvature in the response surface, it is necessary to consider both total component effects (change in predicted values due to a maximum possible change in the component) and partial component effects (change in predicted values due to a smaller than maximum change in the component). The crux of the technique is the choosing of a line through the experimental region for each component along which the component of interest varies from its lower to upper bound while the proportions of the other components vary within small ranges. This line is determined for each component by the centroid of the pseudo-component experimental region and the pseudocomponent simplex vertex for that component. This is shown schematically in Figure 6 for the hypothetical three-component example of Section 2.1. Formulas that precisely define the direction within the experimental region along which component effects are computed are presented in Appendix $A$.

In the presentation of results, each property prediction equation is used to predict along each component effect line. Graphical presentation of these predicted values provides an easily understood view of the effect of each component, and plotting of these component effect predicted values for all components on the same graph allows comparison. Hence, a graph is provided for each property showing predictions along the component effect lines for all components plotted versus mol\% change in the component from the centroid. An illustration of this graphical technique for the three-component example is given in Figure 7. Since this is a hypothetical example (not based on a real property or real data), a prediction equation (given in both original and pseudocomponents) was chosen to illustrate certain points. When predictions are 


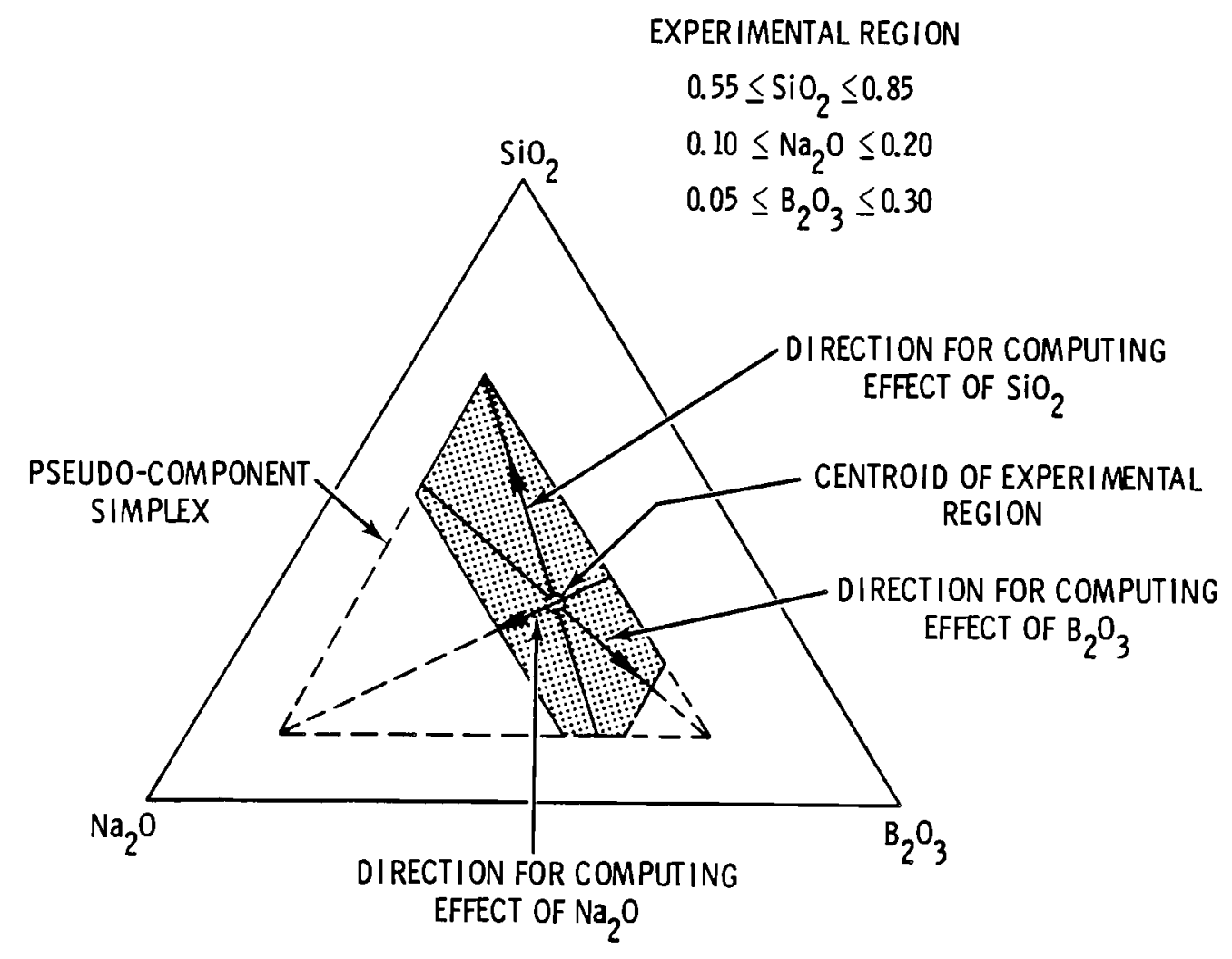

FIGURE 6. Hypothetical Three-Component Example Showing Directions Within Experimental Region Along Which Component Effects Are Calculated

made with this equation, they will have some variability, with the amount depending upon the experimental design and how well the model fits the property data. Examples of minimum and maximum prediction standard errors for the three-component case are also given in Figure 7 . The bar length shown represents \pm 1 prediction standard error.

When analyzing the component effects plots, there are three points to keep in mind. First, the slope (positive or negative) of a component effect curve indicates the type of effect that component has (increases or decreases response). The steeper the curve, the more effect per unit of change in the component. If a component effect curve is approximately horizontal, then the component has no effect on the property response. When considering any component effect curve, care must be taken to evaluate the curve relative to prediction standard errors. For rough consideration, one may assume that a prediction at any one point could be in error by \pm 2 or 3 standard errors. 


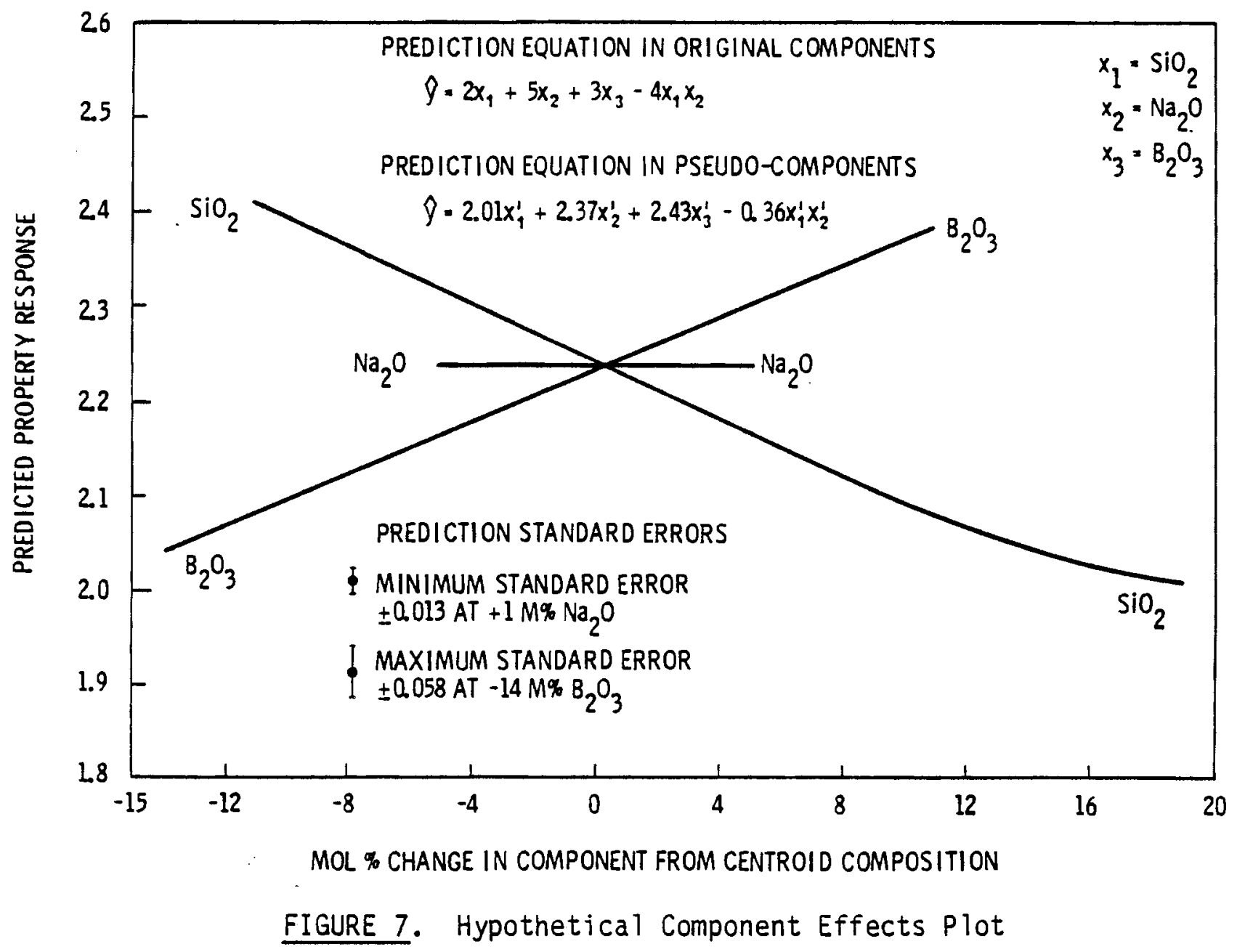

Whole effect curves could be in error by several standard errors on a pointby-point basis (see Appendix A, Section A.4.4). Precise statistical tests for significance of effects are also presented in Appendix $A$.

Second, when analyzing the component effects plots presented in this document, consider how they were developed. The effects plots are predictions along a specially selected direction within the experimental region for each component. These directions are selected so that a total effect can be computed for every component. To do this, the direction lines within the experimental region must go through the centroid and stay within the middle of the experimental region. Such a plot certainly cannot give a total picture of the 11-dimensional response surface; however, it does give what might be called the 
"best first look," given the restrictions placed on the components. Some components may have quite different effects if unrestricted. Similar plots using a base glass that is different than the centroid of the experimental region or a variety of other techniques should be used to investigate partial component effects in other parts of (or directions in) the experimental region.

Third, when evaluating component effects, consider how to interpret the cross-product terms in the prediction equation. The presence of curvature (cross-product) terms in the prediction equation may not show up as curved (versus straight line) effects plots but as changes in the slope of effects curves for different base glasses. Curvature terms are added to the prediction equation because of the interaction of various components; however, the component effects plots presented here are computed so that interactions have very little influence. Interaction effects can be investigated by basing effects plots on base glasses different than the centroid.

When considering these three topics in relation to the hypothetical threecomponent example effects plot in Figure 7 and keeping in mind prediction standard errors, $\mathrm{SiO}_{2}$ has a negative effect on the property response, $\mathrm{B}_{2} \mathrm{O}_{3}$ has a positive effect, and $\mathrm{Na}_{2} \mathrm{O}$ has no effect. Although there is a cross-product term in the prediction equation, very little curvature is seen in the effects curves.

Samples for use in building property models were prepared and tested in three groups: $A, B$, and $C$. Because of changes in testing methods, Group $A$ data often could not be combined with Group $B$ and $C$ data. Hence, models were built using Group $B$ and $C$ data; and effects plots are presented using these models.

\subsection{COMPARISON OF OBSERVED VERSUS PREDICTED COMPONENT TOTAL EFFECTS}

Section 2.2 discussed the statistical modeling of properties as a function of the composition of a melt. Two measures of how well the model fit the experimental data, $R_{A}{ }^{2}$ and LOF-F, were also discussed. However, these measures do not indicate how well a model predicts property values for compositions not used to fit the model. Therefore, 33 additional compositions 
(Group D) were melted; and property measurements were made for use in validating the models. These compositions included 22 points that represented the end points of the curves along which the total component effects were predicted.

The Group $D$ melts were produced several months after Groups B and C, from which the models were built. While there are indications of time effect differences, it is believed that the 22 component total effect end points are not greatly biased and will suffice for a crude validation process.

In the results section for each property, the predicted total effect of each component (calculated from the fitted model) is compared to the observed effect (calculated from the observed property values for Group $D$ end points). In these comparisons, it is determined whether the difference between the observed and predicted total effects is statistically significant when viewed in light of prediction and experimental errors. As noted in Section 2.3, the revised estimates of experimental error are used in these comparisons.

In each property section, an effects plot and an observed versus predicted comparison table--two very helpful items to refer to when reading the discussion of results--are presented. It should be noted that the predicted total effects in the comparison tables may not precisely match the results plotted in the effects plots. The effects plots are predictions based on the theoretical (as-designed) end points; while for comparison purposes, it was necessary to make predictions for as-melted end points in the comparison tables. Infrequently, differences between the two may occur. 

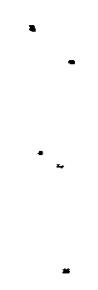


\subsection{SAMPLE PREPARATION}

The glasses in this study were prepared from batch chemicals; and oxides, nitrates, and carbonates of the required components were used. Table 3 shows the components used in the study and the batch chemicals used to introduce them into the glass.

After the chemicals were weighed with a top-loading balance (accuracy of $0.01 \mathrm{~g}$ ), the required chemicals for a $500 \mathrm{~g}$ glass batch were placed in an $\mathrm{Al}_{2} \mathrm{O}_{3}$ mortar and manually mixed. The mixed batch was placed in a Pt-5\% Au crucible, which was inserted into a resistance-heated furnace that had been preheated to the anticipated melting temperature for that composition and held at this temperature in air for $2 \mathrm{~h}$. If the batch did not react sufficiently to form a melt, a series of test melts were made at higher temperatures to determine the required melting temperature. Once this was determined, the glass was rebatched and remelted. The melting temperature for each batch is included in Appendix B, Tables B.8, B.9, B.10, and B.11.

After melting for $2 \mathrm{~h}$, the melt was removed from the furnace and air quenched in its crucible; and when it had cooled to room temperature, it was

TABLE 3. Oxide Components and Batch Chemicals

\begin{tabular}{|c|c|c|}
\hline $\begin{array}{l}\text { Glass Oxide } \\
\text { Component }\end{array}$ & \multicolumn{2}{|c|}{$\begin{array}{l}\text { Batch } \\
\text { Chemical }\end{array}$} \\
\hline $\mathrm{SiO}_{2}$ & $\mathrm{SiO}_{2}$ & \\
\hline $\begin{array}{l}\mathrm{B}_{2} \mathrm{O}_{3} \\
\mathrm{Al}_{2} \mathrm{O}_{3} \\
\mathrm{CaO}\end{array}$ & $\begin{array}{l}\mathrm{Na}_{2} \mathrm{~B}_{4} \mathrm{O}_{7} \\
\mathrm{Al}_{2} \mathrm{O}_{3} \\
\mathrm{CaCO}_{3}\end{array}$ & $5 \mathrm{H}_{2} \mathrm{O}$ \\
\hline $\mathrm{MgO}$ & $\mathrm{Mg}\left(\mathrm{NO}_{3}\right)_{2}$ & $6 \mathrm{H}_{2} \mathrm{O}$ \\
\hline $\mathrm{Na}_{2} \mathrm{O}$ & $\mathrm{Na}_{2} \mathrm{CO}_{3}$ & \\
\hline $\begin{array}{l}\mathrm{TiO}_{2} \\
\mathrm{ZnO}\end{array}$ & $\begin{array}{l}\mathrm{T}_{10} 2 \\
\mathrm{ZnO}\end{array}$ & \\
\hline $\mathrm{Cr}_{2} \mathrm{O}_{3}$ & $\mathrm{Cr}\left(\mathrm{NO}_{3}\right)_{3}$ & $9 \mathrm{H}_{2} \mathrm{O}$ \\
\hline $\mathrm{Fe}_{2} \mathrm{O}_{3}$ & $\mathrm{Fe}_{2} \mathrm{O}_{3}$ & \\
\hline $\mathrm{NiO}$ & $\mathrm{Ni}\left(\mathrm{NO}_{3}\right)_{2}$ & $6 \mathrm{H}_{2} \mathrm{O}$ \\
\hline
\end{tabular}


removed from the crucible. The entire sample was then crushed to $-1.651 \mathrm{~mm}$ ( -10 mesh U.S. standard sieve); and the crushed glass was mixed, coned, and quartered to assure representative samples for each characterization test. 


\subsection{BULK CHEMICAL ANALYSIS}

Two-gram samples were coned and quartered out of each air-quenched, crushed melt; and the samples were chemically analyzed using inductivelycoupled argon plasma (ICAP) emission spectroscopy. Since liquid samples are required for ICAP analysis, fusion techniques were used for decomposition.

A Jarrel1-Ash Model 975 ICAP Atom Comp Spectrometer was used under the following conditions:

- power to generator - 1200 watts

- coolant gas flow - $20 \mathrm{1} / \mathrm{min}$

- sample gas flow - $0.61 / \mathrm{min}$

- solution uptake - $1.1 \mathrm{ml} / \mathrm{min}$.

The melt samples were decomposed using either a potassium hydroxidepotassium nitrate fusion mixture or a sodium peroxide fusion in either a nickel or zirconium metal crucible. The choice of fusion mixture and crucible was governed by the components to be analyzed. When the sample contained both sodium and potassium, the sodium peroxide fusion was made in the zirconium crucible; and the potassium hydroxide-potassium nitrate fusion was made in the nickel crucible since sodium peroxide severely attacks nickel crucibles.

The samples were fused in the following manner:

- Between 0.25 and $0.30 \mathrm{~g}$ of finely ground glass samples were weighed and placed in the appropriate metal crucible.

- For the $\mathrm{KOH}-\mathrm{KNO}_{3}$ fusion, approximately $1.5-\mathrm{g} \mathrm{KOH}$ and $0.5-\mathrm{g} \mathrm{KNO}_{3}$ were placed in the crucible; for the $\mathrm{Na}_{2} \mathrm{O}_{2}$ fusion, approximately $2.0 \mathrm{-g}$ $\mathrm{Na}_{2} \mathrm{O}_{2}$ were placed in the crucible.

- The samples were preheated on a hot plate for about 10 min to expe 1 moisture, which helped prevent spattering during fusion over the gas flame.

- Samples were then fused over a Meeker burner for about 10 min.

- The samples were cooled, and demineralized water was added to dissolve the fusion mixture. The peroxide fusions were covered with a watch glass since gas was evolved when water was added. 
- Samples were transferred from the crucible into a 250-m1 volumetric flask using the minimum amount of water from a wash bottle.

- $50 \mathrm{ml}$ of $40 \%$ hydrochloric acid was added to the volumetric flask and heated gently if required to completely dissolve the sample.

- The solution was cooled to room temperature and diluted to volume with demineralized water.

- A 10-ml aliquot of the sample was transferred to a 100-ml volumetric flask and diluted to volume with demineralized water. Samples were then ready for ICAP analysis.

The acid content of the solutions to be analyzed was approximately $0.1-\mathrm{M} \mathrm{HCl}$, the sodium from the $\mathrm{Na}_{2} \mathrm{O}_{2}$ fusion was $0.02 \mathrm{M}$, and the potassium from the $\mathrm{KOH}-\mathrm{KNO}_{3}$ was about $0.013 \mathrm{M}$. Standard solutions analyzed with sodium chloride and potassium chloride added in these concentrations indicated good standard recoveries.

When the generic melt samples were fused and analyzed, the calculated values of melt constituents as metal oxides showed a material balance of $100 \% \pm 4 \%$. Since the variations from $100 \%$ appeared to be random, they could not be attributed to any particular components. Thus, the resulting melt compositions were normalized to $100 \%$ and are listed as such in Appendix B, Tables B.1 through B.4. 


\subsection{PHASE BEHAVIOR}

It would be strictly incorrect to call the materials studied here "glasses" since they are definitely not fully vitreous and homogeneous as are familiar glasses. Many melts produced materials containing crystalline inclusions that were characterized by the two techniques that are discussed in the first part of this section. All melts, whether fully vitreous or not, apparently contained glass-in-glass phase separation produced by separation of the melt into two immiscible liquid phases similar to a dispersion of oil droplets in water. The last part of this section discusses glass-in-glass phase separation behavior.

\subsection{CRYSTALLINITY}

Crystal phases were characterized by x-ray diffraction (XRD). The technique was applied to samples with three heat treatments: air quenched, water quenched, and slow cooled.

\subsubsection{X-Ray Diffraction Procedure}

Diffractograms were generated for each specimen using a General Electric/ Diano XRD system, and the peak area above background for all detected peaks in the range of 10 to $65^{\circ} 2 \theta$ was measured for each sample. For glasses having more than one identified crystalline component, each peak corresponding to a particular phase $x$-ray trace was identified and the total integrated peak area attributable to each phase was summed. This total integrated intensity measurement was then converted to equivalent weight percent (wt\%) of the $x$-ray standard using a conversion curve that was generated with a reference standard.

For this study, the reference standard used was a mixture of equal wt\% of alpha- $\mathrm{Al}_{2} \mathrm{O}_{3}, \mathrm{CeO}_{2}$, and $\mathrm{NiFe}_{2} \mathrm{O}_{3}$ in a vitreous glass filler. Repeated analys is of one specimen usually yields results that have a range of about $1 \mathrm{wt} \%$ while specimen replication results usually have a slightly larger range--typically 2 wt\%. This method is admittedly nonspecific for the phases identified in each sample, but the error from estimated to actual crystallinity is less than 5 wt\% 
and is linearly divergent from 0 to about $50 \mathrm{wt} \%$ crystallinity (Turcotte and Wald 1978). Thus, since this error is consistent, component effects can be reasonably assessed.

\subsubsection{Sample Preparation}

Air-cooled samples were allowed to cool from melt temperature in the platinum crucible in room air. Water-quenched samples were prepared by dipping the crucible containing the melt into a pail of water immediately after removal from the melting furnace.

About $10 \mathrm{~g}$ of each melt was further heat treated by loading the powder into an alumina crucible and remelting the glass at the initial melt temperature for $2 \mathrm{~h}$. These specimens were then slow cooled at a continuously controlled rate of $6^{\circ} \mathrm{C} / \mathrm{h}$ from the melt temperature of $500^{\circ} \mathrm{C}$ and then air cooled to room temperature.

Using a ball mill with tungsten-carbide $\left(W_{2}\right)$ balls, specimens were powdered to pass through 325 mesh. Contamination of the specimens with $W_{2}$ was negligible since the two strongest peaks of $W_{2}$ were broad and barely discernible by XRD in the worst case. Each powder specimen was loaded into a sample holder in a manner demonstrated by prior experience to avoid preferred orientation effects.

\section{1 .3 Results}

The results for water-quenched and air-cooled specimens were almost identical as can be seen by comparing the appropriate columns in Appendix $B$, Table B.6. Therefore, only the air-quenched and slow-cooled data are discussed.

The devitrification phases observed to form in the slow-cooled specimens generally fell into one of four compositional or structural types: a silicate, an aluminate, a titanate, or a spinel-type structure frequently involving chromium. This last classification is observed to dominate in air-cooled specimens, but it is usually a secondary phase in slow-cooled specimens where formation of silicates seems to be favored. 
A tabular summary of the XRD results is shown in Appendix B, Tables B.5 and B.6. There are one or two principal phases listed for each melt composition/heat treatment; however, these were not the only crystalline phases identified in the specimens. Several melts were observed to have at least five crystalline phases, but phases present at less than 2 wt\% in the sample were not listed unless dominant. In addition, the phase compositions listed should not be viewed as precise since it is unlikely that phase-pure crystals are obtained in these multicomponent melts.

A model was successfully fit to the total wt\% air-quenched crystallinity data obtained by XRD for extreme vertices glasses of Group $B$ and part of Group C (see Appendix C, Table C.5). These measurements ranged from 0 to 30 wt\%. The maximum standard error within the prediction model was \pm 0.43 , and the total error used in comparing observed to predicted total effects was $\pm 2.4 \mathrm{wt}^{(\mathrm{a})}$ (see Table 4). There is a significant difference between the observed and predicted total effects for two components--CaO and $\mathrm{Cr}_{2} \mathrm{O}_{3}$, but these two components are included on the effects plot (Figure 8) because the model merely underestimates the magnitude of their effects while correctly predicting the sign.

$\mathrm{B}_{2} \mathrm{O}_{3}$ was included on Figure 8 despite some disagreement between the predicted and observed total effects (Table 4 ). The dotted line in the figure shows the more probable effect of $\mathrm{B}_{2} \mathrm{O}_{3}$ on air-quenched crystallinity. This effect agrees more with the observed total effect (melts 72 and 73 in Group D) and with the effect found for slow-cooled crystallinity (see Figure 9).

A model was successfully fit to the Group B and C slow-cooled crystallinity data; however, since this property was not measured on the Group $D$ samples, a comparison of observed versus predicted total effects could not be made. Since the effects for slow-cooled crystallinity were not tested by observation, only those effects shown in Figure 8 for air-quenched crystallinity were included in Figure 9.

(a) See Appendix A, Section A.4 for a discussion of standard errors, standard deviations, and comparison errors. 
TABLE 4. Comparison of Observed and Predicted Total Effects for Air-Quenched Crystallinity

\begin{tabular}{|c|c|c|c|c|}
\hline \multirow[b]{2}{*}{ Element } & \multicolumn{2}{|c|}{ Total Effect } & \multirow{2}{*}{$\begin{array}{l}\text { Observed } \\
95 \% \text { CI (a) }\end{array}$} & \multirow{2}{*}{$\begin{array}{l}\text { Predicted } \\
95 \% \mathrm{CI}(\mathrm{a}) \\
\end{array}$} \\
\hline & Observed & Predicted & & \\
\hline $\mathrm{SiO}_{2}$ & -8.1 & -6.6 & $(-10.5,-5.7)$ & $(-9.2,-4.0)$ \\
\hline $\mathrm{B}_{2} \mathrm{O}_{3}$ & -3.6 & 1.0 & $(-6.0,-1.2)$ & \\
\hline $\mathrm{Al}_{2} \mathrm{O}_{3}$ & 4.0 & 2.8 & $(1.6,6.4)$ & $(0.2, \quad 5.4)$ \\
\hline $\mathrm{CaO}^{2}$ & -12.3 & $-7.1^{(b)}$ & $(-14.7,-9.9)$ & $(-9.7,-4.5)$ \\
\hline $\mathrm{MgO}$ & -1.3 & -5.1 & & $(-7.6,-2.6)$ \\
\hline $\mathrm{Na}_{2} \mathrm{O}$ & -6.3 & -3.7 & $(-8.7,-3.9)$ & $(-6.4,-1.0)$ \\
\hline $\mathrm{ZnO}$ & 3.5 & 4.1 & $(1.1,5.9)$ & $(1.6,6.6)$ \\
\hline $\mathrm{TiO}_{2}$ & -2.5 & 1.7 & $(-4.9,-0.1)$ & \\
\hline $\mathrm{Cr}_{2} \mathrm{O}_{3}$ & 18.8 & $7.9^{(b)}$ & $(16.4,21.2)$ & $(5.4,10.4)$ \\
\hline $\mathrm{Fe}_{2} \mathrm{O}_{3}$ & 2.1 & 2.5 & & $(0,5.0)$ \\
\hline $\mathrm{NiO}$ & 5.4 & 3.6 & $(3.0,7.8)$ & $(1.0,6.2)$ \\
\hline
\end{tabular}

(a) Confidence interval (CI) is given only if the total effect is significantly different from 0 .

(b) The predicted value is significantly different $(\alpha<0.01)$ from the associated observed value.

\subsubsection{Discussion}

The principal glass network former is silica, and it is not suprising that it suppresses devitrification (see Figures 8 and 9). Its negative effect on crystallinity has been long noted (Van Vlack 1964). $\mathrm{B}_{2} \mathrm{O}_{3}$ has a negative effect on devitrification when the glass is deliberately devitrified by slow cooling (Figure 9), which is consistent with its role as a network former and with the fact that there are very few possible crystalline borate compounds.

The intermediates ( $\mathrm{NiO}, \mathrm{Cr}_{2} \mathrm{O}_{3}, \mathrm{Fe}_{2} \mathrm{O}_{3}$, and $\mathrm{ZnO}$ ) had similar positive effects in the air-cooled plot (Figure 8 ) with the component slope seemingly reflecting the tendency with which each participated in forming a crystalline phase; $\mathrm{Cr}_{2} \mathrm{O}_{3}$ had the strongest such tendency. It is noteworthy that the effect of $\mathrm{Cr}_{2} \mathrm{O}_{3}$ becomes slightly negative in the slow-cooled plot (Figure 9). A plausible explanation for this is difficult at best. The rapidly formed phases 


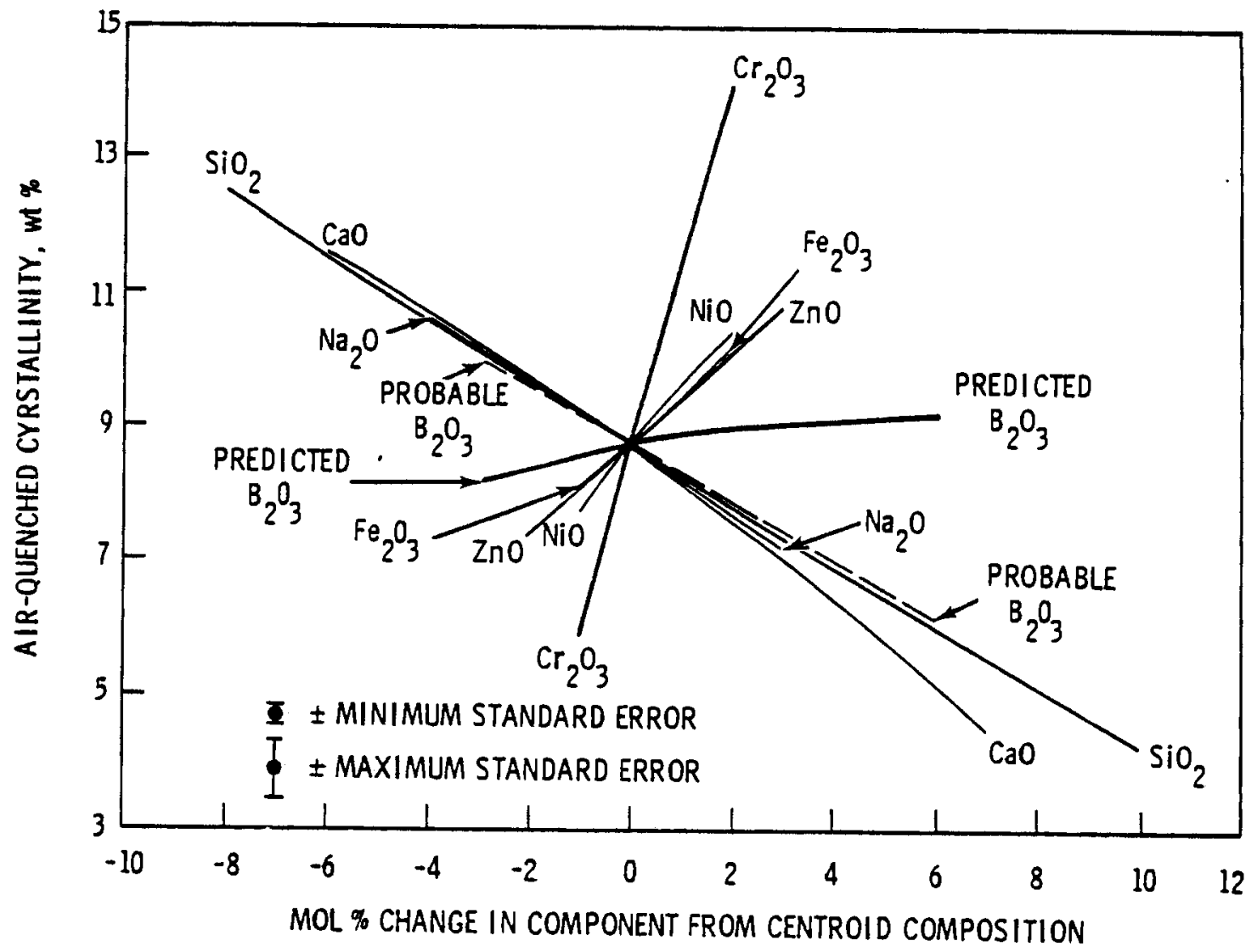

FIGURE 8. Effects of Components on Air-Quenched Crystallinity

caused by chromium in the air-quenched samples must still be present in the slow-cooled specimens. These chromium-containing phases must be overshadowed by other slowly forming phases. It seems more likely that $\mathrm{Cr}_{2} \mathrm{O}_{3}$ would have a small positive effect in Figure 9, this is a reasonable possibility considering the magnitude of the prediction error bars.

The network modifiers, $\mathrm{CaO}$ and $\mathrm{Na}_{2} \mathrm{O}$, showed strong negative effects during air-cooling; but the effect of sodium disappeared (became flat) for slow cooling. The negative effects can best be explained by observing that, as modifiers, these components tend to destory even the short-range order necessary for crystallization. However, upon slow-cooling the effect of $\mathrm{Na}_{2} \mathrm{O}$ to decrease viscosity and allow crystal-building components to continue diffusing at lower temperatures may offset the aforementioned propensity to destroy structural order, which would explain the shift of $\mathrm{Na}_{2} \mathrm{O}$ effect. 


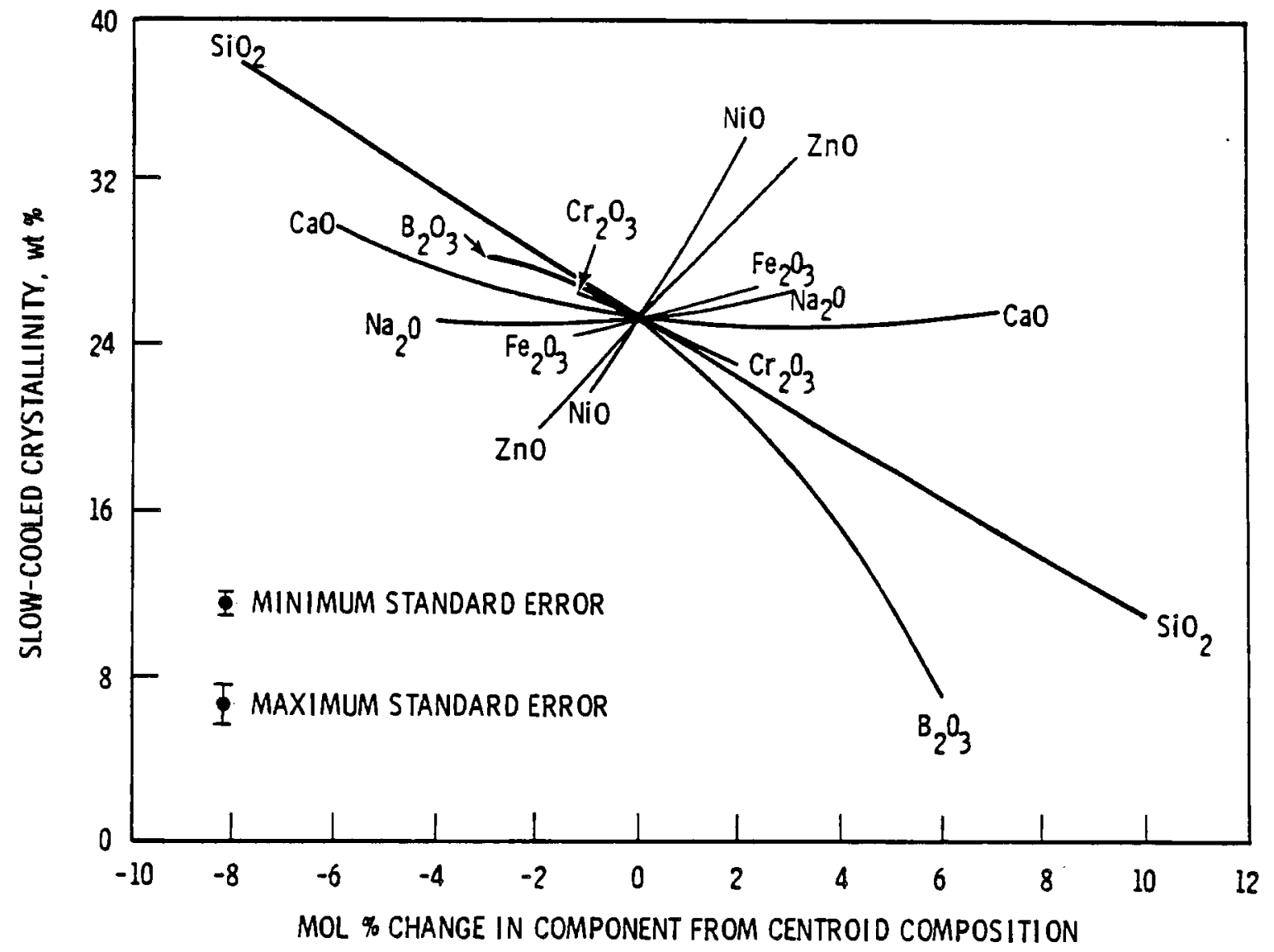

FIGURE 9. Effects of Components on Slow-Cooled Crystallinity

\subsection{GLASS-IN-GLASS PHASE SEPARATION}

Several Group B melts were studied by M. Tomozawa at Rensselaer Polytechnic Institute for evidence of glass-in-glass phase separation. Melts 29, $30,32,33,34$, and 39 showed no evidence of crystallinity via XRD after air quenching (see Appendix B, Table B.5). Tomozawa prepared one-stage replicas of the fractured and etched surfaces of these samples, and replicas were similarly prepared of remelted and water-quenched samples. When viewed on a transmission electron microscope (TEM), all replicas clearly showed evidence of glass-in-glass phase separation, even with water quenching. Figure 10 shows TEM photographs of samples 29,33 , and 34 in both the air-quenched and water-quenched condition; samples 30,32 , and 39 had similar microstructures.

These melts represent a broad range of compositions within the field of study except that none contain $\mathrm{Cr}_{2} \mathrm{O}_{3}$. Since $\mathrm{Cr}_{2} \mathrm{O}_{3}$ produces crystallinity, it can probably be concluded that all the study melts are inhomogeneous due to 


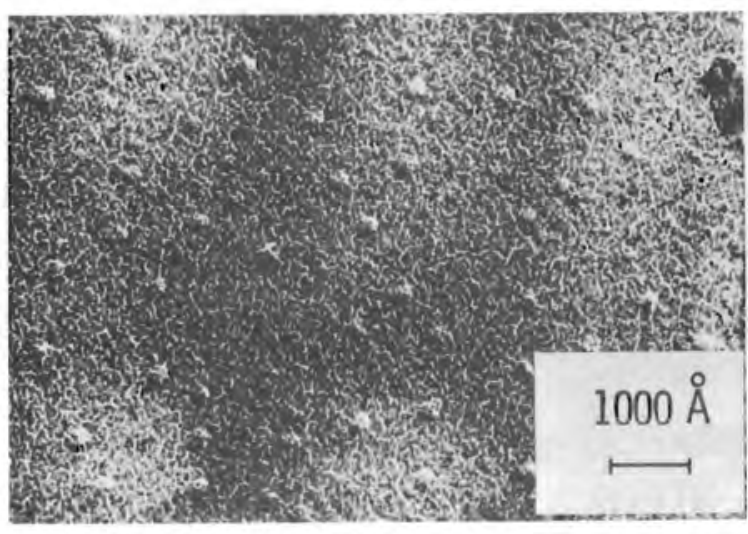

a) Me1t 29, Air-Quenched

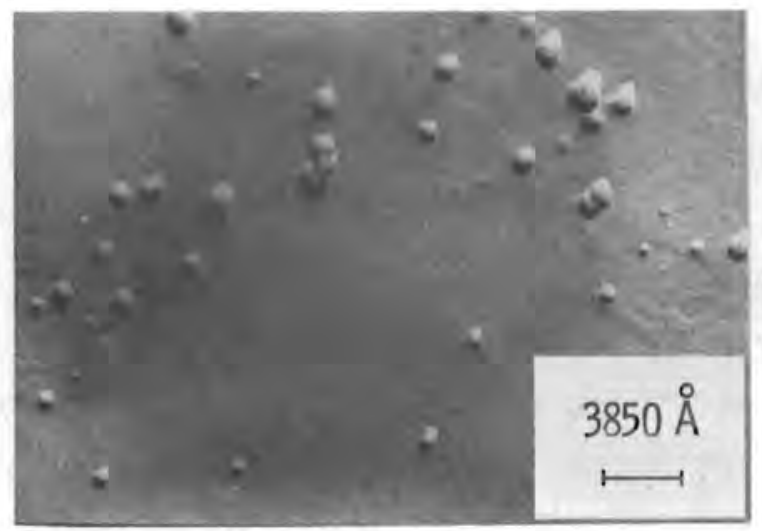

c) Melt 33, Air-Quenched

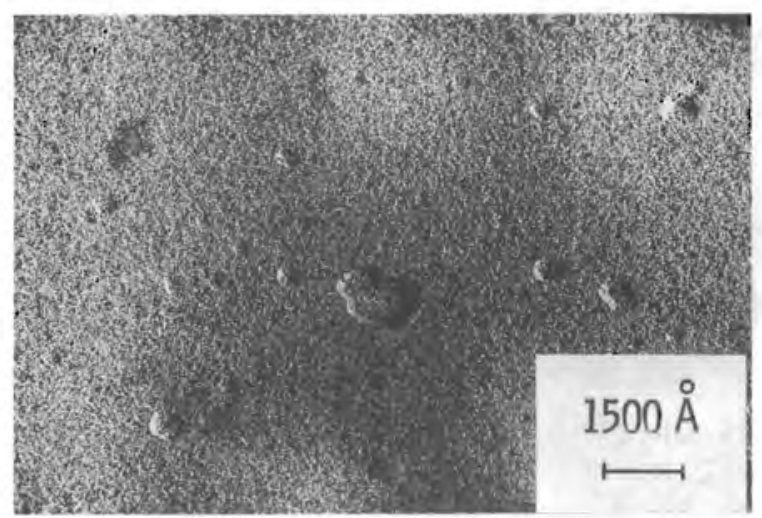

e) Me1t 34, Air-Quenched

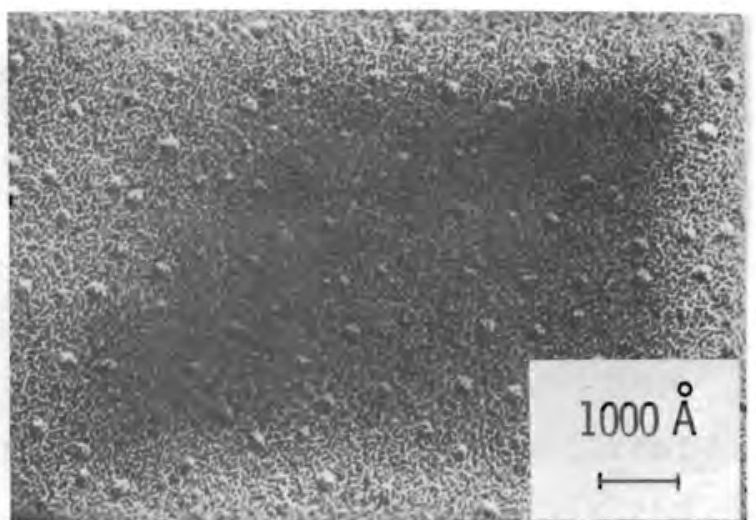

b) Me1t 29, Water-Quenched

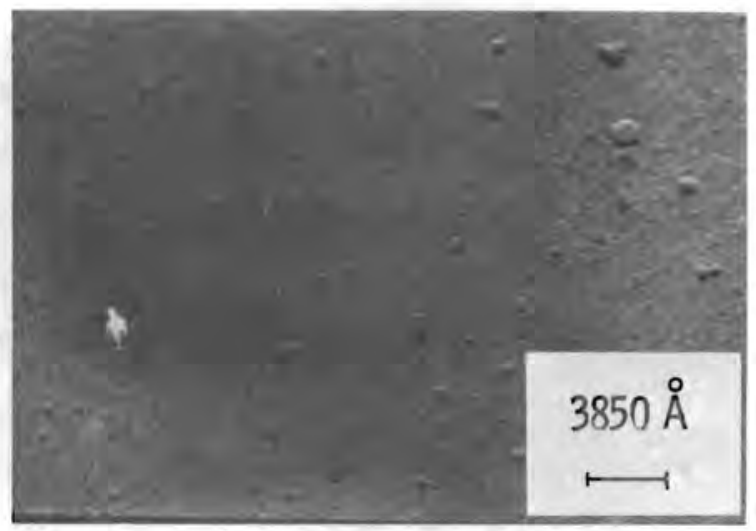

d) Melt 33, Water-Quenched

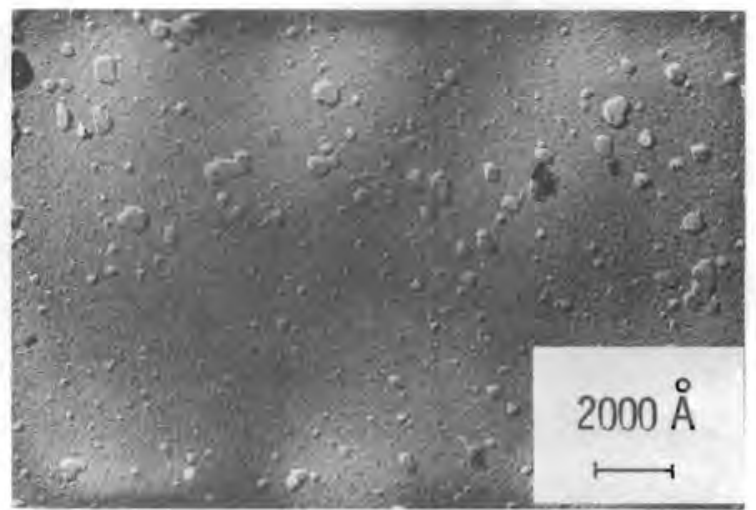

f) Melt 34, Water-Quenched

FIGURE 10. TEM Photographs of Glass-in-Glass Separation for Samples 29, 33, and 34 
either crystallinity or glass-in-glass phase separation. It is likely that those samples with crystallinity also have glass-in-glass phase separation although no glasses that contained crystals were observed in TEM photographs to substantiate this. The fact that phase separation was observed even in the water-quenched samples indicates that the immiscibility temperature is high-probably above $1000^{\circ} \mathrm{C}$. The kinetics of the phase separation are apparently rapid, which suggests that in the air-quenched specimens the phase separation has already completed. Heat treatments attainable in a large-scale processing plant could not prevent phase separation; however, addition of reducing agents to the melts may act to alleviate this tendency (Tomozawa et al. 1979).

In all six melts studied by TEM, the dispersed (droplet) phase protrudes from the etched surface, which indicates that the droplet phase is more durable in the acid etchant. This may be because this phase is enriched in $\mathrm{SiO}_{2}$. The continuous matrix phase is likely to be enriched in $\mathrm{Na}_{2} \mathrm{O}$ and $\mathrm{B}_{2} \mathrm{O}_{3}$. Since this phase controls the chemical durability (Takamori and Tomozawa 1978), it is expected that the phase separation may act to reduce the chemical durability of these materials. Further study is necessary to understand the degree to which glass-in-glass phase separation influences chemical durability and other properties in these glasses. The present lack of this understanding leads to some uncertainty in interpreting component effects for the properties discussed in other sections of this report. Clearly, the study samples are not simple homogeneous materials and their behavior cannot be interpreted solely as if they were.

\subsection{CONCLUSIONS}

- Principal crystalline phases found in these materials after air quenching from the melt temperature are spinels including chromium, nickel, and iron with minor amounts of zinc, titanium, and magnesium.

- Sodium, calcium, boron, and silicon tend to inhibit air-quenched crystallinity.

- Principal crystalline phases found after slow cooling include silicates, aluminates, titanates, and some chromium spinels. 
- Boron and silicon tend to inhibit slow-cooled crystallinity.

- Most, if not all, compositions in the field of study contain glassin-glass phase separation. The continuous matrix phase is probably depleted in silica. 


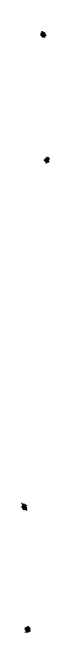




\subsection{VISCOSITY}

\subsection{PROCEDURE}

Glass viscosities were measured using a rotating spindle technique (shown schematically in Figure 11). The glass is contained in a platinum crucible, which is heated in air in a resistance-heated furnace. A platinum viscosity spindle is suspended from the viscometer-a Brookfield model RVT, and the spindle is held in the melt at a controlled depth. Furnace temperature is measured with a type $R$ thermocouple whose output is read with a Fluke model 2100 A digital thermocouple indicator.

The viscometer rotates the spindle in the glass at known speeds, and the instrument measures the sheer force required to rotate the spindle. Two viscometers are used: One translates the sheer force into a 0 to 100 value that is read directly from a scale on the instrument, and the second transforms the reading to a 0 to $10-\mathrm{mV}$ signal that is displayed on a digital millivoltmeter (Fluke model 2100A) and recorded on a strip chart recorder.

Two spindle/crucible combinations were employed (shown in Figure 11). The bowl-shaped crucible was used for making measurements on all melts because readings could be taken quickly, sample change time was minimal, and less sample was required. The second combination consisted of a standard viscosity crucible and spindle; measurements were made with this apparatus on a selected number of melts to confirm the readings from the other system.

Both spindle/crucible combinations were calibrated using a standard viscosity glass obtained from the National Bureau of Standards (NBS glass No. 711). The plot of log viscosity versus reciprocal absolute temperature of this material as determined by NBS is shown in Figure 12 . The systems were calibrated by measuring the viscosity of the standard glass at a number of temperatures. The calibration factor was calculated by the formula:

$$
\text { Calibration Factor }=\text { NBS Viscosity }\left(\frac{\text { Rotation Speed }}{\text { Viscometer Reading }}\right)
$$




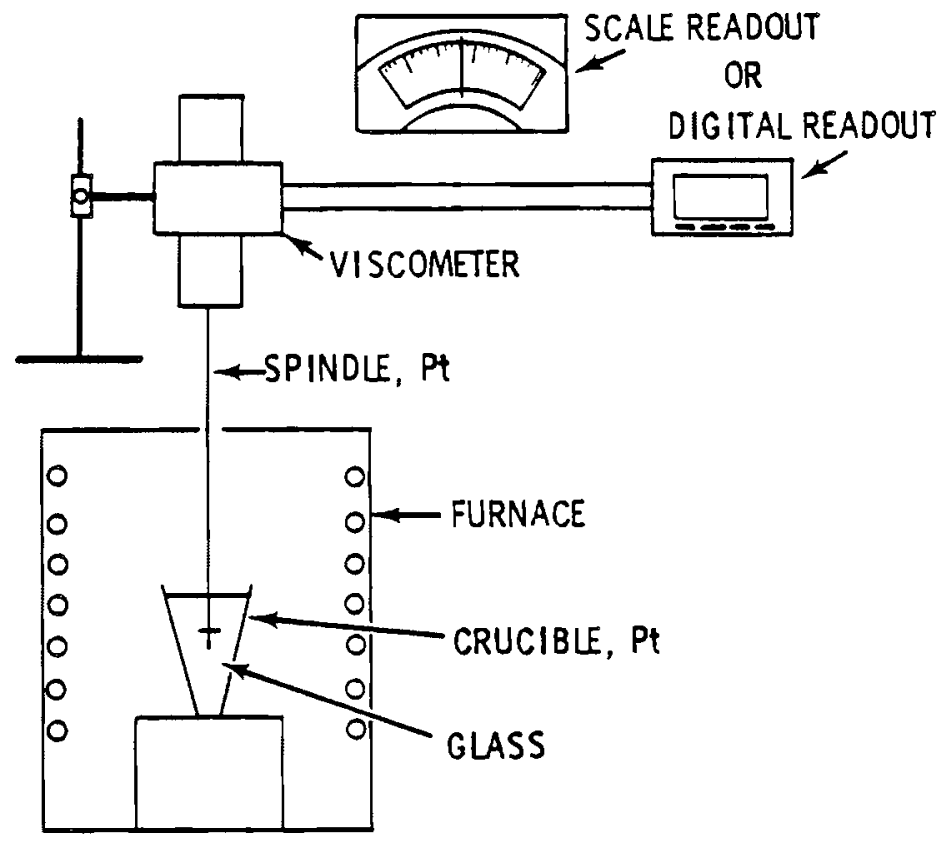

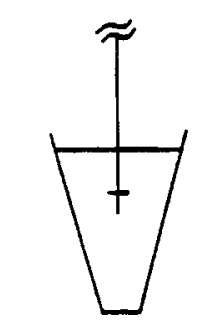

STANDARD

CRUCIBLE AND

SPINDLE

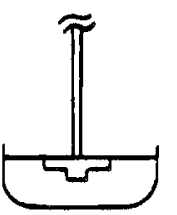

SPINDLE AND CRUCIBLE USED FOR MOST

MEASUREMENTS

FIGURE 11. Schematic of Viscosity Measurement Apparatus and Spindle/ Crucible Combinations

Viscosity measurements were made for each melt at at least two temperatures, and the results were plotted versus inverse temperature. The value at $1250^{\circ} \mathrm{C}$ was interpolated. If extrapolation was necessary, measurements were made at at least four temperatures.

\subsection{RESULTS}

The viscosity model does a good job of predicting for Group D melts. $\mathrm{Cr}_{2} \mathrm{O}_{3}, \mathrm{Al}_{2} \mathrm{O}_{3}$, and $\mathrm{SiO}_{2}$ were found to increase viscosity while $\mathrm{Na}_{2} \mathrm{O}, \mathrm{CaO}$, and $\mathrm{B}_{2} \mathrm{O}_{3}$ were found to decrease it (see Figure 13). 


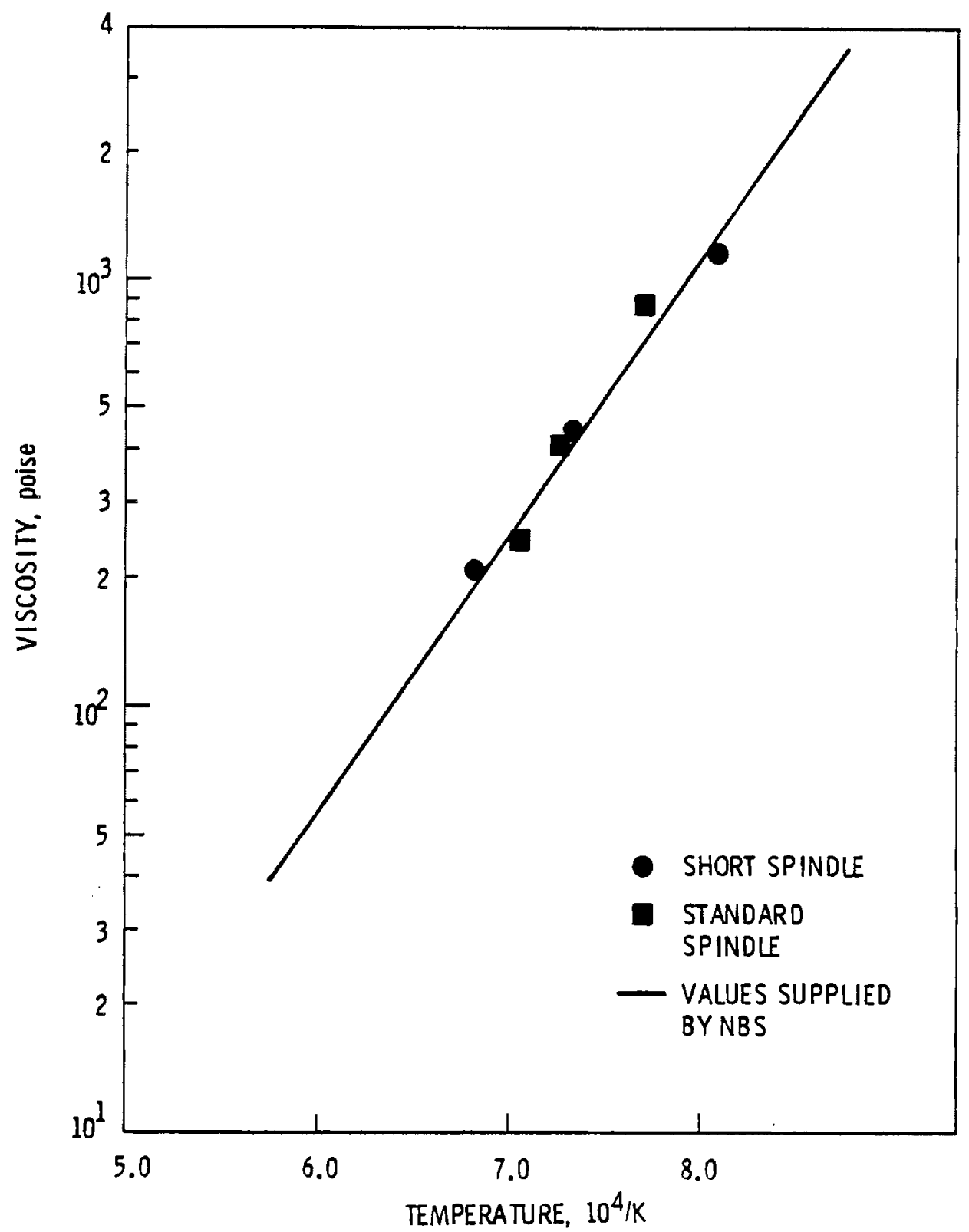

FIGURE 12. Comparison of Measured Viscosity of Standard Glass with Values Supplied by NBS

Viscosity data are presented in Appendix B, Tables B.8, B.9, B.10, and B.11. The minimum observed viscosity was 1.3 poise for melt 30 . Several melts had viscosities above the measurable range of our device and are thus reported as greater than 5800 poise. These data were not included in the set used to calculate the viscosity model. Data for points 20,37 , and 45 were also rejected as outliers based on preliminary modeling efforts. 


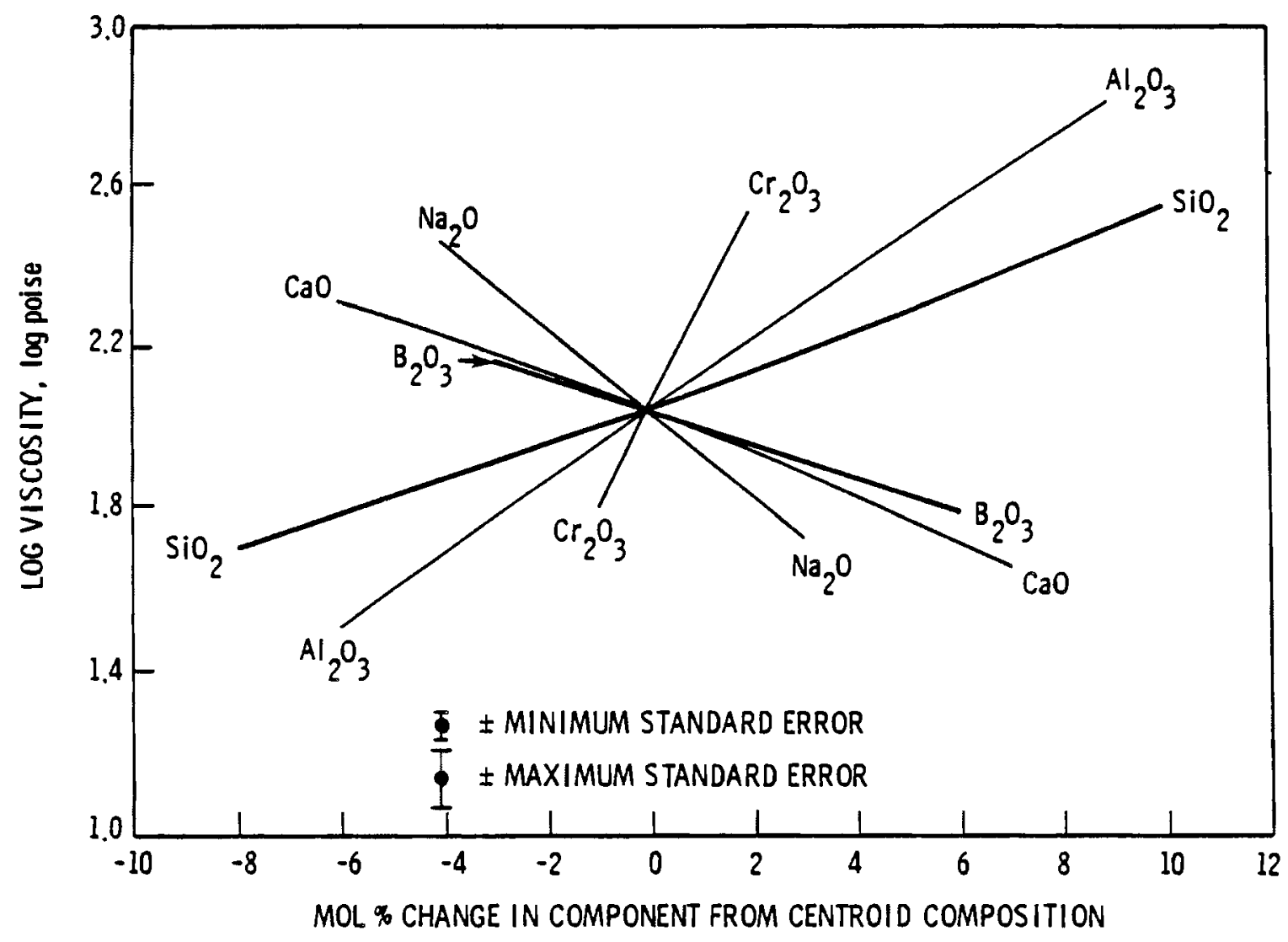

FIGURE 13. Effects of Components on Viscosity at $1250^{\circ} \mathrm{C}$

Figure 13 is based on a model from 37 Group $B$ and $C$ data points (see Appendix C, Table C.3). The maximum standard error is $\pm 0.063 \mathrm{log}$ poise (the range of data observed in the extreme vertices is 0.11 to $3.15 \log$ poise). Table 5 shows that there is no significant difference between the observed and predicted total effects for viscosity; therefore, it appears that the model does a good job of predicting given the limits of experimental error. MgO, $\mathrm{ZnO}, \mathrm{TiO}_{2}, \mathrm{Fe}_{2} \mathrm{O}_{3}$, and $\mathrm{NiO}$ are not included on the effects plot because neither their observed nor predicted total effects were significantly different from zero.

\subsection{DISCUSSION}

The effects of $\mathrm{Al}_{2} \mathrm{O}_{3}, \mathrm{SiO}_{2}, \mathrm{Na}_{2} \mathrm{O}$, and $\mathrm{CaO}$ in Figure 13 can be explained from the classical interpretation of glass structure (Zachiarasen 1932). $\mathrm{SiO}_{2}$ and $\mathrm{Al}_{2} \mathrm{O}_{3}$ are network formers acting to bind the oxide structure in linked polyhedra, and they therefore act to increase viscosity. Sodium and the alkaline 
TABLE 5. Comparison of Observed and Predicted Total Effects for Log Viscosity

\begin{tabular}{|c|c|c|c|c|}
\hline \multirow[b]{2}{*}{ Element } & \multicolumn{2}{|c|}{ Total Effect } & \multirow{2}{*}{$\begin{array}{r}\text { Observed } \\
95 \% \text { CI (a) } \\
\end{array}$} & \multirow{2}{*}{$\begin{array}{l}\text { Predicted } \\
95 \% \text { CI (a) }\end{array}$} \\
\hline & Observed & Predicted & & \\
\hline $\mathrm{SiO}_{2}$ & 0.30 & $1.02^{(b)}$ & & $(0.41,1.63)$ \\
\hline $\mathrm{B}_{2} \mathrm{O}_{3}$ & -0.61 & -0.41 & $(-1.18,-0.04)$ & \\
\hline $\mathrm{Al}_{2} \mathrm{O}_{3}$ & 1.11 & 1.45 & $(0.54,1.68)$ & $(0.87,2.03)$ \\
\hline $\mathrm{CaO}$ & -1.41 & -0.75 & $(-1.98,-0.84)$ & $(-1.33,-0.17)$ \\
\hline $\mathrm{MgO}$ & -0.14 & -0.41 & & \\
\hline $\mathrm{Na}_{2} \mathrm{O}$ & -0.70 & -0.80 & $(-1.27,-0.13)$ & $(-1.39,-0.21)$ \\
\hline $\mathrm{ZnO}$ & 0.15 & -0.20 & & \\
\hline $\mathrm{TiO}_{2}$ & -0.26 & -0.17 & & \\
\hline $\mathrm{Cr}_{2} \mathrm{O}_{3}$ & 1.20 & 1.03 & $(0.63,1.77)$ & $(0.45,1.61)$ \\
\hline $\mathrm{Fe}_{2} \mathrm{O}_{3}$ & 0.39 & 0.01 & & \\
\hline $\mathrm{NiO}$ & -- & -0.06 & & \\
\hline
\end{tabular}

(a) Confidence interval (CI) is given only if the total effect is significantly different from 0 .

(b) There were no significant differences $(\alpha \leq 0.05)$ between observed and predicted values for any component.

earths are modifiers that enter the structure by breaking $M-0-M$ bonds at the corners of the polyhedra: $M-0-M-0+N a \rightarrow M-0-N a+M-0$ (where $M$ is a network former cation). The polyhedra are then free to rotate at their unattached corners; therefore, modifiers act to reduce viscosity.

The effect of $\mathrm{Cr}_{2} \mathrm{O}_{3}$ on viscosity is expected. $\mathrm{Cr}_{2} \mathrm{O}_{3}$ forms crystalline phases in the air-quenched melts, and solid particles provide extra friction in melts undergoing shear movement. That the crystals, predominantly spinels, are present at high temperature is indicated in Appendix B, Table B.6, which shows XRD-determined crystallinity for water-quenched Group $C$ melts.

\subsection{CONCLUSIONS}

- Chromium, aluminum, and silicon increase viscosity at $1250^{\circ} \mathrm{C}$ in this melt system. 
- Spinel crystals probably exist and increase viscosity at $1250^{\circ} \mathrm{C}$.

- Sodium, calcium, and boron decrease viscosity in this compositional region. 


\subsection{VOLATILITY}

\subsection{PROCEDURE}

Two devices were used for vaporization measurements. In the first, which was described previously by Gray (1979), a sample was suspended from a recording balance into a vertical tube furnace with dry air $\left(<50-\mathrm{ppm}_{2} \mathrm{O}\right)$ flowing downward past the sample at a velocity of $\sim 10 \mathrm{~mm} / \mathrm{s}$. Vapors from the sample were collected on a water-cooled cold finger that was removed after $4 \mathrm{~h}$ for chemical analys is of the condensed material; weight losses were recorded for a total of $24 \mathrm{~h}$. Each sample was run a second time for $4 \mathrm{~h}$ to provide another cold-finger sample for chemical analys is. X-ray florescence, atomic absorption spectroscopy, and plasma emission spectroscopy were used to detect all of the elements, except oxygen, that the samples contained. Since the two analytical results generally agreed with in $\pm 5 \%$, they were simply averaged.

In the second device, four samples were heated simultaneously in a vertical tube furnace with room air flowing upward past the samples at a velocity of $\sim 7.8 \mathrm{~mm} / \mathrm{s}$. Weight losses were determined by before-and-after weight measurements on samples heated for $3 \mathrm{~h}$. Results from a previous study indicate that the small amount of moisture $(<1 \%)$ in room air would not yield significantly different results from the dry air used in the first device.

Both devices used 2-g samples in cylindrical platinum crucibles with 200- $\mathrm{m}^{2}$ cross-sectional areas. The glass depth was about $1 \mathrm{~cm}$. In both cases, the furnaces were preheated and the samples were quickly inserted (in 1 to 3 min) into the hot furnace and quickly removed at the end of each run.

The two devices did not give the same results; weight losses in the first device were about two-thirds those in the other device; however, this was not considered important because both devices gave consistent comparisons between the different glasses.

\subsection{RESULTS}

The volatility model predicts Group $\mathrm{D}$ data well. $\mathrm{Na}_{2} \mathrm{O}, \mathrm{CaO}$, and $\mathrm{B}_{2} \mathrm{O}_{3}$ have positive effects while $\mathrm{SiO}_{2}$ and $\mathrm{Al}_{2} \mathrm{O}_{3}$ have negative effects (see Figure 14). A 
negative correlation was found between viscosity and volatility. The main volitalizing species was found to be a sodium borate compound of the form $\left(\mathrm{NaBO}_{2}\right)^{\cdot} \cdot$

Three-hour weight loss results are shown in Appendix B, Tables B.8, B.9, $B .10$, and B.11; and values range from $1.8-$ to $151-\mathrm{mg}$ loss at $1300^{\circ} \mathrm{C}$. A model was successfully fit to Group $B$ and $C$ log volatility data at $1300^{\circ} \mathrm{C}$ (see Appendix C, Table C.4). The maximum standard error in the model was \pm 0.035 ( $\log \mathrm{mg} \operatorname{loss}$ ). There is no significant disagreement between observed and predicted total effects (Table 6) except for $\mathrm{Cr}_{2} \mathrm{O}_{3}$ where the observation is positive and the prediction is negative. However, neither value is large compared to more important components. $\mathrm{Cr}_{2} \mathrm{O}_{3}$ is deleted from the effects plot (Figure 14). $\mathrm{MgO}, \mathrm{ZnO}, \mathrm{TiO}_{2}, \mathrm{Fe}_{2} \mathrm{O}_{3}$, and $\mathrm{NiO}$ were also deleted from the plot since their effects, although in agreement for observed and predicted values, were not significantly different from zero.

TABLE 6. Comparison of Observed and Predicted Total Effects for Log Volatility

\begin{tabular}{|c|c|c|c|c|}
\hline \multirow[b]{2}{*}{ Element } & \multicolumn{2}{|c|}{ Total Effect } & \multirow{2}{*}{$\begin{array}{r}\text { Observed } \\
95 \% \text { CI (a) }\end{array}$} & \multirow{2}{*}{$\begin{array}{l}\text { Predicted } \\
95 \% \text { CI (a) }\end{array}$} \\
\hline & Observed & Predicted & & \\
\hline $\mathrm{SiO}_{2}$ & -0.21 & -0.32 & $(-0.34,-0.08)$ & $(-0.49,-0.15)$ \\
\hline $\mathrm{B}_{2} \mathrm{O}_{3}$ & 0.43 & 0.38 & $(0.30,0.56)$ & $\left(\begin{array}{ll}0.22, & 0.54\end{array}\right)$ \\
\hline $\mathrm{Al}_{2} \mathrm{O}_{3}$ & -0.89 & -0.83 & $(-1.02,-0.76)$ & $(-0.99,-0.67)$ \\
\hline $\mathrm{CaO}$ & 0.44 & 0.39 & $(0.31,0.57)$ & $\left(\begin{array}{lll}0.24, & 0.54)\end{array}\right.$ \\
\hline $\mathrm{MgO}$ & 0.04 & 0.07 & & \\
\hline $\mathrm{Na}_{2} \mathrm{O}$ & 0.62 & 0.43 & $\left(\begin{array}{ll}0.49, & 0.75\end{array}\right)$ & $\left(\begin{array}{ll}0.27, & 0.59\end{array}\right)$ \\
\hline $\mathrm{ZnO}$ & -0.08 & 0.04 & & \\
\hline $\mathrm{TiO}_{2}$ & -0.15 & -0.08 & $(-0.28,-0.02)$ & \\
\hline $\mathrm{Cr}_{2} \mathrm{O}_{3}$ & 0.17 & $-0.26(b)$ & $\left(\begin{array}{ll}0.04, & 0.30\end{array}\right)$ & $(-0.41,-0.11)$ \\
\hline $\mathrm{Fe}_{2} \mathrm{O}_{3}$ & -0.05 & -0.10 & & \\
\hline $\mathrm{NiO}$ & -0.09 & -0.08 & & \\
\hline
\end{tabular}

(a) Confidence interval (CI) is given only if the total effect is significantly different from 0 .

(b) The predicted value is significantly different $(\alpha<0.01)$ from the associated observed value. 


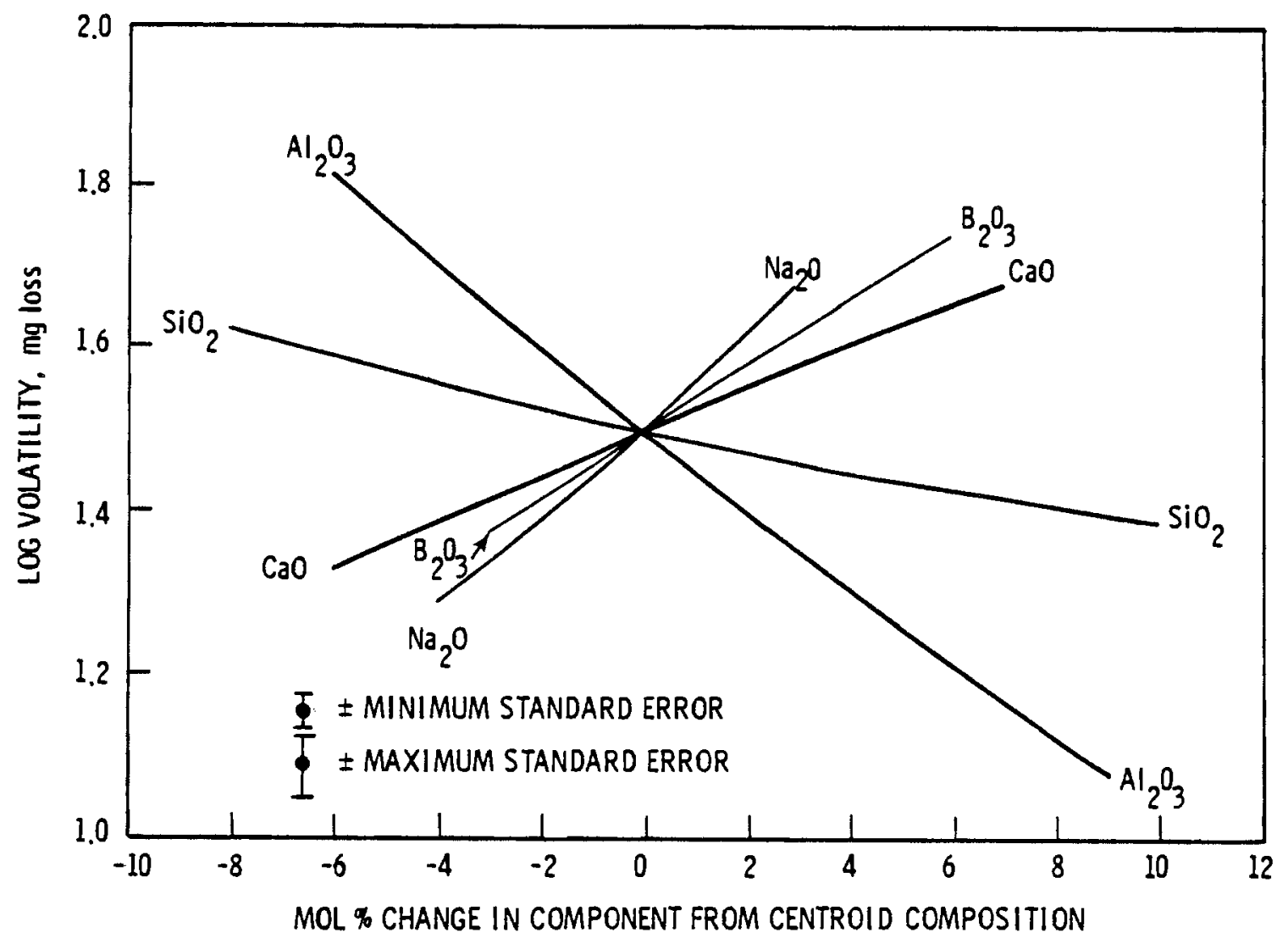

FIGURE 14. Effects of Components on Volatility at $1300^{\circ} \mathrm{C}$ for $3 \mathrm{~h}$

A Pearson correlation coefficient of -0.73 was found between the viscosity data ( $\log$ poise) and the volatility data (log $\mathrm{mg}$ loss). A zero coefficient would indicate no correlation between the properties whereas a coefficient of \pm 1.0 would indicate perfect (positive or negative) correlation. Large positive correlation was found between volatility and three leaching properties. These are discussed in Section 8.2.

The composition of vaporized material was determined only on Group B samples. Only $\mathrm{B}, \mathrm{Na}$, and $\mathrm{Cr}$ were found; and the amount of $\mathrm{Cr}$ was always only slightly above detection limits. Mass balance considerations suggest that $B$ and $\mathrm{Na}$ vaporized as $\mathrm{Na}_{2} \mathrm{O}$ and $\mathrm{B}_{2} \mathrm{O}_{3}$ although oxygen was not analyzed. The amount of $\mathrm{Cr}$ found was too small to determine its form; if it is assumed to be $\mathrm{Cr}_{2} \mathrm{O}_{3}$, then it comprised 0.5 to $2.6 \mathrm{wt} \%$ of the total condensed vapor. $\mathrm{Na}_{2} \mathrm{O}$ and $\mathrm{B}_{2} \mathrm{O}_{3}$ comprised the remainder in nearly equal molar ratios. The average for all 20 samples was $50.8 \mathrm{mo}_{\%} \% \mathrm{Na}_{2} \mathrm{O}$ and $48.8 \mathrm{~mol} \% \mathrm{~B}_{2} \mathrm{O}_{3}$ with one standard deviation 
for the individual samples being $2.0 \mathrm{~mol} \%$. The fact that the $\mathrm{Na}_{2} \mathrm{O}_{\mathrm{B}} \mathrm{B}_{2} \mathrm{O}_{3}$ ratio in the vapor remains equal to unity while it ranges from 0.92 to 2.67 in the different melts suggests that the vaporizing species is $\left(\mathrm{NaBO}_{2}\right)_{X}$.

Figure 15 shows weight loss data as a function of time for two samples with the maximum and minimum weight losses. Interestingly, the curves have similar shapes even though $\sim 70 \%$ of the $\mathrm{B}_{2} \mathrm{O}_{3}$ and $\sim 60 \%$ of the $\mathrm{Na}_{2} \mathrm{O}$ were lost from melt 30 , whereas the corresponding losses for melt 37 were $\sim 7 \%$ and $\sim 4 \%$. Data for the other 18 samples in Group B show similar time dependencies; that is, between about 1 and $10 \mathrm{~h}$ they are proportional to the square root of time, which implies that diffusion limits vaporization rates. Slight deviations from this relationship occur for shorter and longer times, however.

\subsection{DISCUSSION}

The significant effects shown in Figure 14 are readily explained. Since $\mathrm{Na}_{2} \mathrm{O}$ and $\mathrm{B}_{2} \mathrm{O}_{3}$ are the volatile materials, increasing their concentrations can reasonably be expected to increase volatility. Both the present study and an earlier one (Gray 1979) show that there is a strong negative correlation between volatility and viscosity. Thus, components such as $\mathrm{Al}_{2} \mathrm{O}_{3}$ and $\mathrm{SiO}_{2}$ that increase viscosity tend to decrease volatility; and components that decrease viscosity should increase volatility. This explains the effect of CaO.

Whether volatility of these glasses is diffusion limited as implied by the square root-time dependencies discussed above or whether convective currents control the process, viscosity would logically have similar effects on both mechanisms. Thus, the component effects shown in Figure 15 cannot be used to differentiate between volatility mechanisms.

\subsection{CONCLUSIONS}

- Only $\mathrm{Na}_{2} \mathrm{O}$ and $\mathrm{B}_{2} \mathrm{O}_{3}$ are vaporized in significant quantities although a small amount of $\mathrm{Cr}_{2} \mathrm{O}_{3}$ was also found in the vapor.

- $\mathrm{Na}_{2} \mathrm{O}$ and $\mathrm{B}_{2} \mathrm{O}_{3}$ vaporize in approximately equal molar quantities independent of the glass composition. 


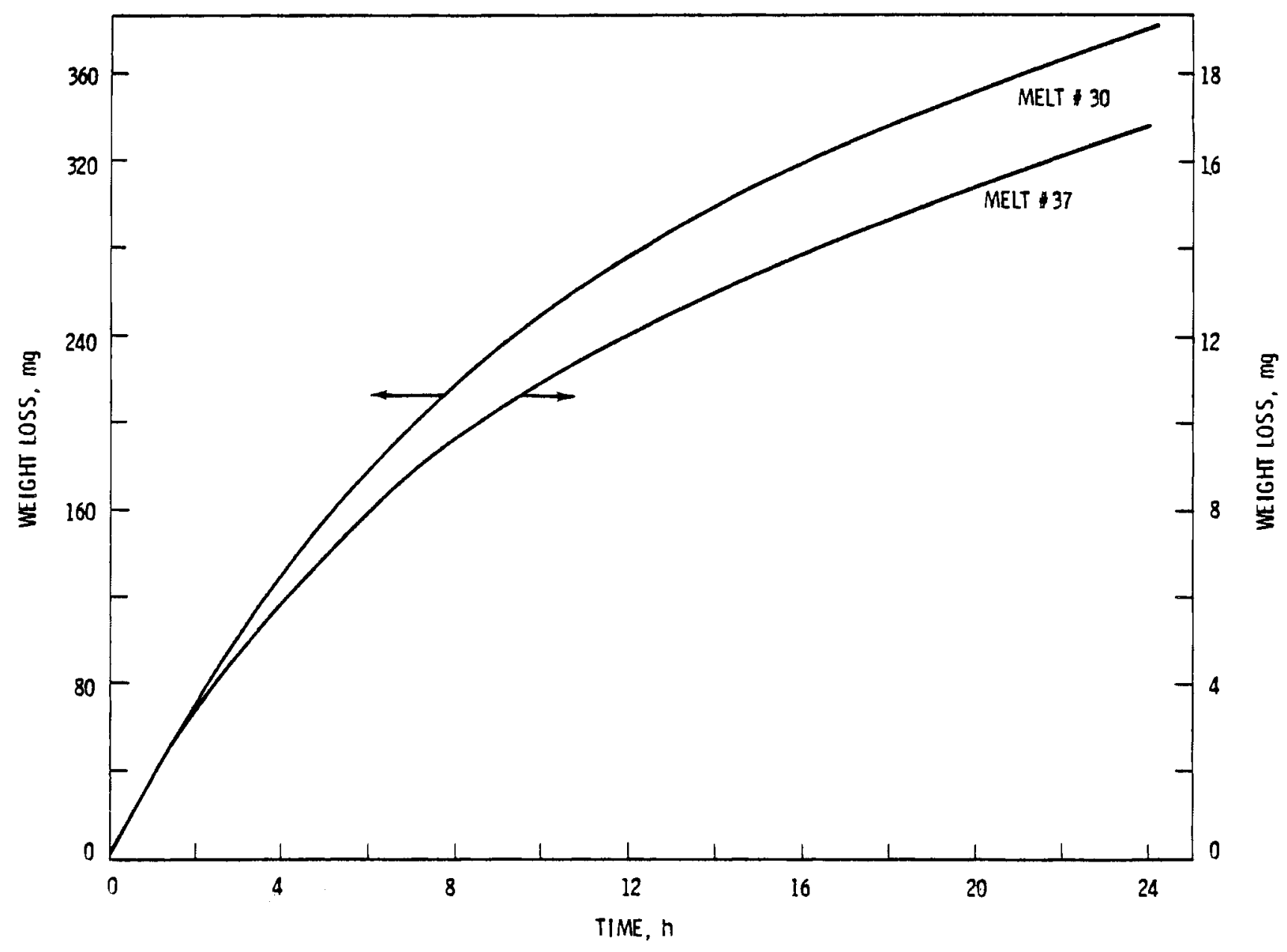

FIGURE 15. Volatility Weight Loss Versus Time

- Volatilities can be reasonably well predicted from the model developed.

- Volatility is negatively correlated with viscosity. Thus, components that increase viscosity $\left(\mathrm{SiO}_{2}, \mathrm{Al}_{2} \mathrm{O}_{3}\right)$ decrease volatility; and components that decrease viscosity $\left(\mathrm{Na}_{2} \mathrm{O}, \mathrm{B}_{2} \mathrm{O}_{3}, \mathrm{CaO}\right)$ increase volatility. 


\subsection{CHEMICAL DURABILITY}

\subsection{PROCEDURE}

Chemical durability of the study samples was measured in three leaching tests: two of the weight loss-type and one using solution analysis. Table 7 and Figure 16 summarize the procedures.

The Soxhlet test was performed on samples that had been air quenched from the melting temperature. This material was crushed and screened to yield a sample of particle size range from 0.250 to $0.425 \mathrm{~mm}(-40$ to +60 mesh, U.S. standard sieve). One gram of this material was placed in a 200-mesh stainless steel envelope that had been cleaned in acetone and weighed prior to filling. The filled envelope was placed in a small acetone-filled beaker in an ultrasonic bath to remove any -200-mesh particles that might be adhering to the larger fraction. The envelope with sample was then dried and weighed.

The sample was placed in the Soxhlet extractor $(a)$ and leached for $24 \mathrm{~h}$; the device intermittently recirculates freshly condensed water over the sample. Leached elements collect in the boiling chamber and are thus not

\section{TABLE 7. Summary of Weight Loss Leaching Tests}

\begin{tabular}{|c|c|c|c|c|c|}
\hline Test & Sample Type & $\begin{array}{c}\text { Temperature, } \\
{ }^{\circ} \mathrm{C} \\
\end{array}$ & $\begin{array}{c}\text { Duration, } \\
\mathrm{h}\end{array}$ & Leachant & $\begin{array}{l}\text { Measured } \\
\text { Property }\end{array}$ \\
\hline Soxhlet & $\begin{array}{c}1-g, \\
-40+60 \text { mesh }\end{array}$ & 98 & 24 & $\begin{array}{c}\text { distj } \\
\mathrm{H}_{2} \mathrm{O}\end{array}$ & wt\% loss \\
\hline ph 4 & $\begin{array}{c}1-g, \\
-40+60 \text { mesh }\end{array}$ & 25 & 19 & $\operatorname{ph}_{\text {acid }} 4(b)$ & wt\% loss \\
\hline
\end{tabular}

(a) Leachant is continuously condensed from boiling bath and drips into sample holder. Sample holder siphons empty at w15-min intervals and is refilled with freshly condensed leachant. Leached products collect in boiling bath, not in contact with sample.

(b) Sodium acetate-buffered acetic acid solution. Makeup: 25.20-g $\mathrm{NaC}_{2} \mathrm{H}_{3} \mathrm{O}_{2} \cdot 3 \mathrm{H}_{2} \mathrm{O}+\mathrm{H}_{3} \mathrm{O}_{2}+67.0-\mathrm{ml} \mathrm{CH} 3 \mathrm{COOH}+$ distilled $\mathrm{H}_{2} \mathrm{O}$ to make 1 liter. Sample remains immersed in leachant with leached products.

(a) For details of the Soxhlet apparatus, see Mendel et al. 1977. 
1.

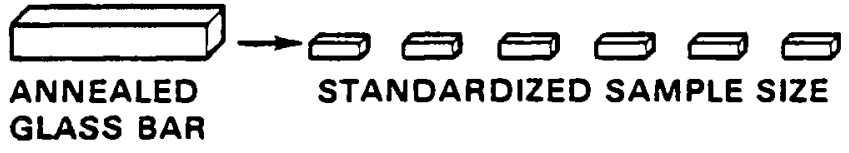

a) CUT

b) SANDED

c) MEASURED WITH MICROMETER

d) ULTRASONICALLY CLEANED

2.
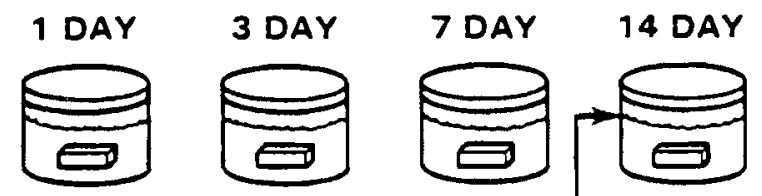

28 DAY

INDIVIDUAL SEALED SAMPLE CONTAINERS IN CONTROLLED

AMOUNT OF SOLUTION TEMPERATURE LEACH BATH MEASURED TO GIVE CONSTANT

SAMPLE SURFACE AREA SOLUTION VOLUME

RATIO

3.

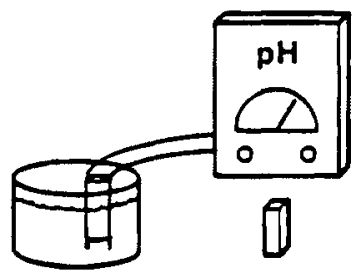

AT EACH TIME INTERVAL, A SAMPLE IS REMOVED FROM ITS CONTAINER, THE PH OF THE SOLUTION IS MEASURED. AND THE SOLUTION IS ANALYZED BY ICP FOR ELEMENTAL CONCENTRATIONS.

\section{FIGURE 16. Static Leaching Procedure}

in contact with the sample. After this treatment, the sample was placed in a drying oven for $4 \mathrm{~h}$, reweighed, and the wt\% loss resulting from leaching was calculated. Three samples of each glass were leached in this manner. Prior to the experiments, the metal screens were tested for weight loss in the Soxhlet, none was found.

Sample preparation for $\mathrm{pH} 4$ testing was identical to that used for Soxhlet leaching. The weighed samples were suspended in polyethylene jars containing 
1 liter of leachant, and the jars were agitated for $19 \mathrm{~h}$. Leached elements built up in the contacting solution in these experiments. The samples were then removed, washed in distilled water, and dried. Two samples of each glass were leached; wt\% loss was calculated. No weight loss was found when the metal screen envelopes were subjected to this test without glass present. This test was performed once on Group A melts and twice each on Group B, C, and D melts.

The static (solution analysis) test is essentially the same as the socalled MCC-1 standard test except that polypropylene containers in gylcerine baths were used instead of teflon in ovens. The test was performed on melts from Group B, half of Group C, and Group D. Bars were poured from the melt into a stee 1 mold approximately $1 \times 1 \times 10 \mathrm{~cm}$ and then annealed $2 \mathrm{~h}$ at $500^{\circ} \mathrm{C}$. Melts that were too viscous to pour were annealed in their platinum melting crucibles. Rectangular blocks approximately $2 \times 5 \times 8 \mathrm{~mm}$ were diamond sawed in oil from the bars. All sides of each sample were sanded with 600-grit silicon carbide paper to yield a uniform surface with no saw marks. The geometric surface area was determined using an electronic micrometer. Samples were then ultrasonically cleaned in acetone and absolute ethyl alcohol. A loop of 6-mil polypropylene filament suspended each sample in a polypropylene bottle with the top end of the filament bonded to the container lid.

Enough deionized water ( $\mathrm{pH} 5.5$ to 5.9) was added to each bottle to bring the sample surface area-to-solution volume ratio to $10 \mathrm{~m}^{-1}$. The lids of the bottles were sealed by welding the plastic, and the bottles were placed in a circulating glycerine bath maintained at $90^{\circ} \mathrm{C} \pm 0.5^{\circ} \mathrm{C}$. The duration of the test was 28 days. Some samples were also tested at $1,3,7$, and 14 days to yield time-dependent curves.

Before leaching, the $\mathrm{pH}$ was measured in each solution using a calibrated Markson digital Model 88 meter. An ICAP analys is procedure similar to that employed for chemical analysis of the samples was used on the leach solutions to determine their elemental content. On several runs, the inside surfaces of the bottle were acid stripped and analyzed to assure that no significant amounts of leached elements were adsorbed by the container material. Less than $10 \%$ of the solution inventory of any glass element was found to have been adsorbed. 


\subsection{RESULTS}

The Soxhlet and pH 4 weight-loss-type tests produced successful models; however, the effects of $\mathrm{SiO}_{2}$ and $\mathrm{Al}_{2} \mathrm{O}_{3}$ in the Soxhlet and static tests were confused. In the static test, the beneficial effect of $\mathrm{Al}_{2} \mathrm{O}_{3}$ was so overwhe $1 \mathrm{~m}-$ ing that effects of other components could not be successfully predicted. A strong correlation was found between resulting solution $\mathrm{pH}$ and elemental release on the static test.

Results of the weight loss leaching tests are shown in Tables B.8, B.12, B.13, and B.14. Weight losses for the Soxhlet test ranged from $0.38 \%$ (average for three tests) on melt 37 to $14.3 \%$ for melt 24 .

A model was successfully fit to base 10 logarithms of Soxhlet data from Groups $B$ and $C$ (see Appendix C, Table C.1). The maximum prediction standard error from the model was \pm 0.012 log wt\% loss.

The comparison between observed and predicted total effects using total error of $\pm 0.18 \mathrm{log} w \mathrm{t} \%$ is shown in Table 8. Effects of five components $\left(\mathrm{SiO}_{2}\right.$, $\mathrm{B}_{2} \mathrm{O}_{3}, \mathrm{Al}_{2} \mathrm{O}_{3}, \mathrm{CaO}$, and $\mathrm{Na}_{2} \mathrm{O}$ ) were observed to be significantly different from zero and are thus included on the effects plot (Figure 17). There is a significant difference between observed and predicted total effects of $\mathrm{SiO}_{2}$. The model underestimates the beneficial effect of $\mathrm{SiO}_{2}$ in increasing Soxhlet durability, which probably results from the correlation between $\mathrm{SiO}_{2}$ and $\mathrm{Al}_{2} \mathrm{O}_{3}$ imposed in the experimental design. The correlation and its effect will be discussed later.

Results of the buffered $\mathrm{pH} 4$ test ranged from no measurable weight loss for melts 28 and 29 to 96.6 wt\% loss for melt 63. A model was fit to Group B and $\mathrm{C}$ pH 4 data (see Appendix $C$, Table C.2); the maximum prediction standard error for the model was $\pm 0.037 \log w t \%$ loss.

Seven components were observed to have significant total effects on $\mathrm{pH} 4$ wt\% loss as shown in Table 9. The seven-- $\mathrm{SiO}_{2}, \mathrm{~B}_{2} \mathrm{O}_{3}, \mathrm{Al}_{2} \mathrm{O}_{3}, \mathrm{CaO}, \mathrm{Na}_{2} \mathrm{O}, \mathrm{TiO}_{2}$, and $\mathrm{Cr}_{2} \mathrm{O}_{3}$--are shown in the effects plot (Figure 18). There are significant differences between two of the observed effects and the corresponding predictions. The model correctly predicts the signs of these two effects but underestimates the beneficial effect of $\mathrm{TiO}_{2}$ and overestimates the detrimental effect of $\mathrm{B}_{2} \mathrm{O}_{3}$. There are significant differences between the observed and 
TABLE 8. Comparison of Observed and Predicted Total Effects for Log Soxh let

\begin{tabular}{|c|c|c|c|c|}
\hline Element & \multicolumn{2}{|c|}{ Total Effect } & $\begin{array}{l}\text { Observed } \\
95 \% \text { CI (a) }\end{array}$ & $\begin{array}{l}\text { Predicted } \\
95 \% \text { CI }\end{array}$ \\
\hline $\mathrm{SiO}_{2}$ & -0.34 & $-0.02^{(b)}$ & $(-0.47,-0.21)$ & \\
\hline $\mathrm{B}_{2} \mathrm{O}_{2}^{\mathrm{C}}$ & 0.16 & 0.11 & $(0.03,0.29)$ & \\
\hline $\mathrm{A}]_{2} \mathrm{O}_{3}$ & -0.45 & -0.49 & $(-0.58,-0.32)$ & $(-0.62,-0.36)$ \\
\hline $\mathrm{CaO}$ & 0.28 & 0.20 & $(0.15, \quad 0.41)$ & $\left(\begin{array}{ll}0.07, & 0.33\end{array}\right)$ \\
\hline $\mathrm{MgO}$ & 0.06 & 0.09 & & \\
\hline $\mathrm{Na}_{2} \mathrm{O}$ & 0.15 & 0.04 & $\left(\begin{array}{ll}0.02, & 0.28)\end{array}\right.$ & \\
\hline $\mathrm{ZnO}$ & 0.01 & -0.06 & & \\
\hline $\mathrm{TiO}_{2}$ & -0.10 & 0.01 & & \\
\hline $\mathrm{Cr}_{2} \mathrm{O}_{3}$ & 0.01 & 0.04 & & \\
\hline $\mathrm{Fe}_{2} \mathrm{O}_{3}$ & 0.03 & -0.08 & & \\
\hline $\mathrm{NiO}$ & 0.12 & 0.10 & & \\
\hline
\end{tabular}

(a) Confidence interval (CI) is given only if the total effect is significantly different from 0 .

(b) The predicted value is significantly different $(\alpha<0.01)$ from the associated observed value.

predicted total effects of $\mathrm{Fe}_{2} \mathrm{O}_{3}$ and $\mathrm{NiO}$ as well; and on these, the signs of the effects were not predicted. However, these were not observed to be significant effects and are not included on the effects plot.

Tables B.15, B.16, and B.17 show solution analyses results for the static leaching test. Data are reported as normalized elemental mass losses in units of $\mathrm{g} / \mathrm{m}^{2}$. The solution data were transformed by:

$$
\left[\begin{array}{c}
\text { normalized } \\
\text { elemental } \\
\text { mass loss } \\
\text { for element }
\end{array}\right]\left(\mathrm{g} / \mathrm{m}^{2}\right)=\frac{\text { mass of } x \text { in solution }(\mathrm{g})}{\left[\begin{array}{c}
\text { geometric } \\
\text { sample } \\
\text { surface } \\
\text { area }
\end{array}\right]\left(\mathrm{m}^{2}\right)\left[\begin{array}{c}
\text { weight } \\
\text { fraction } \\
\text { of } x \text { in } \\
\text { sample }
\end{array}\right] \text { (unitless) }}
$$

Normalization of the data by the weight fraction of the element in the samples allows comparison to congruent dissolution. Such dissolution, signified by equal normalized elemental mass losses for all elements in a particular sample, would occur if the elements went into solution uniformly, leaving a 


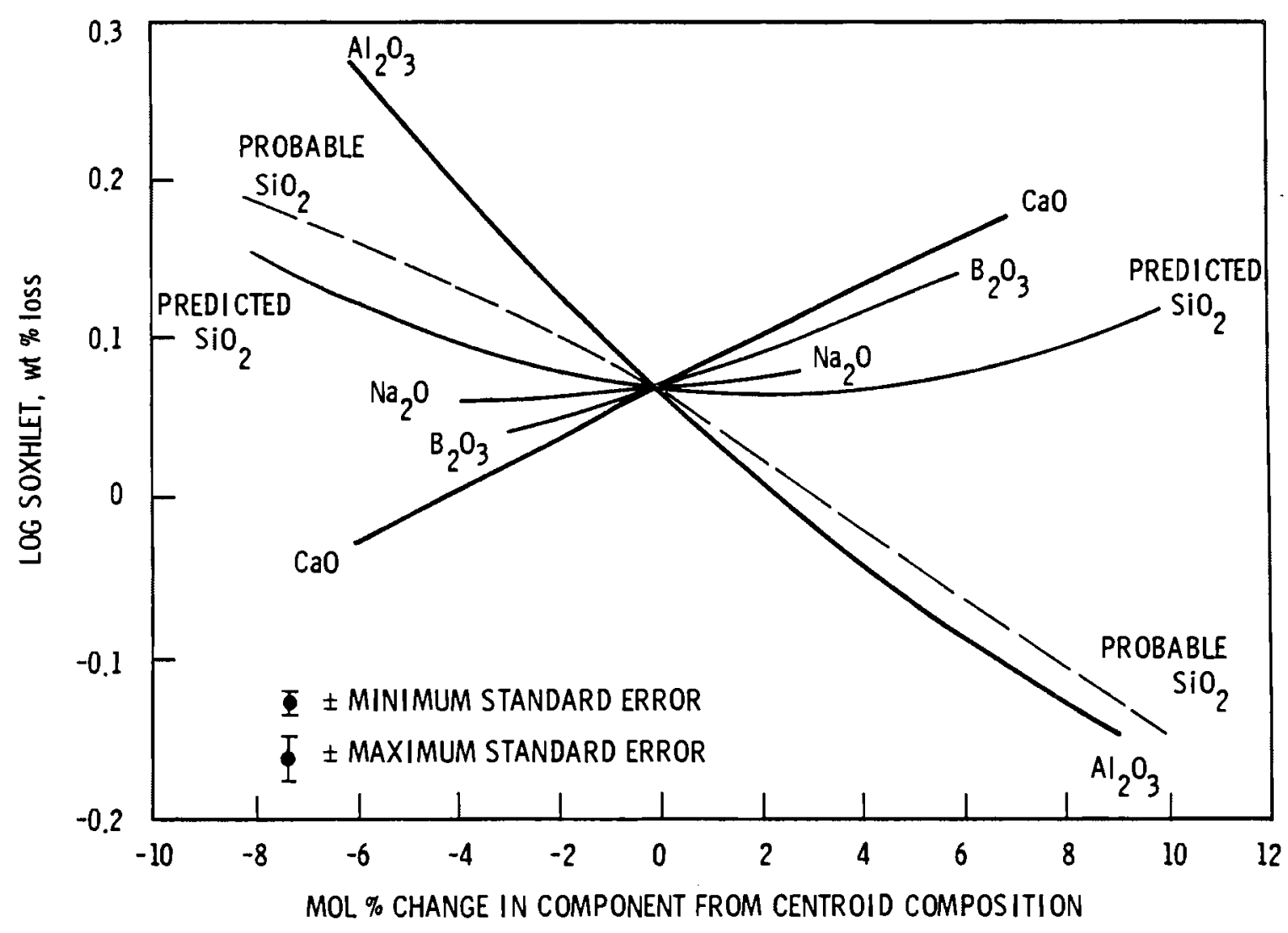

FIGURE 17. Effects of Components on Soxhlet Leaching Weight Loss

leached surface of the same composition as the bulk sample. As can be seen in Tables B.15, B.16, and B.17, none of the samples tested appeared to leach congruently. Sample 32 in Table B.18 comes about as close to congruent leaching as any, and yet its sodium release is about threefold higher than its aluminum release. Factors of 10 to 100 difference between normalized elemental releases for the same glasses are more typical, with sodium usually yielding the highest release and chromium or aluminum the lowest.

On the basis of silicon release, sample 27 was least durable (55 norma1ized $\mathrm{g} / \mathrm{m}^{2}$ ) and sample 37 was most durable ( 1.3 normalized $\mathrm{g} / \mathrm{m}^{2}$ ).

The static leaching data did not produce satisfactory models; several factors contributed to the difficulties. The major problem was that the beneficial effect of alumina was so large that the effects of other components were lost in the "noise" of the experimental error. This is illustrated by comparing the observed total effect of $\mathrm{Al}_{2} \mathrm{O}_{3}$ on silicon and sodium releases to 
TABLE 9. Comparison of Observed and Predicted Total Effects for Log pH 4

\begin{tabular}{|c|c|c|c|c|}
\hline Element & $\frac{\text { Tot }}{\text { Observed }}$ & $\frac{\text { ffect }}{\text { Predicted }}$ & $\begin{array}{c}\text { Observed (a) } \\
95 \% \text { CI } \\
\end{array}$ & $\begin{array}{c}\text { Predicted (a) } \\
95 \% \text { CI }\end{array}$ \\
\hline $\mathrm{SiO}_{2}$ & -1.47 & -2.09 & $(-1.82,-1.12)$ & $(-2.45,-1.73)$ \\
\hline $\mathrm{B}_{2} \mathrm{O}_{3}^{\mathrm{C}}$ & 0.47 & $1.22^{(b)}$ & $(0.12,0.82)$ & $(0.85,1.59)$ \\
\hline $\mathrm{Al}_{2} \mathrm{O}_{3}$ & 0.53 & 1.02 & $(0.18,0.88)$ & $(0.66,1.38)$ \\
\hline $\mathrm{CaO}$ & 0.97 & 0.35 & $(0.62,1.32)$ & \\
\hline $\mathrm{MgO}$ & 0.27 & -0.25 & & \\
\hline $\mathrm{Na}_{2} \mathrm{O}$ & 0.85 & 0.49 & $(0.50,1.20)$ & $(0.13,0.85)$ \\
\hline $\mathrm{ZnO}$ & -0.11 & -0.34 & & \\
\hline $\mathrm{TiO}_{2}$ & -1.26 & $-0.19^{(b)}$ & $(-1.61,-0.91)$ & \\
\hline $\mathrm{Cr}_{2} \mathrm{O}_{3}$ & -0.50 & -0.59 & $(-0.85,-0.15)$ & $(-0.95,-0.23)$ \\
\hline $\mathrm{Fe}_{2} \mathrm{O}_{3}$ & 0.16 & $-0.61^{(b)}$ & & $(-0.97,-0.25)$ \\
\hline $\mathrm{NiO}^{3}$ & -0.01 & $0.70^{(b)}$ & & $(0.34,1.06)$ \\
\hline
\end{tabular}

(a) Confidence interval (CI) is given only if the total effect is significantly different from 0 .

(b) The predicted value is significantly different $(\alpha<0.01)$ from the associated observed value.

those of the other components in Table 10. The observed effect of $\mathrm{Al}_{2} \mathrm{O}_{3}$ is six times the next largest $\left(\mathrm{SiO}_{2}\right)$ for silicon release and nine times the next largest for sodium release. In each case, it is 20 times as large as the third largest observed total effect (that for $\mathrm{CaO}$ ). Comparison of the solution data for replicates listed in Table B. 15 reveals that the experimental error is nearly as large as most of the observed total effects. The confounding of the effects of $\mathrm{SiO}_{2}$ and $\mathrm{Al}_{2} \mathrm{O}_{3}$ due to their correlation in the experimental design became a major problem in modeling the static leaching results. Whereas only the magnitude of the total predicted $\mathrm{SiO}_{2}$ effect was distorted in the Soxhlet model by this problem, the attempts at modeling the static data produced predictions indicating that $\mathrm{SiO}_{2}$ had a significant detrimental effect on durability. Based on both the observed total $\mathrm{SiO}_{2}$ effect and the pertinent literature on the chemical durability of silicate glasses, $\mathrm{SiO}_{2}$ clearly has a beneficial effect on leach rate. In view of these difficulties, an effects plot is not shown for the static leaching data. Instead, Table 10, which lists 


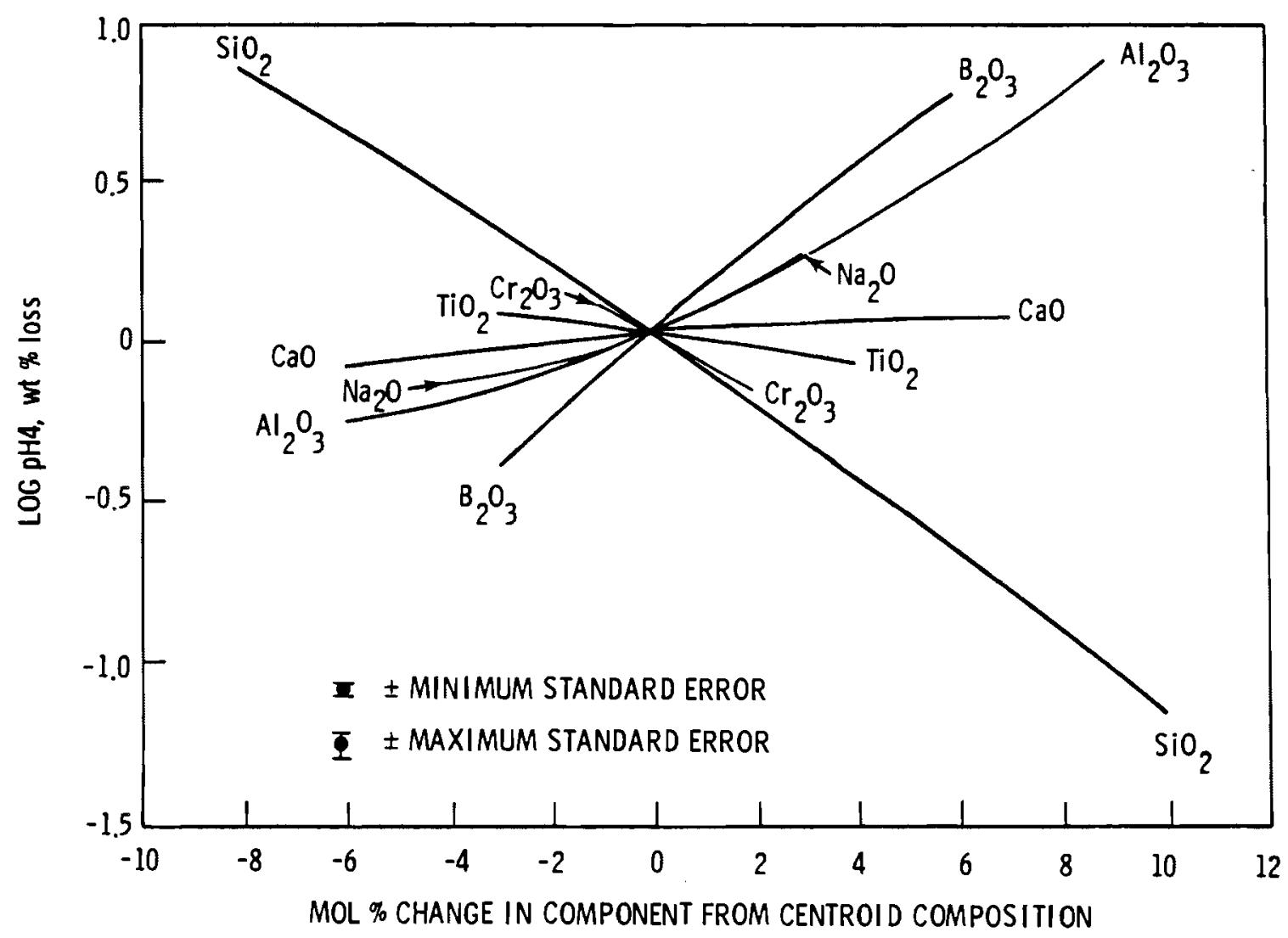

FIGURE 18. Effects of Components on pH 4 Leaching Weight Loss

TABLE 10. Observed Total Effects for Static Leach

$\begin{array}{ccc}\text { Component } & \begin{array}{c}\text { Silicon, } \\ \text { normalized } \mathrm{g} / \mathrm{m}^{2}\end{array} & \begin{array}{c}\text { Sodium, } \\ \text { normalized } \mathrm{g} / \mathrm{m}^{2}\end{array} \\ \mathrm{Si} & -4.7 & -6.5 \\ \mathrm{~B} & -0.2 & +0.4 \\ \mathrm{Al} & -27 & -59 \\ \mathrm{Ca} & +1.6 & +3.1 \\ \mathrm{Mg} & -0.4 & 0.0 \\ \mathrm{Na} & +0.4 & +1.6 \\ \mathrm{Zn} & +1.3 & +1.8 \\ \mathrm{Ti} & -0.5 & +0.6 \\ \mathrm{Cr} & -1.5 & -1.9 \\ \mathrm{Fe} & +0.8 & +0.6 \\ \mathrm{Ni} & +0.9 & +1.0\end{array}$


observed total effects; Figures 19, 20, and 21, which show elemental releases versus time; and Figure 22, which shows the observed relationship between silicon release and resulting $\mathrm{pH}$, are discussed in the next section.

Strong positive correlations were found between volatility and Soxhlet weight loss $(+0.77),{ }^{(a)} 28$-day static leach solution $\mathrm{pH}(+0.79)$, and $\mathrm{Si}$ in 28-day static leach solution $(+0.83)$, indicating that glasses that vaporize readily also have high leach rates.

\subsection{DISCUSSION}

It is generally accepted that the corrosion of soda-lime-silica glass by water involves two processes: a) ion exchange between alkali ions from the

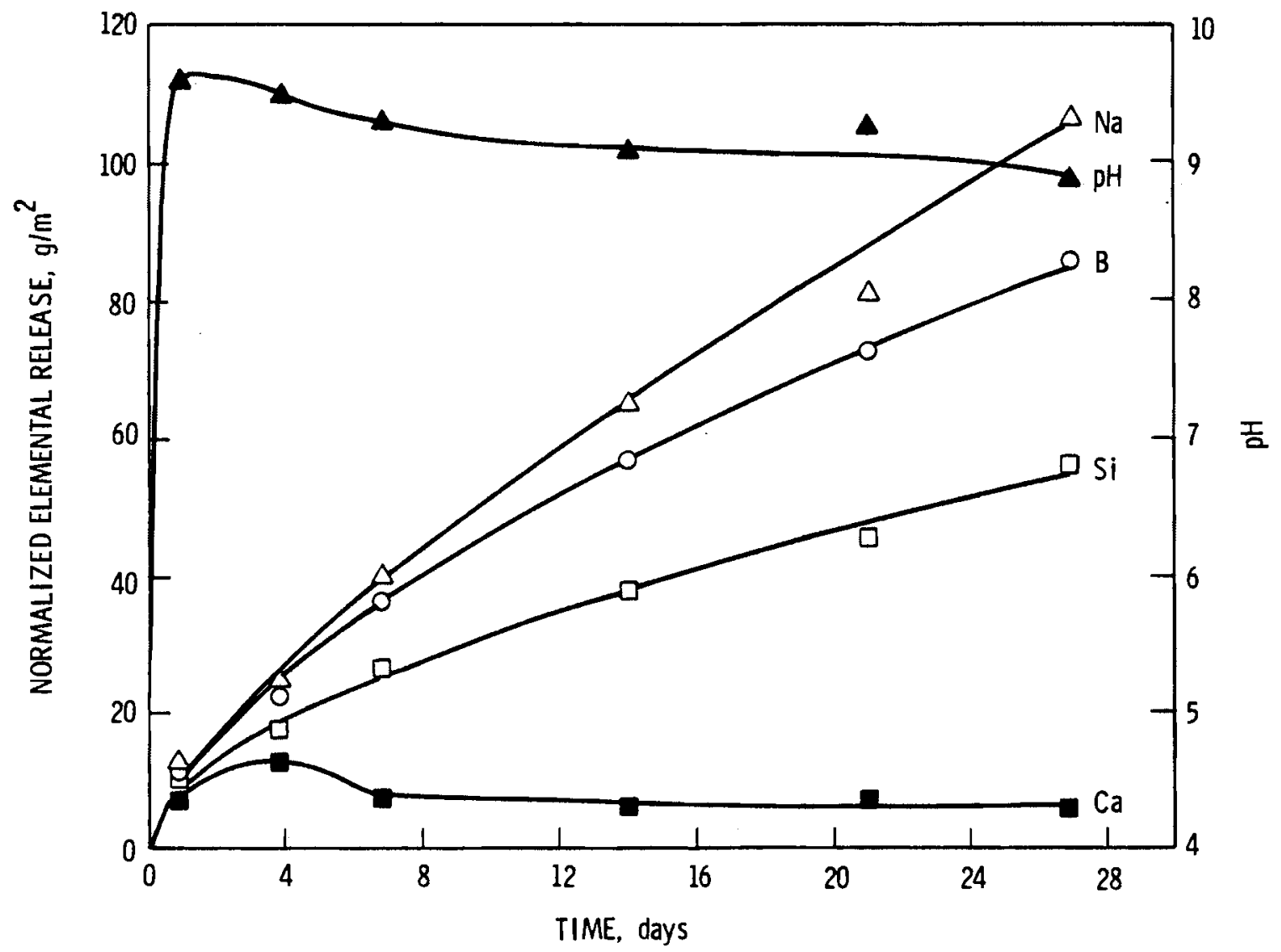

FIGURE 19 . Sample $27-90^{\circ} \mathrm{C}$ Static Leaching

(a) A Pearson correlation coefficient of zero indicates no correlation whereas 1.0 indicates perfect positive correlation. 


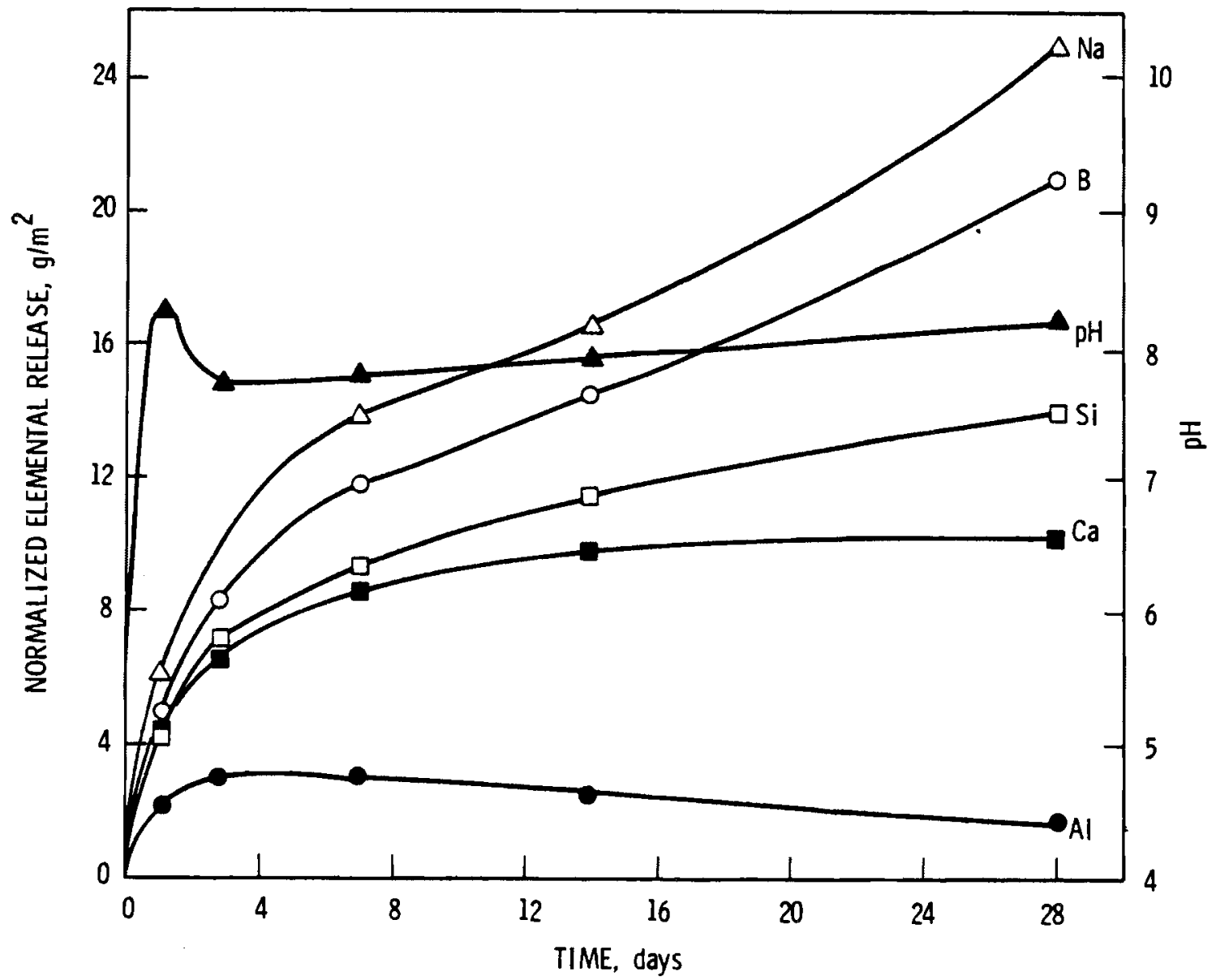

FIGURE 20. Sample $56-90^{\circ} \mathrm{C}$ Static Leaching

glass and hydrogen ions (or, more probably $\mathrm{H}_{3} \mathrm{O}^{+}$) from solution and b) $\mathrm{OH}^{-}$ attack and subsequent dissolution of the silica matrix. The two "stages" of reaction are shown in Figure 23 (see Clark, Pantano, and Hench 1979). The alkali ion exchange effectively consumes $\mathrm{H}^{+}$from solution, which increases the $\mathrm{pH}$ of the attacking solution as well as creating a silica-rich surface. $\mathrm{OH}^{-}$is thus increasingly available during the first stage to attack the Si-O network. The dissolution of silica increases rapidly as the pH rises above 9. Thus, the tendency of the ion exchange to increase $\mathrm{pH}$ acts to facilitate total glass dissolution. If the solubility limits of an element are exceeded in the increasingly concentrated solution, precipitation back onto the corroding surface may occur (Clark et al. 1976). 


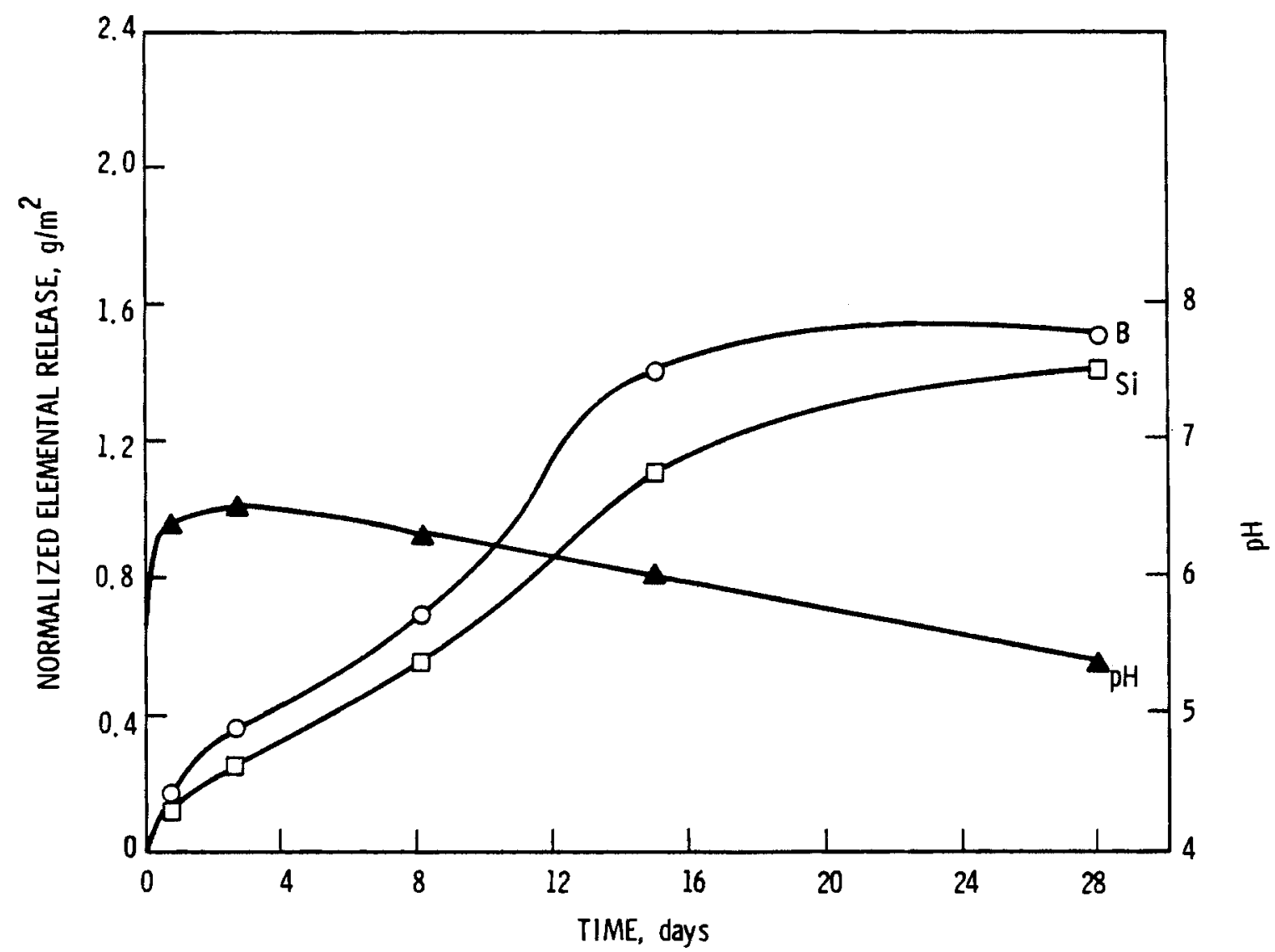

FIGURE 21. Sample $42-90^{\circ} \mathrm{C}$ Static Leaching

The above scenario for corrosion of soda-lime-silica glasses also appears to be valid for the borosilicate glasses tested in this study. The solution $\mathrm{pH}$ appears to be a key factor in borosilicate corrosion as in soda-lime-silica corrosion; however, a wider range of resulting solution $\mathrm{pH}$ was observed in this study than has been reported previously for glasses. Figures 19, 20, and 21 show elemental releases and pH versus time for samples 27, 56, and 42, respectively. These exemplify a range of static leaching of about a factor of 40 .

In Figure 19, there is a rapid rise of the $\mathrm{pH}$ to 9.6 within one day as $\mathrm{Ca}, \mathrm{Na}, \mathrm{B}$, and Si pass rapidly into solution. As time goes on, the $\mathrm{pH}$ gradually falls off to 8.9 as $\mathrm{Na}, \mathrm{B}$, and $\mathrm{Si}$ leach rates decrease. Meanwhile, Ca appears to have reached saturation at about four days and its concentration in solution actually decreases until at 28 days its level is about half of its maximum. This may be an example of precipitation back onto the sample surface. The initial rapid increase in $\mathrm{pH}$ is probably due to absorption of $\mathrm{H}^{+}$or $\mathrm{H}_{3} \mathrm{O}^{+}$by 


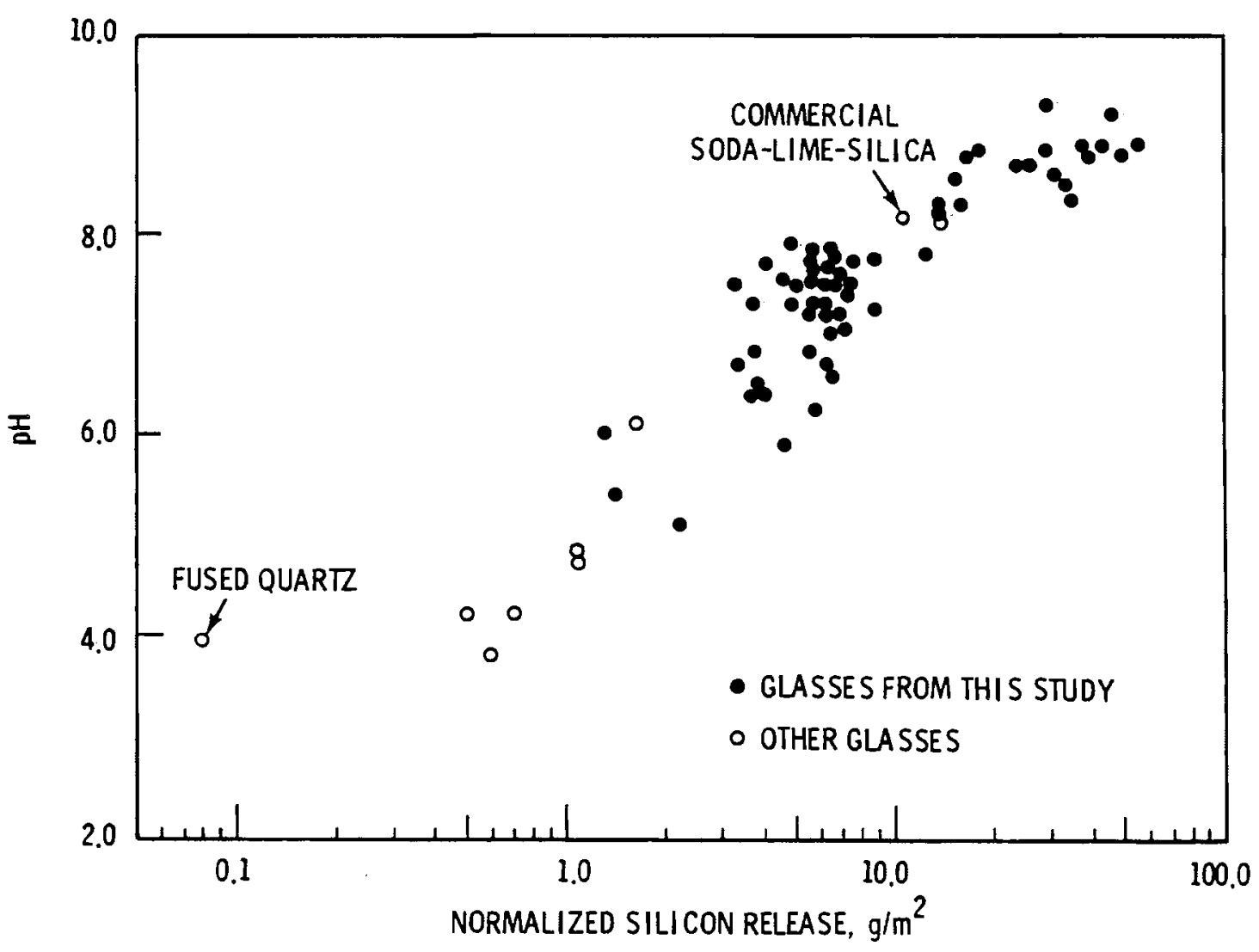

FIGURE 22. Silicon Release Versus Resulting pH for Static Leaching of a Variety of Glass Compositions

the glass and release of $\mathrm{Na}^{+}$and $\mathrm{Ca}^{++}$into solution. The subsequent gradual reduction in $\mathrm{pH}$ may be due to calcium hydroxide precipitation as well as the formation of boric and silicic acid in solution.

In Figure 20, there is a similar rapid $r$ ise of $\mathrm{pH}$ and elemental release with in the first day for sample 56. However, the pH peaks at 8.3 and falls off to below 8.0 within three days. The $\mathrm{pH}$ then slowly rises back to 8.2 after 28 days. Levels of $\mathrm{Na}, \mathrm{B}$, and $\mathrm{Si}$ from sample 56 only reach about one-fourth of their levels in sample 27 at 28 days. The calcium never saturates with sample 56 although it reaches about twice the level in solution as it did with sample 27. The solubility of calcium in the solution for sample 56 is probably 


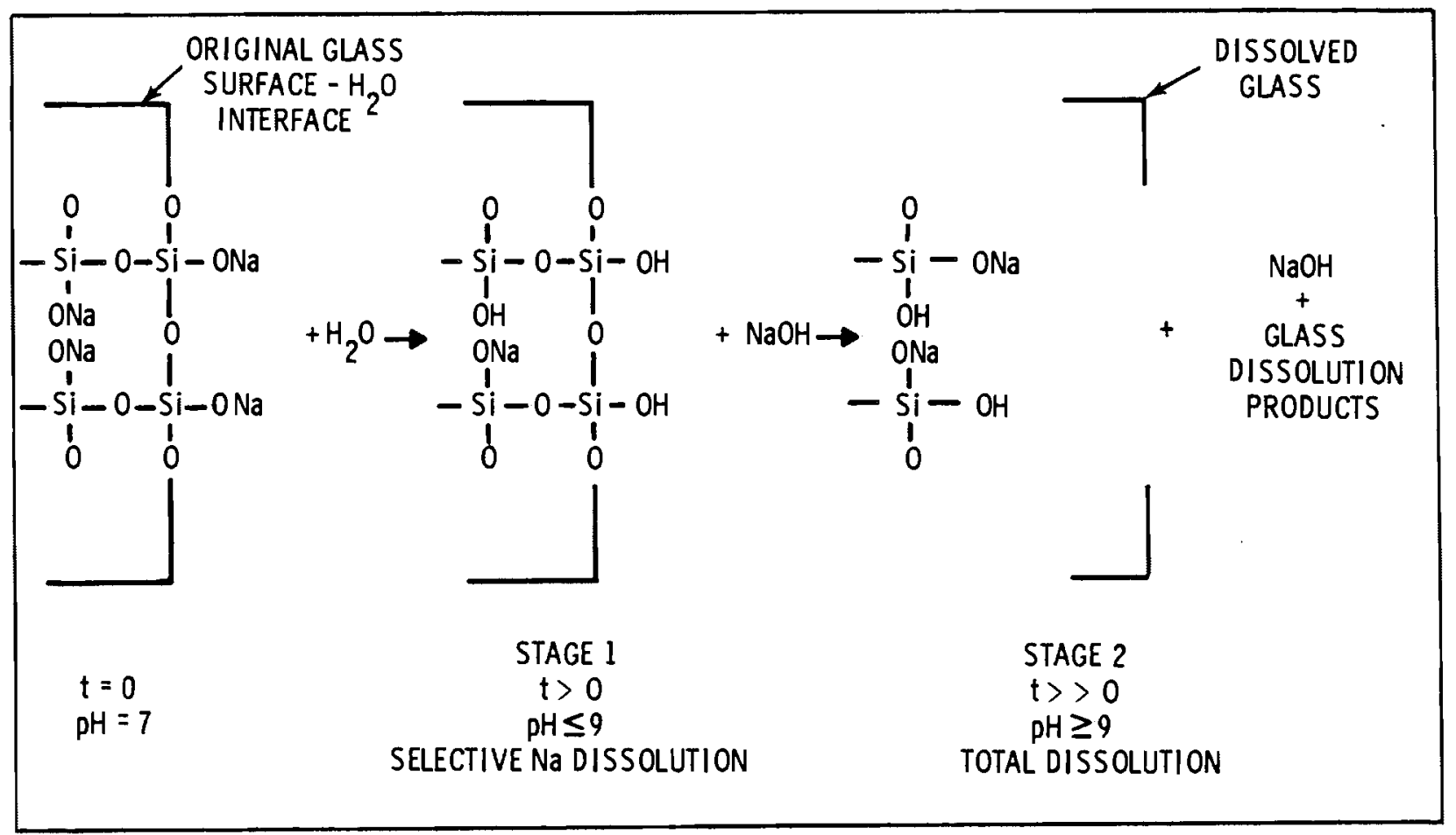

FIGURE 23. Mechanisms of Glass Corrosion for a Soda-Silica Glass (source Clark, Pantano, and Hench 1979)

higher than with sample 27 because of less common ion effects caused by the comparatively lower levels of other ions in solution. Sample 56 contains A1, and this element apparently saturates and precipitates as an hydroxide as $\mathrm{Ca}$ did with sample 27.

Figure 21 illustrates the leaching behavior of sample 42--one of the most durable samples. The $\mathrm{pH}$ never exceeds neutrality: After a small rise (to 6.5) from its starting value of 5.6 , it steadily decreases to 5.3 at 28 days. Boron and silicon releases are only one-tenth those seen from sample 56 . Sodium release is not shown on Figure 21 because of uncertainty in the measurements at such low levels in solution. It is suspected that much of the pH decrease is caused by the polypropylene container and/or the glycerine bath. This suspicion is based on runs with blanks (no glass) that reached a pH of 4.2 in seven days. This sample dissolves slowly enough so that the weak acids formed by the container dominate the solution chemistry. Aside from this "container effect," however, it is evident that this relatively durable sample results in lower solution pH than the less durable samples (56 and 27). 
The notable relationship between durability and resulting solution $\mathrm{pH}$ is illustrated in Figure 22, a plot of 28-day $\mathrm{Si}$ release versus $\mathrm{pH}$. The glasses used in this study are included as are several more durable borosilicate nuclear waste glass formulations (Chick and Buckwalter 1980), a commercial soda-lime-silica (float glass) formulation, and fused quartz. The lower end of the curve is probably somewhat depressed due to the aforementioned container effect; however, the influence of the container should have less effect on the middle and upper parts of the curve representing solutions more concentrated in glass dissolution products. The possibility of acid pH resulting from leaching of high silica glasses is consistent with the expected formation of silicic acid in solution as discussed by Alexander, Heston, and Iler (1954 and 1957).

The correlation between $\mathrm{pH}$ and dissolution is consistent with the ion exchange/hydroxyl attack scenario discussed earlier. Glasses that resist ion exchange $\left(\mathrm{H}^{+}\right.$or $\mathrm{H}_{3} \mathrm{O}^{+}$for alkali) also avoid the resulting rapid $\mathrm{pH}$ increase that accelerates $\mathrm{OH}^{-}$attack of the silica network.

The observed effects for the static test (shown in Table 10) and the effects plots for the Soxhlet and pH 4 tests (Figures 17 and 18) illustrate the roles of various components in conditioning these glasses to resist ion exchange. Hench and $\mathrm{Clark}$ (1978) have shown that composition changes that improve glass durability can be attributed to an increased ability to form protective surface films. The very large beneficial effect of aluminum can certainly be attributed to its tendency to form a protective layer on the surface of the glass during leaching. The comparatively small amounts of aluminum that were found in solution in the static test indicate that it was left behind on the samples or returned by precipitation. Leached layer profiling by electron scattering for chemical analyses (ESCA) (Pederson, Thomas, and McVay 1981) has shown aluminum along with transition elements concentrated at the leached surface, probably in hydroxylated form.

The detrimental effect of $\mathrm{Al}_{2} \mathrm{O}_{3}$ on $\mathrm{pH} 4$ leaching (see Figure 18) can probably be attributed to the increasing solubility of $\mathrm{Al}^{+3}$ ions in the acid range (Paul and Zaman 1978). Apparently, the protective layer formed by aluminum hydroxides in deionized water cannot form under acidic conditions (Doremus 1973). 
The beneficial effect on chemical durability of increasing the $\mathrm{SiO}_{2}$ level in these glasses is clearly illustrated in Table 10 for the static test and in Figure 18 for the $\mathrm{pH} 4$ test. Since $\mathrm{SiO}_{2}$ forms the structural matrix of these $\mathrm{glasses,}$ this effect is expected. Pure fused $\mathrm{SiO}_{2}$ has a very low leach rate $\left(<0.1\right.$ normalized $\left.\mathrm{g} / \mathrm{m}^{2}\right)$ in the static test (Figure 22$)$. The detrimental effect attributed to $\mathrm{SiO}_{2}$ in the Soxhlet effects plot (Figure 17) is probably erroneous and most likely caused by the correlation of $\mathrm{Al}_{2} \mathrm{O}_{3}$ and $\mathrm{SiO}_{2}$ in the experimental design.

Boron, sodium, and calcium all have detrimental effects on durability in the Soxhlet and pH 4 tests (see Figures 17 and 18). The role of sodium in breaking Si-0-Si network bonds is consistent with its detrimental effects. In simple glasses, CaO can be beneficial (Clark, Pantano, and Hench 1979) as can $\mathrm{B}_{2} \mathrm{O}_{3}$ (Adams and Evans 1978); however, their effects in these more complex nuclear waste materials are somewhat contrary to experience in simple glasses. These detrimental effects may be explained by their roles in phase separation.

Chromium probably derives its beneficial effect on $\mathrm{pH} 4$ leaching from the stability of its hydroxide down to $\mathrm{pH} 3.5$. The similar effects of titanium can be attributed to the stability of its hydrated oxide down to $\mathrm{pH} 2.5$ (Pourbaix 1974).

\subsection{CONCLUSIONS}

- The complex borosilicate glasses studied here leach with a two-stage process similar to, though generally slower than, the process for simple soda-lime-silica glasses studied extensively in the literature.

- There is a strong, positive correlation between amounts of elements released and resulting solution $\mathrm{pH}$ in the static leaching test.

- In neutral solutions, aluminum in the glass has a strong beneficial effect on chemical durability, probably related to its tendency to form a protective hydroxylated layer on the glass. 


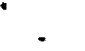

.

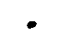




\subsection{RECOMMENDATIONS FOR FUTURE WORK}

The objective of this study was to determine if a complex glass system could be sampled to produce empirical prediction models for various properties. Useful models were produced to predict crystallinity, viscosity, volatility, and weight-loss-type chemical durability; but problems were encountered with the models for some other properties. We conclude that development of useful predictive models is possible for such complex materials systems if certain guidelines are followed.

Only components that have significant effects on properties should be included as variables in the experimental design. Components that are found in the actual system that do not vary enough to affect properties significantly could be held constant and studied later in simpler experimental designs. Screening tests should be conducted to identify and eliminate insignificant components.

Those components found to be significant should be varied over as large a range as possible. It was found in this study that, with the exception of $\mathrm{Cr}_{2} \mathrm{O}_{3}$, those components with narrow ranges ( 0 to $3 \%$ ) of ten produced confusing or insignificant effects. The effects of boron, which was varied between 6 and 12 (mol\%), would probably have been more clearly resolved if it had varied between 0 and $12 \mathrm{mo} 1 \%$.

The trend toward wider composition ranges must be tempered by the inclusion of a number of internally situated melts and the avoidance of gross crystallinity. All of the melts used for modeling except the centroid were extreme vertices--compositions situated on the extreme boundaries (corners) of the study region. If compositions falling we 11 within the boundaries of the region are included, a better resolution of component interactions and effects will result. Analogue compositions of probable nuclear waste glasses would be good candidates for these internal test points. Gross crystallinity in numerous test melts makes property testing needlessly bothersome. Some understanding of the effects of crystals is necessary, but large amounts interfere with the resolution of property changes caused by noncrystal-producing components. Those components that are relatively insoluble in the melts should have carefully limited ranges. 
Restrictions on the sums of groups of components should be avoided if possible. Such restrictions result in component correlations and hence can confound component effects. In the present study, for example, the limits placed on the sum of the mol\% of formers in any test glass only allowed glasses with high $\mathrm{Al}_{2} \mathrm{O}_{3}$ and low $\mathrm{SiO}_{2}$ content or high $\mathrm{SiO}_{2}$ and low $\mathrm{Al}_{2} \mathrm{O}_{3}$ content. Glasses with both formers at their low level or both at their high level were not adequately tested. As a result, the effect of increasing the level of $\mathrm{SiO}_{2}$ on a property was confounded with the effect of lowering the level of $\mathrm{Al}_{2} \mathrm{O}_{3}$. Spurious results were produced in several cases since it is very difficult for statistical modeling techniques to correctly separate the confounded effects. Extreme compositions with both $\mathrm{SiO}_{2}$ and $\mathrm{Al}_{2} \mathrm{O}_{3}$ at low or high levels would be unreasonable to propose as nuclear waste immobilization materials and difficult to test; but they would provide valuable information about the effects of these components within more practical compositions.

Careful attention to accurate, reproducible data is of critical importance in this type of study; spurious points are difficult to detect in a group of data from a set of widely varying experimental compositions required to obtain good prediction models. Use of averaged values from repeated measurements (as in the Soxhlet leach test) is a helpful technique, especially when the total property range produced throughout the field is relatively small.

All measurements of a given property should be performed within one block of time. If this is not possible, a range of standards should be repeatedly measured within each testing period so that systematic error between test groups can be factored out of the results. Several compositions should be replicated extensively to provide reliable estimates of experimental error even if all tests are performed in one block of time.

Two additional recommendations should be incorporated into any future work. The first involves a thorough check of the predictive ability of the property approximation models. While the $R_{A}{ }^{2}$ and the LOF F-test values provide an indication of how well the model fits the data, they do not indicate how well the model predicts for compositions not used to fit the model. An additional 20 to 25 points that are spaced throughout the experimental 
region should be melted and all properties should be measured for this purpose. These data should not be used to help fit the property models, thus allowing an independent measure of the prediction error of the models.

The second recommendation involves additional analyses that would provide further insight into understanding property models and the effects of the components on the properties. The main analytical technique employed in this report was based on use of the centroid of the experimental region as a reference point. Component effects were measured through the interior portions of the multidimensional experimental region and were dependent upon the component restrictions.

Other techniques for determining component effects should be considered. One method uses the technique of this report with noncentroid reference points. This type of analysis can yield important information because the effects of components can and do change slope at different locations within the experimental region. A second technique involves measuring component effects in an experiment without component restrictions. This may provide a more "independent" component effect measurement. These techniques are discussed in more detail in Piepel (1981) and Snee and Marquardt (1976).

If these suggestions are incorporated, the use of the study techniques developed herein for effective development of empirical property models in complex glass systems can be recommended. 

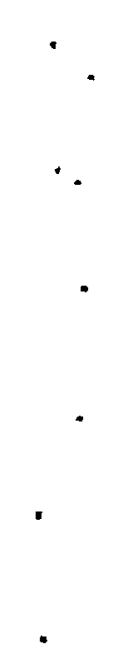


\subsection{REFERENCES}

Adams, P. B., and D. L. Evans. 1978. Chemical Durability of Borate Glasses from Borate Glasses: Structure, Properties, Applications. Plenum Press, New York.

Alexander, G. B., W. M. Heston, and R. K. Iler. 1954, 1957. J. Phys. Chem. $58: 453,61: 1539$.

Chick, L. A., and C. Q. Buckwalter. 1980. "Low-Leach Rate Glasses for Immobilization of Nuclear Wastes." PNL-3522, Pacific Northwest Laboratory, Richland, Washington.

Clark, D. E., et al. 1976. "Aqueous Corrosion of Soda-Silica and Soda-LimeSilica Glass." J. Am. Ceram. Soc. 59(1-2):62-65.

Clark, D. W., C. G. Pantano, Jr., and L. L. Hench. 1979. Corrosion of Glass. Magazines for Industry, Inc., New York.

Doremus, R. H. 1973. Glass Science. Wiley \& Sons, New York.

Gray, W. J. 1979. "Volatility of Some Potential High-Level Radioactive Waste Forms." Radioactive Waste Management 1:147-169.

Hench, L. L., and D. E. Clark. 1978. "Physical Chemistry of Glass Surfaces." J. Non-Cryst. Solids 28(1):83-105.

Marquardt, D. W., and R. D. Snee. 1974. "Test Statistics for Mixture Models." Technometrics 16:533-537.

McLean, R. A., and V. L. Anderson. 1966. "Extreme Vertices Design of Mixture Experiments." Technometrics 8:447-454.

Mende 1, J. E., et a1. 1977. Annual Report on the Characteristics of HighLevel Waste Glasses. BNWL-2252, Pacific Northwest Laboratory, Richland, Washington.

Pederson, L. R., M. T. Thomas, and G. L. McVay. 1981. "Application of ESCA to Corrosion Studies of Glasses Containing Simulated Nuclear Wastes." J. of Vacuum Sci. and Tech. 18(3):732-736.

Paul, A., and M. S. Zaman. 1978. "The Relative Influences of $\mathrm{Al}_{2} \mathrm{O}_{3}$ and $\mathrm{Fe}_{2} \mathrm{O}_{3}$ on the Chemical Durability of Silicate Glasses at Different $\mathrm{pH}$ values." J. of Mat1. Sci. 13:1499-1502.

Piepe1, G. F. 1980. "Component Effects in Mixture Experiments." In Proceedings of the 1979 DOE Statistical Symposium, pp. 7-19, Oak Ridge National Laboratory, Oak Ridge, Tennessee. 
Piepe1, G. F. 1981. "Measuring Component Effects in Constrained Mixture Experiments." Presented at the 1981 American Statistical Association Annual Meetings, August, 1981, Detroit, Michigan.

Pourbaix, M. 1974. Atlas of Electrochemical Equilibria in Aqueous Solutions. National Association of Corrosion Engineers, Houston, Texas.

Snee, R. D. 1975. "Experimental Designs for Quadratic Models in Constrained Mixture Spaces." Technometrics 17:149-159.

Snee, R. D., and D. W. Marquardt. 1974. "Extreme Vertices Designs for Linear Mixture Models." Technometrics 16:399-408.

Snee, R. D., and D.W. Marquardt. 1976. "Screening Concepts and Designs for Experiments with Mixtures." Technometrics 18:19-29.

St. John, R. C., and N. R. Draper. 1975. "D-Optimality for Regression Designs: A Review." Technometrics 17:15-23.

Takamori, T., and M. Tomozawa. 1978. "HCl Leaching Rate and Microstructure of Phase-Separated Borosilicate Glasses. J. Am. Ceram. Soc. 61:509.

Tomozawa, M., et a1. May 1979. "Phase Separation in Nuclear Waste Glasses." In Proceedings of Ceramics in Nuclear Waste Management, Cincinnati, Ohio.

Turcotte, R. P., and J. W. Wald. March 1978. Devitrification Behavior in a Zinc Borosilicate Nuclear Waste Glass. PNL-2247, Pacific Northwest Laboratory, Richland, Washington.

Van Vlack, L. H. 1964. Physical Ceramics for Engineers. Addison-Wesley Publishing Co., Reading, Massachusetts, pp. 59-67.

Wynn, H. P. 1970. "The Sequential Generation of D-Optimum Experimental Designs." Ann. Math. Statist. 41:1655-1664.

Zachiarasen, W. H. 1932. "The Atomic Arrangement in Glass." J. Amer. Chem. Soc. $54: 3841$. 


\section{APPENDIX A}

DETAILS OF STATISTICAL TECHNIQUES 
APPENDIX A

\section{DETAILS OF STATISTICAL TECHNIQUES}

\section{A.1 PSEUDO-COMPONENT TRANSFORMATION}

A pseudo-component transformation is applied to the proportions of chemical components forming a melt. If $x_{i}$ represents the proportion of the $i^{\text {th }}$ component, then the proportion of the $i^{\text {th }}$ pseudo-component is given by:

$$
x_{i}^{\prime}=\frac{x_{i}-a_{j}}{1-\sum_{j=1}^{11} a_{j}}
$$

where $a_{i}$ is the lower bound of the $i^{\text {th }}$ component. This transformation reduces round-off errors in computer solution for coefficient estimates and also allows meaningful measures of the effect of each component on the response (see Section 2.4). The prime notation $\hat{\beta}^{\prime}$ indicates a pseudo-coefficient estimate obtained by fitting the property data to the transformed pseudo-components.

\section{A.2 ANALYSIS OF VARIANCE TABLE AND COMPUTATION OF $R_{\AA}^{2}$ AND LACK OF FIT-F}

The analysis of variance (AOV) table is a standard part of the output in regression (model-fitting) analysis. The entries in the AOV table are used to calculate $R_{A}^{2}$ and lack of fit (LOF) - F, which indicate how well the model fits the observed data. A sample AOV table and definitions for its entries are given in Table A.1. The entries are modified from the usual AOV entries as discussed by Marquardt and Snee (1974). 
TABLE A.1. Analysis of Variance (AOV) Table

\begin{tabular}{|c|c|c|c|}
\hline Source of Variation & $\begin{array}{c}\text { Degrees of Freedom } \\
\text { (DF) }\end{array}$ & $\begin{array}{c}\text { Sum of Squares } \\
\text { (SS) }\end{array}$ & $\begin{array}{l}\text { Mean Square } \\
\text { (MS) }\end{array}$ \\
\hline Total & $n-1$ & SST & $\frac{S S T}{n-1}$ \\
\hline Regression & $p-1$ & SSR & $\frac{S S R}{p-1}$ \\
\hline Error & $n-p$ & SSE & $\frac{S S E}{n-p}$ \\
\hline Lack of Fit & $n-p-m$ & SSE-SSPE & $\frac{\text { SSE }-S S P E}{n-p-m}$ \\
\hline Pure Error & m & SSPE & $\frac{S S P E}{m}$ \\
\hline
\end{tabular}

Where SST $=\sum_{i=1}^{\ell} \sum_{j=1}^{m_{i}}\left(y_{i j}-\bar{y}\right)^{2}$

$$
\begin{aligned}
\text { SSR } & =\sum_{i=1}^{\ell} \sum_{j=1}^{m_{i}}\left(\hat{y}_{i j}-\bar{y}\right)^{2} \\
S S E & =S S T-S S R=\sum_{i=1}^{\ell} \sum_{j=1}^{m_{i}}\left(y_{i j}-\hat{y}_{i j}\right)^{2} \\
\text { SSPE } & =\sum_{i=1}^{\ell} \sum_{j=1}^{m_{i}}\left(y_{i j}-\bar{y}_{i}\right)^{2} \\
\ell & =\text { number of unique points in experimental design } \\
m_{i} & =\text { number of replicates of } i \text { th point, } i=1,2, \ldots, l, \text { where } m_{i}=1 \\
n & =\text { total number of observations } y_{i j}\left(n=\sum_{i=1}^{\ell} m_{i}\right) \\
m & =\sum_{i=1}^{\ell}\left(m_{i}-1\right) \\
p & =\text { number of parameters }\left(B_{i}, B_{i j}\right) \text { in model } \\
\hat{y}_{i j} & =\text { predicted value from model for }(i, j) \text { th observation. } \\
y_{i j} & =\text { observations (or logarithms thereof) with } i=1,2, \ldots, m_{i} \\
\bar{y}_{i} & =\sum_{j=1}^{m_{i}} y_{i j} / m_{i} \\
& \sum_{i=1}^{\ell} \sum_{j=1} m_{i j} / n
\end{aligned}
$$


$\mathrm{R}_{\mathrm{A}}^{2}$ and LOF-F are computed from the AOV entries:

$$
\begin{aligned}
R_{A}^{2} & =1-\frac{\text { Error Mean Square }}{\text { Total Mean Square }}=1-\frac{\mathrm{SSE} / \mathrm{n}-\mathrm{p}}{\mathrm{SST} / \mathrm{n}-1} \\
\text { LOF }-\mathrm{F} & =\frac{\text { LOF Mean Square }}{\text { Pure Error Mean Square }}=\frac{(\mathrm{SSE}-\mathrm{SSPE}) / \mathrm{n}-\mathrm{p}-\mathrm{m}}{\mathrm{SSPE} / \mathrm{m}}
\end{aligned}
$$

The LOF-F statistic is used to test whether the fit model has a significant LOF; it is compared to an F-distribution table value:

$$
F_{1-\alpha}(n-p-m, m)
$$

where $\quad \alpha=$ significance level of test (commonly $\alpha=0.05$ or 0.01 )

$n-p-m=$ numerator degrees of freedom

$\mathrm{m}=$ denominator degrees of freedom.

If the computed value of the LOF-F statistic is larger than the F-distribution table value $F_{1-\alpha}(n-p-m, m)$, it is concluded that the fit model has a significant LOF (the model has not explained the variability of the data in excess of the experimental error). If the computed LOF-F statistic is smaller than the table F-distribution value, it is concluded that the model adequately fits the data.

\section{A.3 DETERMINATION OF COMPONENT EFFECT COMPUTING DIRECTION}

A precise determination of the component effect computing direction within the experimental region is as follows. A change of $\Delta_{j}^{\prime}$ in the $i$ th pseudocomponent of the base point $\underline{x}^{\prime}=\left(x_{1}^{\prime}, x_{2}^{\prime}, \ldots, x_{j}^{\prime}, \ldots, x_{11}^{\prime}\right)$ is offset by changes

$$
x_{j}^{\prime}+x_{j}^{\prime}-\frac{\Delta_{i}^{\prime} s_{j}^{\prime}}{1-s_{j}^{\prime}} \quad j \neq j
$$


in the other components. To guarantee the existence of a total effect, the line defined by Equation (A.1) must go through the pseudo-component centroid $\underline{s}^{\prime}=\left(s_{1}^{\prime}, s_{2}^{\prime}, \ldots, s_{1}^{\prime}\right)$ of the experimental region. This is easily accomplished by defining the base point $\underline{x}^{\prime}$ to be the centroid $\underline{s}^{\prime}$ and choosing appropriate $\Delta_{j}^{\prime}$ values. Since the pseudo-component system is somewhat awkward, the changes in the original component system are

$$
\begin{aligned}
& x_{i} \rightarrow x_{i}+\Delta_{i} \\
& x_{j} \rightarrow x_{j}-\frac{\Delta_{i}\left(s_{j}-a_{j}\right)}{1-\sum_{k=1}^{11} a_{k}-s_{j}+a_{i}}
\end{aligned}
$$

where $a_{j}$ is the lower bound for the $i^{\text {th }}$ component. See Piepel (1981) for further details.

\section{A.4 STATISTICAL TESTS FOR SIGNIFICANCE OF PREDICTIONS AND COMPONENT EFFECTS}

There are several statistical procedures required to compare and test the significance of predictions, individual component effects, and component effect plots obtained from prediction equations fit to property data. These procedures are valid only when the model does not have a significant LOF and when the model residuals are approximately normally distributed.

In the following subsections, the statistical procedures will present two viewpoints that are based on two interpretations given to a predicted property value. A predicted value can be thought of as a prediction of the true mean value or of an individual observation. While the prediction is the same for either interpretation, the variability is not. The term standard error is used in the text when referring to the variability of a mean value prediction while standard deviation is used for an individual prediction value. 


\section{A.4.1 (1- $\alpha) \%$ Confidence Intervals for Predictions}

Let the prediction equation for a property be represented by

$$
\hat{y}=\underline{\hat{\beta}}^{\prime} \underline{x}^{\prime}=\sum_{i=1}^{11} \hat{\beta}_{i}^{\prime} x_{i}^{\prime}+\sum_{i<j} \sum_{j} \hat{\beta}_{i j}^{\prime} x_{i}^{\prime} x_{j}^{\prime}
$$

where $\underline{\hat{B}}^{\prime}=\left(\underline{U}^{\top} \underline{U}\right)^{-1} \underline{U}^{\top} \underline{y}$,

$\underline{U}=$ pseudo-component matrix of experimental design points

$\underline{y}=$ vector of property observations on experimental design points.

Then the $(1-\alpha) \%$ confidence interval for the mean value of $y_{0}$ at point $\underline{x}_{0}$ ( $\underline{u}_{0}$ in pseudo-components) is

$$
\hat{y}_{0} \pm t_{1-\frac{\alpha}{2}}(n-p) \sqrt{\underline{u}_{0}^{\top}(\underline{u} \underline{\top} \underline{U})^{-1} \underline{u}_{0} \hat{\sigma}^{2}}
$$
$\begin{aligned} \text { where } t_{1-\frac{\alpha}{2}}(n-p)= & \text { table value of student's t-distribution with }(n-p) \text { degrees } \\ & \text { of freedom at } \frac{\alpha}{2} \text { level of significance (see Table A.1) }\end{aligned}$

$$
\hat{\sigma}^{2}=\text { estimate of experimental error. }
$$

The $(1-\alpha) \%$ confidence interval for an individual value of $y_{0}$ at point $\underline{x}_{0}$ $\underline{u}_{0}$ in pseudo-components) is

$$
y_{0} \pm t_{1-\frac{\alpha}{2}}(n-p) \sqrt{\left[1+\underline{u}_{0}^{\top}\left(\underline{u}^{\top} \underline{u}\right)^{-1} \underline{u}_{0}\right] \hat{\sigma}^{2}}
$$

\section{A.4.2 (1- $\alpha) \%$ Confidence Intervals for Component Effects}

A component effect is defined to be the difference in predicted values between two points within the experimental region. In this document, partial and total effects along a special direction are considered. A (1- $\alpha) \%$ conf $i-$ dence interval for a mean component effect between two points $\underline{u}_{1}$, $\underline{u}_{0}$ (in pseudo-components) is 


$$
E \pm t_{1-\frac{\alpha}{2}}(n-p) \sqrt{\left(\underline{u}_{1}-\underline{u}_{0}\right)^{\top}\left(\underline{u}^{\top} \underline{u}\right)^{-1}\left(\underline{u}_{1}-\underline{u}_{0}\right) \hat{\sigma}^{2}}
$$

where $\underline{u}, \hat{\sigma}^{2}, t_{1-\frac{\alpha}{2}}(n-p)$ are as in Section A.4.1.

A $(1-\alpha) \%$ confidence interval for an individual component effect between two points $\underline{u}_{1}$, and $\underline{u}_{0}$ (in pseudo-components) is

$$
E \pm t_{1-\frac{\alpha}{2}}(n-p) \sqrt{\left[2+\left(\underline{u}_{1}-\underline{u}_{0}\right)^{\top}\left(\underline{U}^{\top} \underline{U}\right)^{-1}\left(\underline{u}_{1}-\underline{u}_{0}\right)\right] \hat{\sigma}^{2}}
$$

where $\underline{u}, \hat{\sigma}^{2}, t_{1-\frac{\alpha}{2}}(n-p)$ are as in Section A.4.1.

Of main interest in testing effects is when a component has no effect, i.e., $E=0$. If the $(1-\alpha) \%$ confidence interval on $E$ does not contain zero, the effect is significantly different from zero at a significance level. If it does contain zero, the effect is concluded to be zero at a significance level.

\section{A.4.3 Approximate $(1-\alpha) \%$ Confidence Intervals for Comparison of Observed Versus Predicted Component Effects}

Given that a model has been fit to a set of data and predictions of component effects have been made, it is desirable to validate the predicted effects by comparing them with observed effects (developed from data not used to fit the mode 1$)$. Thus, a $(1-\alpha) \%$ confidence interval on an individual difference of observed and predicted effects is:

$$
\left(E_{0}-E_{p}\right) \pm z_{1-\frac{\alpha}{2}} \sqrt{\left[4+\left(\underline{u}_{01}-\underline{u}_{02}\right)^{\top}\left(\underline{u}^{\top} \underline{u}\right)^{-1}\left(\underline{u}_{01}-\underline{u}_{02}\right)\right] \hat{\sigma}^{2}}
$$

where

$$
\begin{aligned}
& E_{0}=\text { observed component effect } \\
& E_{p}=\text { predicted component effect }
\end{aligned}
$$




$$
\begin{aligned}
& z_{1-\frac{\alpha}{2}}=\text { standardized Gaussian distribution table value at } \frac{\alpha}{2} \text { level of } \\
& \overline{2} \text { significance } \\
& \underline{u}_{01}, \underline{u}_{02}=\text { pseudo-component points used to calculate predicted component } \\
& \text { effect } \\
& \underline{U}=\text { pseudo-component experimental design matrix } \\
& \hat{\sigma}^{2}=\text { estimate of experimental error. }
\end{aligned}
$$

\section{A.4.4 (1- $\alpha) \%$ Confidence Bands on Component Effects Curves}

Although how to set a (1- $\alpha) \%$ confidence interval for a predicted value was described in Section A.4.1, it might be of interest to have confidence bands (curves) on effects plot curves (series of predictions). These confidence bands indicate how the whole effect curve of each component might vary, i.e., if it is possible that the true effect of the component might be opposite in sign to that suggested in the plot. Since we wish to have $(1-\alpha) \%$ confidence simultaneously on an infinite number of predictions, the confidence bands are wider than the corresponding $(1-\alpha) \%$ confidence intervals for each prediction point on the effect curve. Thus, $(1-\alpha) \%$ confidence bands on the effect curve of any component are:

$$
\hat{y}_{i} \pm \sqrt{\mathrm{pF}_{1-\alpha}(p-1, n-p) \operatorname{Var}\left(\hat{y}_{i}\right)} \text { for all } \hat{y}_{i} \text { on effect curve }
$$

where

$$
\begin{aligned}
& \hat{y}_{j}=\text { prediction (on effect curve) for pseudo-component } \\
& \text { point } \underline{u}_{j} \\
& p=\text { number of parameters in fit model } \\
& \mathrm{n}=\text { number of data points } \\
& F_{1-\alpha}(p-1, n-p)=\text { table value from } F \text {-distribution } \\
& \operatorname{Var}\left(\hat{y}_{i}\right)=\left\{\begin{array}{lc}
\underline{u}_{i}^{T}\left(\underline{U}^{\top} \underline{U}\right)^{-1} \underline{u}_{i} \hat{\sigma}^{2} & \text { if mean effects are of interest } \\
{\left[2+\underline{u}_{i}^{T}\left(\underline{U}^{\top} \underline{U}\right)^{-1} \underline{u}_{i}\right]^{\hat{\sigma}^{2}}} & \begin{array}{c}
\text { if individual effects are of } \\
\text { interest }
\end{array}
\end{array}\right.
\end{aligned}
$$




$$
\begin{aligned}
\underline{u}_{i}= & \text { pseudo-component point within experimental region for } \\
& \text { prediction } \\
\underline{U}= & \text { pseudo-component experimental design matrix } \\
\hat{\sigma}^{2}= & \text { estimate of experimental error. }
\end{aligned}
$$

This procedure is extremely important for those interested in analyzing the response surface for each property mainly by considering the component effects plots. The component effects curves contained in these plots, if interpreted without correctly considering prediction variances, can give misleading indications of component effects over the experimental region. While a precise application of the confidence band procedure requires prediction variances at each point (and hence a computer program), rough applications may be applied by inserting the minimum or maximum prediction variance into the formula. Since the minimum and maximum prediction standard errors of all points on any component effects curves are given to scale with each plot, only a table of F-distribution percentage points is required. If the minimum standard error is substituted, the confidence bands will be as narrow as possible, while they would be as wide as possible if the maximum standard error is substituted. This will give an indication if it might be possible for any of the component effects curves in the plot to slope differently than in the plot. That is the purpose of confidence bands, i.e., to indicate if components might have an opposite effect than that suggested by the effects plot.

As an example, consider the log soxhlet leach model (AOV Table C.1 of Appendix C). The term

$$
\begin{aligned}
\sqrt{\mathrm{pF}_{1-\alpha}(p-1, n-p)} & =\sqrt{26 F_{0.95}(25,28)} \\
& =\sqrt{26(2.14)} \\
& =7.46
\end{aligned}
$$


is the multiplier for the prediction standard error. Graphically, the confidence band interval for any effect curve in Figure 19 is at least 7.46 times the minimum standard error and at most 7.46 times the maximum standard error.

\section{A.5 Statistical Tables}

Table values of the student-t distribution are given for several levels of significance in Table A.2. Table values of the F-distribution are given for $\alpha=0.05$ significance level in Table A.3. 
TABLE A.2. The Student-t Probability Function (Values of $t_{1-\alpha}^{(r)}$ )

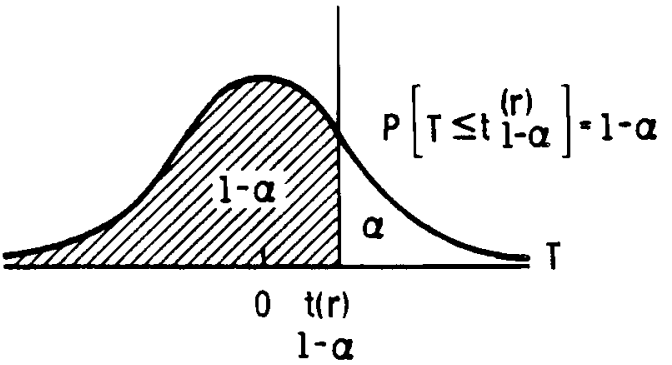

\begin{tabular}{|c|c|c|c|c|c|}
\hline$r$ & 0.90 & 0.95 & $\frac{1-\alpha}{0.975}$ & 0.99 & 0.995 \\
\hline $\begin{array}{r}1 \\
2 \\
3 \\
4 \\
5 \\
6 \\
7 \\
8 \\
9 \\
10 \\
11 \\
12 \\
13 \\
14 \\
15 \\
16 \\
17 \\
18 \\
19 \\
20 \\
21 \\
22 \\
23 \\
24 \\
25 \\
26 \\
27 \\
28 \\
29 \\
30 \\
40 \\
60 \\
80 \\
100 \\
200 \\
500 \\
(a)\end{array}$ & $\begin{array}{l}3.08 \\
1.89 \\
1.64 \\
1.53 \\
1.48 \\
1.44 \\
1.41 \\
1.40 \\
1.38 \\
1.37 \\
1.36 \\
1.36 \\
1.35 \\
1.35 \\
1.34 \\
1.34 \\
1.33 \\
1.33 \\
1.33 \\
1.33 \\
1.32 \\
1.32 \\
1.32 \\
1.32 \\
1.32 \\
1.32 \\
1.31 \\
1.31 \\
1.31 \\
1.31 \\
1.30 \\
1.30 \\
1.29 \\
1.29 \\
1.29 \\
1.28 \\
1.282\end{array}$ & $\begin{array}{l}6.31 \\
2.92 \\
2.35 \\
2.13 \\
2.02 \\
1.94 \\
1.89 \\
1.86 \\
1.83 \\
1.81 \\
1.80 \\
1.78 \\
1.77 \\
1.76 \\
1.75 \\
1.75 \\
1.74 \\
1.73 \\
1.73 \\
1.72 \\
1.72 \\
1.72 \\
1.71- \\
1.71 \\
1.71 \\
1.71 \\
1.70 \\
1.70 \\
1.70 \\
1.70 \\
1.68 \\
1.67 \\
1.66 \\
1.66 \\
1.65 \\
1.65 \\
1.645\end{array}$ & $\begin{array}{r}12.71 \\
4.30 \\
3.18 \\
2.78 \\
2.57 \\
2.45 \\
2.36 \\
2.31 \\
2.26 \\
2.23 \\
2.20 \\
2.18 \\
2.16 \\
2.14 \\
2.13 \\
2.12 \\
2.11 \\
2.10 \\
2.09 \\
2.09 \\
2.08 \\
2.07 \\
2.07 \\
2.06 \\
2.06 \\
2.06 \\
2.05 \\
2.05 \\
2.05 \\
2.04 \\
2.02 \\
2.00 \\
1.99 \\
1.98 \\
1.97 \\
1.96 \\
1.960\end{array}$ & $\begin{array}{r}31.82 \\
6.96 \\
4.54 \\
3.75 \\
3.36 \\
3.14 \\
3.00 \\
2.90 \\
2.82 \\
2.76 \\
2.72 \\
2.68 \\
2.65 \\
2.62 \\
2.60 \\
2.58 \\
2.57 \\
2.55 \\
2.54 \\
2.53 \\
2.52 \\
2.51 \\
2.50 \\
2.49 \\
2.49 \\
2.48 \\
2.57 \\
2.57 \\
2.46 \\
2.46 \\
2.42 \\
2.39 \\
2.37 \\
2.36 \\
2.35 \\
2.33 \\
2.326\end{array}$ & $\begin{array}{l}63.66 \\
9.92 \\
5.84 \\
4.60 \\
4.03 \\
3.71 \\
3.50 \\
3.36 \\
3.25 \\
3.17 \\
3.11 \\
3.05 \\
3.01 \\
2.98 \\
2.95 \\
2.92 \\
2.90 \\
2.88 \\
2.86 \\
2.85 \\
2.83 \\
2.82 \\
2.81 \\
2.80 \\
2.79 \\
2.78 \\
2.77 \\
2.76 \\
2.76 \\
2.75 \\
2.70 \\
2.66 \\
2.64 \\
2.63 \\
2.60 \\
2.59 \\
2.576\end{array}$ \\
\hline
\end{tabular}

(a) Standard normal table values, $z_{1-\alpha}$. 

TABLE A.3. 95th Percentile Values ( $(\rho .05$ Leve 1s), F0.95,
for the F Distribution(a)

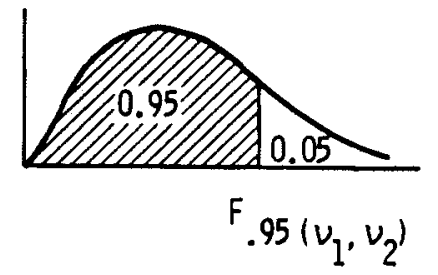

\begin{tabular}{|c|c|c|c|c|c|c|c|c|c|c|c|c|c|c|c|c|c|c|c|}
\hline & 1 & 2 & 3 & 4 & 5 & 6 & 7 & 8 & 9 & 10 & 12 & 15 & 20 & 24 & 30 & 40 & 60 & 20 & - \\
\hline 1 & & 30 & & 5 & 30 & 34 & & 9 & 1 & 2 & 14 & 96 & 8 & 9 & 50 & 1 & 52 & 3 & 254 \\
\hline 2 & .5 & 9.0 & .2 & .2 & .3 & 9.3 & 9.4 & .4 & .4 & 9.4 & 9.4 & 9.4 & 9.4 & .5 & 9.5 & .5 & 9.5 & 3.5 & $\theta$ \\
\hline 3 & .1 & .55 & 28 & 12 & .01 & 94 & 89 & .85 & .81 & .79 & .74 & .70 & .66 & .64 & .62 & .50 & .57 & 55 & .53 \\
\hline 4 & & .94 & 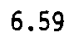 & & & 6 & & & & 96 & & 86 & & & 75 & 72 & 69 & 6 & \\
\hline 5 & & 70 & & & & (20) & & & & & & 62 & & & & & & & \\
\hline 6 & & 1 & 76 & 53 & & 28 & & & 10 & 06 & 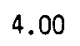 & 94 & & & 01 & & & & \\
\hline 7 & 59 & .74 & 15 & 12 & 7 & 87 & 9 & .73 & 58 & 64 & .47 & 51 & 44 & 41 & 38 & 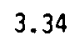 & 30 & .27 & 23 \\
\hline 8 & & 46 & 7 & & & .58 & & & & 35 & & 22 & & 2 & 08 & 04 & 01 & 97 & 93 \\
\hline 9 & & .26 & .86 & & & 3.37 & & .23 & & 4 & .07 & 01 & & 10 & 30 & .83 & 19 & & 71 \\
\hline 10 & & 10 & 71 & & & 7 & & & & (2) & & & & & & & & & \\
\hline 4. & & .98 & & & & 3 & & & & & & & & & & & & & \\
\hline 12 & & 8 & & & & 00 & 2.91 & & & & 69 & & & & & & & & \\
\hline 13 & & .81 & 1 & .18 & 1 & 2.9 & .8 & .77 & 1 & .67 & .60 & .53 & 46 & 2 & 38 & & 30 & & 21 \\
\hline 16 & & .74 & 34 & & & 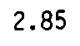 & 6 & 2.7 & & 2.60 & 53 & 46 & & & & & & & \\
\hline 15 & & .68 & .29 & & 90 & 2.79 & 7.1 & 04 & & 14 & 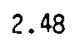 & 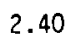 & .33 & 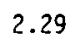 & .25 & & .16 & & 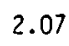 \\
\hline 1 & & & & & & & & & & & & & & & & & & & \\
\hline 17 & & 3.59 & 20 & & 2.81 & 2.7 & 2.6 & & & 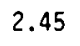 & 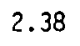 & 31 & & & & & & & \\
\hline 18 & & 5 & 16 & 2 & 77 & 8 & 2.58 & . & & 2.41 & 34 & .27 & & 5 & & & 12 & & \\
\hline 19 & & 5 & 3 & 9 & .7 & 2.6 & 2.5 & 4 & & 2.38 & .31 & 2.23 & & .11 & D7 & 2.0 & 98 & & 88 \\
\hline 20 & & .4 & 0 & .87 & 1 & 2.6 & 1 &. .45 & & 5 & .28 & 20 & & 8 & 44 & & & & .84 \\
\hline 21 & & & & & & & & & & & & & & & & & & & \\
\hline 22 & & & & & & & & & & & & & & & & & & & \\
\hline 23 & & 3.42 & & 2 & & 2. & & & & 7 & & 3 & & 1 & & & & & .76 \\
\hline 24 & 26 & 3.40 & 01 & 78 & .62 & 2.51 & .42 & 2.36 & 2.30 & 2.25 & .18 & 2.11 & 03 & 1.98 & 94 & 9 & 84 & 79 & .73 \\
\hline 25 & & 3 & 19 & 2 & 0 & 2 & 0 & , & & 2.24 & 16 & 09 & & 6 & 32 & 7 & 82 & & 71 \\
\hline 26 & & & & & & & & & & & & & & & & & & & \\
\hline 27 & & & & & & & & & & & & 6 & & & & & & & .67 \\
\hline 28 & 20 & .34 & 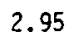 & 1 & 6 & 2 & 36 & 2.29 & 4 & 2.19 & 12 & .04 & 96 & 1.91 & 87 & 32 & 77 & 11 & .65 \\
\hline 29 & & 3.3 & & & & & & 2.2 & & 2.18 & & 2.03 & & 1.90 & & & & & 1004 \\
\hline 30 & & 3.3 & & & & & & & & & & & & & & 1. & 74 & & 6 \\
\hline 40 & & 0 & & 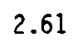 & & 2. & & & & & & 2 & & 1.79 & 1.74 & & 54 & 8 & 51 \\
\hline 60 & & 3.1 & & & & & & & & 9 & & 34 & & 1.70 & 55 & 59 & 53 & & 1.39 \\
\hline 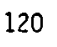 & & 3.07 & 2.68 & 20. & 2.29 & 2.18 & 2.0 & 2.02 & & 1.91 & 1.83 & 1.75 & 1.55 & 1.61 & 1.55 & 1.50 & 1.43 & .35 & 1.25 \\
\hline 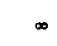 & 3.84 & 3.00 & 2.60 & 2.37 & 2.21 & 2.10 & 2.01 & 1.94 & 1.88 & 1.83 & 1.75 & 1.67 & 1.57 & 1.52 & 1.46 & 1.39 & 1.32 & 1.22 & 1.00 \\
\hline
\end{tabular}

(a) $v_{1}=$ numerator degrees of freedom;

$v_{2}=$ denominator degrees of freedom. 


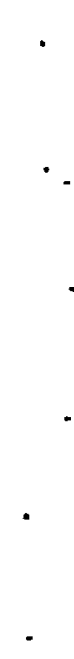


APPENDIX B

MELT COMPOSITION AND PROPERTY TABLES 
TABLE B.1. Group A Compositions by ICAP Analysis, mo 1\%

\begin{tabular}{|c|c|c|c|c|c|c|c|c|c|c|c|}
\hline \multirow{2}{*}{$\begin{array}{c}\text { Melt } \\
\text { Number }\end{array}$} & \multicolumn{3}{|c|}{ Formers } & \multicolumn{3}{|c|}{ Modifiers } & \multicolumn{5}{|c|}{ Intermediates } \\
\hline & $\underline{\underline{S i 0}_{2}}$ & $\underline{B}_{2} \underline{O}_{3}$ & $\mathrm{Al}_{2}{ }^{-}{ }_{3}$ & $\overline{\mathrm{CaO}}$ & $\underline{\mathrm{MgO}}$ & $\mathrm{Na}_{2} 2$ & $\underline{\mathrm{ZnO}}$ & $\mathrm{TiO}_{2}$ & $\mathrm{Cr}_{2}-_{3}$ & $\mathrm{Fe}_{2} \underline{O}_{3}$ & $\underline{\mathrm{NiO}}$ \\
\hline 1 & 57.8 & 12.5 & 1.2 & 3.3 & -- & 10.4 & 6.1 & -- & 2.9 & 3.0 & 2.8 \\
\hline 2 & 57.1 & 13.8 & -- & -- & 7.4 & 13.0 & - & 6.9 & -- & -- & 1.8 \\
\hline 3 & 52.2 & 5.9 & -- & 13.5 & 4.0 & 15.1 & 3.1 & -- & 3.1 & 3.1 & - \\
\hline$[4]^{(a)}$ & 43.7 & 8.8 & -- & 9.8 & 7.8 & 14.4 & 6.1 & 7.1 & 2.3 & -- & -- \\
\hline 5 & 43.0 & 8.5 & -- & 9.6 & 7.9 & 14.5 & 6.2 & 7.1 & 3.2 & -- & -- \\
\hline [6] & 43.5 & 8.3 & -- & 9.5 & 7.7 & 15.0 & 6.1 & 7.0 & 2.9 & -- & -- \\
\hline 7 & 45.8 & 6.1 & 14.3 & 3.9 & 7.6 & 10.6 & 6.0 & -- & 3.0 & -- & 2.7 \\
\hline 8 & 48.4 & 12.0 & 14.5 & - & - & 13.3 & - & 7.1 & -- & 2.0 & 2.7 \\
\hline 9 & 59.0 & 12.0 & 12.6 & -- & 1.1 & 15.3 & -- & -- & -- & -- & -- \\
\hline 10 & 58.8 & 6.5 & -- & 13.5 & 2.0 & 10.3 & 6.2 & - & -- & -- & 2.7 \\
\hline 11 & 43.8 & 11.1 & -- & 13.7 & 7.9 & 10.9 & -- & 6.2 & 3.3 & 3.1 & -- \\
\hline 12 & 41.8 & 9.3 & 14.7 & 12.8 & -- & 15.7 & -- & -- & -- & 3.1 & 2.6 \\
\hline 13 & 47.3 & 14.4 & 5.4 & -- & 3.2 & 16.4 & 6.7 & -- & 3.3 & 3.3 & -- \\
\hline 14 & 59.9 & 6.8 & 14.7 & -- & -- & 10.9 & - & 7.7 & -- & -- & -- \\
\hline 15 & 57.5 & 6.7 & 1.4 & -- & 7.6 & 14.0 & -- & 7.1 & 2.7 & 3.0 & -- \\
\hline 16 & 43.4 & 12.9 & 4.9 & 13.5 & -- & 12.8 & 6.3 & -- & 3.1 & 3.1 & -- \\
\hline 17 & 53.9 & 5.7 & 14.4 & 3.1 & -- & 14.7 & 6.1 & 2.1 & -- & -- & -- \\
\hline$[18]$ & 49.8 & 9.4 & 7.1 & 6.6 & 3.7 & 12.5 & 3.0 & 3.5 & 1.5 & 1.5 & 1.4 \\
\hline 19 & 49.7 & 9.5 & 7.2 & 6.4 & 3.8 & 12.6 & 3.0 & 3.5 & 1.5 & 1.5 & 1.3 \\
\hline 20 & 49.9 & 8.7 & 7.2 & 6.4 & 3.8 & 12.9 & 3.6 & 3.4 & 1.4 & 1.4 & 1.3 \\
\hline 21 & 46.5 & 12.3 & 14.2 & -- & 7.3 & 10.7 & 6.0 & -- & -- & 3.0 & -- \\
\hline 22 & 53.8 & 6.3 & -- & 13.2 & -- & 10.7 & 6.1 & 6.9 & -- & 3.0 & -- \\
\hline 23 & 42.7 & 12.0 & 14.3 & 9.6 & -- & 11.0 & -- & 7.2 & 3.2 & - & - \\
\hline 24 & 51.7 & 12.3 & -- & 9.9 & 7.5 & 15.8 & -- & -- & -- & -- & 2.8 \\
\hline 25 & 53.0 & 6.1 & 14.1 & - & 7.2 & 11.4 & -- & -- & 2.9 & 2.9 & 2.4 \\
\hline
\end{tabular}

(a) Replicate melts are bracketed. 
TABLE B.2. Group B Compositions by ICAP Analysis, mo 1\%

\begin{tabular}{|c|c|c|c|c|c|c|c|c|c|c|c|}
\hline Melt & & Eormer & & & dific & & & & ed & & \\
\hline Number & $\overline{\mathrm{SiO}_{2}}$ & $\mathrm{~B}_{2} \underline{O}_{3}$ & $\overline{\mathrm{A}]} \mathrm{C}_{2} \underline{\mathrm{O}}_{3}$ & $\overline{\mathrm{CaO}}$ & $\mathrm{MgO}$ & $\mathrm{Na}_{2} \underline{O}$ & $\underline{\mathrm{Zn} 0}$ & $\mathrm{TiO}_{2}$ & $\mathrm{Cr}_{2} \mathrm{O}_{3}$ & $\underline{F e}_{2} \underline{O}_{3}$ & $\underline{\mathrm{NiO}}$ \\
\hline 26 & 44.8 & 6.3 & 14.2 & -- & -- & 16.5 & 5.9 & 6.9 & -- & 2.9 & 2.5 \\
\hline 27 & 54.4 & 6.3 & -- & 13.8 & -- & 15.4 & -- & 7.1 & 3.0 & -- & -- \\
\hline 28 & 56.5 & 12.0 & - & -- & -- & 15.3 & 6.1 & 7.0 & 3.1 & -- & -- \\
\hline 29 & 58.1 & 6.1 & 1.2 & -- & 7.9 & 10.8 & 6.1 & 7.0 & -- & 2.8 & -- \\
\hline 30 & 43.3 & 12.6 & -- & 9.8 & 7.9 & 15.8 & -- & 7.0 & -- & 0.9 & 2.8 \\
\hline 31 & 48.6 & 6.4 & -- & 14.0 & -- & 15.9 & 6.3 & -- & 2.8 & 3.1 & 2.9 \\
\hline 32 & 42.9 & 6.0 & 14.5 & 13.9 & 1.3 & 15.2 & 6.2 & -- & -- & -- & -- \\
\hline 33 & 42.9 & 12.4 & 14.4 & 13.8 & -- & 10.5 & 6.0 & -- & -- & -- & -- \\
\hline 34 & 44.3 & 12.0 & -- & 9.9 & 8.0 & 10.1 & 6.1 & 7.0 & -- & 2.6 & -- \\
\hline$[35]^{(}$ & 44.7 & 11.4 & 14.8 & 1.2 & 7.7 & 15.0 & -- & -- & 2.7 & 2.5 & -- \\
\hline 36 & 42.7 & 12.1 & 14.5 & 1.0 & 7.8 & 16.1 & -- & -- & 2.9 & 2.9 & -- \\
\hline 37 & 55.0 & 6.0 & 14.6 & -- & 7.6 & 11.1 & -- & 3.0 & -- & -- & 2.7 \\
\hline 38 & 43.4 & 5.8 & 14.8 & 12.7 & -- & 10.9 & -- & 6.9 & 3.0 & 2.5 & -- \\
\hline$[39]$ & 58.0 & 12.2 & -- & 13.5 & -- & 11.0 & -- & -- & -- & 2.5 & 2.8 \\
\hline 40 & 57.5 & 12.3 & -- & 13.4 & -- & 11.2 & -- & -- & -- & 2.8 & 2.8 \\
\hline 41 & 49.8 & 6.6 & -- & 13.4 & 8.0 & 10.5 & 5.9 & -- & 3.0 & -- & 2.8 \\
\hline 42 & 43.5 & 11.8 & 14.5 & -- & 3.1 & 10.2 & 6.0 & 5.1 & 3.1 & -- & 2.7 \\
\hline$[43]$ & 49.6 & 9.2 & 7.2 & 6.7 & 3.8 & 12.5 & 3.1 & 3.5 & 1.5 & 1.5 & 1.4 \\
\hline 44 & 49.7 & 9.1 & 7.2 & 6.6 & 3.9 & 12.9 & 2.9 & 3.4 & 1.4 & 1.5 & 1.4 \\
\hline โ45] & 49.7 & 9.1 & 7.2 & 6.7 & 3.9 & 12.7 & 3.0 & 3.4 & 1.4 & 1.5 & 1.4 \\
\hline
\end{tabular}

(a) Replicate melts are bracketed. 
TABLE B.3. Group C Compositions by ICAP Analysis, mo $1 \%$

\begin{tabular}{|c|c|c|c|c|c|c|c|c|c|c|c|}
\hline \multirow{2}{*}{$\begin{array}{c}\text { Melt } \\
\text { Number }\end{array}$} & \multicolumn{3}{|c|}{ Formers } & \multicolumn{3}{|c|}{ Modifiers } & \multicolumn{5}{|c|}{ Intermediates } \\
\hline & $\underline{\mathrm{SiO}} 2$ & $\underline{\mathrm{B}}_{2} \underline{\mathrm{O}}_{3}$ & $\overline{\mathrm{Al}} 2 \underline{-}_{3}$ & $\mathrm{CaO}$ & MgO & $\underline{\mathrm{Na}} 2 \underline{\underline{0}}$ & $\underline{\mathrm{Zn} 0}$ & $\mathrm{TiO}_{2}$ & $\mathrm{Cr}_{2} \mathrm{O}_{3}$ & $\underline{F e}_{2} \underline{O}_{3}$ & $\overline{\mathrm{NiO}}$ \\
\hline 46 & 56.5 & 12.5 & -- & 1.0 & 3.6 & 16.3 & -- & $7.0^{\circ}$ & 3.1 & -- & -- \\
\hline 47 & 42.8 & 6.8 & 7.3 & 11.7 & 8.4 & 10.8 & -- & 7.1 & -- & 2.7 & 2.4 \\
\hline 48 & 43.3 & 6.4 & 15.5 & 4.7 & - & 15.9 & -- & 7.3 & 2.8 & 2.2 & 1.9 \\
\hline 49 & 55.0 & 14.1 & -- & -- & -- & 15.6 & 6.3 & 7.9 & -- & 1.1 & -- \\
\hline$[50]^{(a)}$ & 57.7 & 12.7 & 2.3 & -- & 8.6 & 9.4 & 6.0 & -- & 3.3 & -- & -- \\
\hline 51 & 58.6 & 12.6 & 2.4 & -- & 7.9 & 9.3 & 5.8 & -- & 3.4 & -- & -- \\
\hline 52 & 58.5 & 12.8 & 2.3 & -- & 8.2 & 9.1 & 5.9 & -- & 3.2 & -- & -- \\
\hline 53 & 57.9 & 6.8 & - & -- & 8.8 & 14.6 & 6.1 & $\rightarrow$ & -- & 3.1 & 2.7 \\
\hline 54 & 54.1 & 6.4 & 15.3 & 7.2 & - & 11.3 & -- & -- & 3.1 & 2.6 & -- \\
\hline 55 & 41.7 & 12.7 & 15.2 & 1.0 & 8.0 & 16.2 & -- & -- & 3.1 & -- & 2.1 \\
\hline 56 & 42.9 & 13.3 & 3.1 & 13.0 & -- & 14.4 & 5.9 & 7.4 & -- & -- & -- \\
\hline 57 & 45.4 & 6.7 & 14.2 & -- & - & 14.5 & 6.0 & 7.7 & 3.3 & -- & 2.2 \\
\hline 58 & 42.0 & 13.0 & 13.8 & -- & 8.3 & 15.5 & -- & 7.4 & -- & -- & -- \\
\hline 59 & 57.4 & 6.6 & -- & 11.4 & -- & 10.8 & -- & 7.7 & 3.4 & -- & 2.7 \\
\hline 60 & 58.4 & 6.7 & 3.1 & 12.8 & -- & 16.5 & -- & -- & -- & 2.5 & -- \\
\hline 61 & 46.4 & 6.7 & 14.2 & 12.6 & 8.3 & 11.8 & -- & -- & - & -- & -- \\
\hline 62 & 43.3 & 13.4 & 14.2 & 3.8 & -- & 9.3 & 5.8 & 7.2 & -- & 3.0 & -- \\
\hline 63 & 43.2 & 13.4 & 1.2 & 12.9 & 8.3 & 9.6 & 5.9 & -- & -- & 3.0 & 2.5 \\
\hline$[64]$ & 43.4 & 6.8 & 12.7 & 13.1 & -- & 15.3 & 6.1 & -- & -- & -- & 2.6 \\
\hline 65 & 43.2 & 6.7 & 13.8 & 13.1 & -- & 14.6 & 6.0 & -- & -- & -- & 2.6 \\
\hline L66. & 43.1 & 6.7 & 13.9 & 13.2 & -- & 14.9 & 6.1 & -- & -- & -- & 2.1 \\
\hline 67 & 41.3 & 12.7 & 15.1 & 1.1 & 8.0 & 16.5 & -- & -- & 3.0 & -- & 2.3 \\
\hline 68 & 43.0 & 13.3 & 14.4 & 12.7 & -- & 11.1 & -- & -- & 3.1 & -- & 2.4 \\
\hline 69 & 59.6 & 6.8 & -- & 1.1 & -- & 13.6 & 6.3 & 7.7 & 2.4 & -- & 2.5 \\
\hline
\end{tabular}

(a) Replicate melts are bracketed. 
TABLE B.4. Group D Compositions by ICAP Analysis, mo 1\%

\begin{tabular}{|c|c|c|c|c|c|c|c|c|c|c|c|}
\hline \multirow{2}{*}{$\begin{array}{c}\text { Melt } \\
\text { Number }(a) \\
\end{array}$} & \multicolumn{3}{|c|}{ Formers } & \multicolumn{3}{|c|}{ Modifiers } & \multicolumn{5}{|c|}{ Intermediates } \\
\hline & $\overline{\mathrm{SiO}_{2}}$ & $\underline{B}_{2} \underline{O}_{3}$ & $\overline{\mathrm{Al}_{2}{ }_{2}-3}$ & $\mathrm{CaO}$ & $\underline{\mathrm{MgO}}$ & $\mathrm{Na}_{2} \underline{0}$ & $\underline{\mathrm{ZnO}}$ & $\mathrm{TiO}_{2}$ & $\mathrm{Cr}_{2} \underline{-}_{3}$ & $\mathrm{Fe}_{2} \underline{O}_{3}$ & $\underline{\mathrm{NiO}}$ \\
\hline 70 & 42.1 & 9.6 & 8.2 & 7.9 & 4.5 & 14.8 & 3.4 & 4.6 & 1.5 & 1.8 & 1.6 \\
\hline 71 & 0.2 & 7.2 & 5.0 & 4.6 & 2.9 & 11.9 & 2.1 & 2.8 & 1.1 & 1.1 & 1.1 \\
\hline 72 & 9.9 & 5.4 & 7.3 & 7.0 & 4.1 & 14.1 & 3.2 & 4.1 & 1.6 & 1.7 & 1.6 \\
\hline 73 & 7.9 & 14.3 & 5.8 & 5.6 & 3.4 & 13.4 & 2.5 & 3.2 & 1.3 & 1.3 & 1.3 \\
\hline 74 & 0.6 & 9.5 & -- & 7.7 & 4.8 & 14.6 & 3.4 & 4.4 & 1.5 & 1.8 & 1.7 \\
\hline 75 & 3.6 & 7.7 & 15.1 & 5.0 & 2.9 & 12.3 & 2.2 & 3.1 & 1.0 & 1.1 & 1.0 \\
\hline 76 & 0.6 & 9.1 & 7.9 & -- & 4.6 & 14.5 & 3.5 & 4.6 & 1.8 & 1.8 & 1.6 \\
\hline 77 & .3 & 8.2 & 5.4 & 13.4 & 3.2 & 13.1 & 2.3 & 3.4 & 1.2 & 1.2 & 1.3 \\
\hline 78 & .3 & 8.8 & 7.4 & 7.1 & -- & 14.3 & 3.1 & 4.1 & 1.6 & 1.7 & 1.6 \\
\hline 79 & .8 & 8.4 & 5.9 & 5.9 & 8.8 & 13.3 & 2.6 & 3.3 & 1.3 & 1.4 & 1.3 \\
\hline 80 & .0 & 8.8 & 7.3 & 7.1 & 4.1 & 9.3 & 3.2 & 4.5 & 1.6 & 1.6 & 1.5 \\
\hline 81 & .2 & 8.4 & 6.1 & 6.0 & 3.4 & 16.8 & 2.6 & 3.5 & 1.3 & 1.4 & 1.3 \\
\hline 82 & 9.9 & 9.1 & 7.1 & 6.8 & 4.1 & 14.0 & -- & 4.0 & 1.6 & 1.6 & 1.8 \\
\hline 83 & .3 & 8.5 & 6.3 & 4.8 & 3.7 & 13.5 & 6.2 & 3.5 & 1.4 & 1.4 & 1.4 \\
\hline 84 & 9 & 9.0 & 7.2 & 7.0 & 4.4 & 14.3 & 3.2 & -- & 1.6 & 1.7 & 1.7 \\
\hline 85 & .2 & 8.2 & 6.1 & 5.9 & 3.6 & 13.2 & 2.7 & 8.0 & 1.4 & 1.4 & 1.3 \\
\hline 86 & 49.0 & 9.1 & 7.0 & 6.8 & 4.2 & 14.0 & 3.0 & 3.9 & -- & 1.6 & 1.5 \\
\hline 87 & & 7.7 & 6.5 & 6.2 & 3.6 & 12.8 & 2.8 & 3.9 & 3.4 & 1.4 & 1.4 \\
\hline 88 & & 8.8 & 7. & 6.7 & 4.0 & 13. & 3.0 & 3.9 & 1.5 & -- & 1.5 \\
\hline 89 & & 8.6 & 6.5 & 6.0 & 3.9 & 14. & 2.8 & 3.6 & 1.4 & 3.4 & 1.4 \\
\hline an & & 9. & 6 & 6.6 & 3.9 & 13 & 2.9 & 3.9 & 1.5 & 1.5 & - \\
\hline 91 & & 8. & 6. & 6.1 & 3.8 & 13. & 2.8 & 3.7 & 1.4 & 1.5 & 3.4 \\
\hline Q? & & 5. & 14.1 & 4.0 & -- & 9 & -- & $=$ & -- & 3.5 & 3.4 \\
\hline 93 & & 5.2 & 14.3 & 4.0 & -- & 10. & -- & 7.3 & -- & -- & -- \\
\hline an & & 2. & 14. & 4.1 & -- & & -- & 3.7 & 3.5 & . & -. \\
\hline 95 & & 5.4 & 16.1 & $\ldots$ & -- & 16.1 & -- & -- & -- & -- & 3.0 \\
\hline 96 & & 12.3 & - & 11.4 & -- & & 6.4 & 7.9 & 3.6 & 3.4 & 3.3 \\
\hline 97 & & 14 . & -- & 2.2 & 9.6 & 17 & 7.1 & -- & -- & 3.9 & - \\
\hline & & 12. & - & 13.5 & 8.9 & 10 & - & 7.0 & 3.6 & - & 3.4 \\
\hline & & 11.9 & -- & 13.8 & -- & & 6.5 & -- & 3.6 & 3.5 & 1.5 \\
\hline 10 & & 11.3 & 9.9 & 4.3 & -- & & 5.1 & -- & -- & -- & -- \\
\hline & & 12. & -- & 4.6 & - & & 5.5 & -- & - & 3.4 & -- \\
\hline & & 9. & 2.6 & 12.5 & 6.2 & 13.9 & 2.7 & 5.8 & 0.1 & 2.1 & 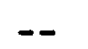 \\
\hline
\end{tabular}

(a) Points 70 through 91 are the melts used to compute observed total effects for each component. 


\section{TABLE B.5. Group B Crystallinity Data}

X-Ray Diffraction

Melt Air-Quenched Crystallinity

Number Total wt\% Principal Phases

26

24.5

$\mathrm{NiFe}_{2} \mathrm{O}_{4} / \mathrm{Zn}_{2} \mathrm{Ti}_{3} \mathrm{O}_{8}$

$3.5 \mathrm{Cr}_{2} \mathrm{O}_{3} / \mathrm{CaTiSiO}_{5}$

$15.0 \quad 2 n C_{2}{ }^{0}$

28

29

30

31

32

33

34

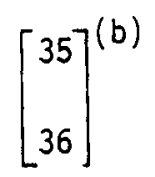

37

38

$\left[\begin{array}{l}39 \\ 40\end{array}\right]$

41

42

$\left[\begin{array}{c}43 \\ 44 \\ 45\end{array}\right]$
15.5

15.

0.0

0.0

10.5

$(\mathrm{Ni}, \mathrm{Zn})(\mathrm{Fe}, \mathrm{Cr})_{2} \mathrm{O}_{4}$

0.0

0.0

0.0

$\mathrm{Mg}(\mathrm{Cr}, \mathrm{Fe}, \mathrm{Al})_{2} \mathrm{O}_{4}$

$4.0 \quad$ AlNi $_{2}{ }^{T i}$

$6.5 \quad(\mathrm{Fe}, \mathrm{Ti}) \mathrm{Cr}_{2} \mathrm{O}_{4}$

0.0

0.0

13.5

$(\mathrm{Zn}, \mathrm{Ni}) \mathrm{Cr}_{2} \mathrm{O}_{4} / \mathrm{Cr}_{2} \mathrm{O}_{3}$

$30.0 \quad(\mathrm{Mg}, \mathrm{Ni}, \mathrm{Zn})(\mathrm{Al}, \mathrm{Cr})_{2} \mathrm{O}_{4} / \mathrm{TiO}_{2}$

$9.0(\mathrm{Mg}, \mathrm{Ni}, \mathrm{Zn})(\mathrm{Cr}, \mathrm{Fe})_{2} \mathrm{O}_{4}$

$9.0(\mathrm{Mg}, \mathrm{Ni}, \mathrm{Zn})(\mathrm{Cr}, \mathrm{Fe})_{2} \mathrm{O}_{4}$

$9.0(\mathrm{Mg}, \mathrm{Ni}, \mathrm{Zn})(\mathrm{Cr}, \mathrm{Fe})_{2} \mathrm{O}_{4}$
$X$-Ray Diffraction

Slow-Cooled Crystallinity Total wt\% Principal Phases

$65.0 \quad \mathrm{NaAlSiO}_{4} / \mathrm{NiFe}_{2} \mathrm{O}_{4}$

$18.0 \quad \mathrm{CaTiSiO} \mathrm{O}_{5} / \mathrm{Cr}_{2} \mathrm{O}_{3}$

$21.0^{(\mathrm{a})} \quad \mathrm{ZnCr}_{2} \mathrm{O}_{4} / \mathrm{TiO}_{2}$

$12.5 \quad \mathrm{MgTi}_{2} \mathrm{O}_{5}$

$27.0 \quad \mathrm{CaTiSiO}_{5} / \mathrm{NiFe}_{2} \mathrm{O}_{4}$

$18.0 \quad(\mathrm{Ni}, \mathrm{Zn})(\mathrm{Fe}, \mathrm{Cr}) \mathrm{CrO}_{4}$

$93.5 \quad \mathrm{NaAlSiO}_{4} / \mathrm{ZnAl}_{2} \mathrm{O}_{4}$

$11.5 \quad \mathrm{ZnAl}_{2} \mathrm{O}_{4}$

$11.5 \quad \mathrm{MgTi}_{2} \mathrm{O}_{5}$

$19.0 \quad \mathrm{Mg}(\mathrm{Cr}, \mathrm{Fe}, \mathrm{Al})_{2} \mathrm{O}_{4}$

$22.0 \mathrm{Mg}(\mathrm{Cr}, \mathrm{Fe}, \mathrm{Al})_{2} \mathrm{O}_{4}$

$16.5 \quad \mathrm{MgAl}_{2} \mathrm{O}_{4} / \mathrm{MgTi}_{2} \mathrm{O}_{5}$

49.5 $\mathrm{NaAlSiO}_{4} /(\mathrm{Fe}, \mathrm{Cr}) \mathrm{Cr}_{2} \mathrm{O}_{3}$

$3.0 \quad \mathrm{NiFe}_{2} \mathrm{O}_{4} /(\mathrm{Ca}, \mathrm{Na}) \mathrm{FeSi}_{2} \mathrm{O}_{6}$

4.5 $\quad \mathrm{NiFe}_{2} \mathrm{O}_{4} /(\mathrm{Ca}, \mathrm{Na}) \mathrm{FeSi}_{2} \mathrm{O}_{6}$

$42.0 \quad(\mathrm{Ca}, \mathrm{Na}) \mathrm{FeSi}_{2} \mathrm{O}_{6} /(\mathrm{Zn}, \mathrm{Ni}) \mathrm{Cr}_{2} \mathrm{O}_{4}$

$35.5 \quad(\mathrm{Ca}, \mathrm{Na}) \mathrm{FeSi}_{2} \mathrm{O}_{6} /(\mathrm{Zn}, \mathrm{Ni}) \mathrm{Cr}_{2} \mathrm{O}_{4}$

$18.5(\mathrm{Mg}, \mathrm{Ni}, \mathrm{Zn})(\mathrm{Cr}, \mathrm{Fe})_{2} \mathrm{O}_{4} /(\mathrm{Mg}, \mathrm{Fe}) \mathrm{Al}_{2} \mathrm{O}_{4}$.

$22.5(\mathrm{Mg}, \mathrm{Ni}, \mathrm{Zn})(\mathrm{Cr}, \mathrm{Fe})_{2} \mathrm{O}_{4} /(\mathrm{Mg}, \mathrm{Fe}) \mathrm{Al}_{2} \mathrm{O}_{4}$

20.5

(a) Not included in modeling.

(b) Replicate melts are bracketed. 


\section{TABLE B.6. Group C Crystallinity Data}

\begin{tabular}{|c|c|c|c|c|c|}
\hline \multirow{2}{*}{$\begin{array}{l}\text { Melt } \\
\text { Number }\end{array}$} & \multirow{2}{*}{$\begin{array}{c}\text { X-Ray Diffraction } \\
\text { Total } \\
\text { Water-Quenched } \\
\text { Crystallinity, wt\% }\end{array}$} & \multicolumn{2}{|c|}{$\begin{array}{c}\text { X-Ray Diffraction } \\
\text { Air-Quenched Crystallinity }\end{array}$} & \multicolumn{2}{|c|}{$\begin{array}{c}\text { X-Ray Diffraction } \\
\text { Slow-Cooled Crystallinity }\end{array}$} \\
\hline & & Total wt\% & Principal Phases & Tota $1 \mathrm{wt} \%$ & Principal Phases \\
\hline 46 & 9.5 & 7.0 & $\mathrm{MgCr}_{2} \mathrm{O}_{4} / \mathrm{Cr}_{2} \mathrm{O}_{3}$ & 14.0 & $\mathrm{Cr}_{2} \mathrm{O}_{3} / \mathrm{TiO}_{2}$ \\
\hline 47 & 0.0 & 4.5 & $\mathrm{Ni}(\mathrm{Fe}, \mathrm{Ti})_{2} \mathrm{O}_{4}$ & 32.0 & $(\mathrm{Ca}, \mathrm{Fe}, \mathrm{Mg}) \mathrm{SiO}_{3} / \mathrm{CaTiSiO}_{5}$ \\
\hline 48 & 14.0 & 13.5 & $\mathrm{Cr}_{2} \mathrm{O}_{3} / \mathrm{Ni}(\mathrm{Cr}, \mathrm{Ti}, \mathrm{Fe})_{2} \mathrm{O}_{4}$ & 55.0 & $\mathrm{NaAlSiO}_{4} / \mathrm{TiO}_{2}$ \\
\hline 49 & 0.0 & 0.0 & -- & $4.0(a)$ & $\mathrm{TiO}_{2}$ \\
\hline$[50]^{(b)}$ & 18.5 & 18.5 & $(\mathrm{Mg}, \mathrm{Zn}) \mathrm{Cr}_{2} \mathrm{O}_{4}$ & 18.5 & $(\mathrm{Mg}, \mathrm{Zn}) \mathrm{Cr}_{2} \mathrm{O}_{4}$ \\
\hline 51 & 20.0 & 20.5 & $(\mathrm{Mg}, \mathrm{Zn}) \mathrm{Cr}_{2} \mathrm{O}_{4}$ & 19.0 & $(\mathrm{Mg}, \mathrm{Zn}) \mathrm{Cr}_{2} \mathrm{O}_{4}$ \\
\hline$\lfloor 52$ & 19.0 & 20.0 & $(\mathrm{Mg}, \mathrm{Zn}) \mathrm{Cr}_{2} \mathrm{O}_{4}$ & 18.5 & $(\mathrm{Mg}, \mathrm{Zn}) \mathrm{Cr}_{2} \mathrm{O}_{4}$ \\
\hline 53 & 0.0 & 0.0 & - & 6.5 & $\mathrm{NiSiO}_{4}$ \\
\hline 54 & 10.0 & 9.5 & $(\mathrm{Cr}, \mathrm{Fe}) \mathrm{CrO}_{3}$ & 2.4 & $(\mathrm{Cr}, \mathrm{Fe}) \mathrm{CrO}_{3} /(\mathrm{Na}, \mathrm{Ca}) \mathrm{Al}_{3} \mathrm{Si}_{5} \mathrm{O}_{16}$ \\
\hline 55 & 14.0 & 16.5 & $(\mathrm{Ni}, \mathrm{Mg})(\mathrm{Cr}, \mathrm{A} 1) \mathrm{CrO}_{4}$ & 17.0 & $(\mathrm{Ni}, \mathrm{Mg})(\mathrm{Cr}, \mathrm{Al}) \mathrm{CrO}_{4} / \mathrm{NiAl}_{2} \mathrm{O}_{4}$ \\
\hline 56 & 0.0 & 0.0 & -- & 4.0 & $\mathrm{Ca}_{4}{ }^{\mathrm{T}} \mathrm{i}_{3} \mathrm{O} 10$ \\
\hline 57 & 24.0 & 27.5 & $(\mathrm{Ni}, \mathrm{Zn})(\mathrm{Cr}, \mathrm{Ti}, \mathrm{Al}) \mathrm{CrO}_{4}$ & 40.5 & $(\mathrm{Ni}, \mathrm{Zn})(\mathrm{Cr}, \mathrm{Ti}, \mathrm{Al}) \mathrm{CrO}_{4} / \mathrm{NaAlSiO}_{4}$ \\
\hline 58 & 0.0 & 0.0 & -- & 15.5 & $\mathrm{NaAlSiO}_{4} / \mathrm{MgTi}_{2} \mathrm{O}_{5}$ \\
\hline 59 & 7.0 & 11.5 & $\mathrm{Cr}_{2} \mathrm{O}_{3} / \mathrm{TiO}_{2}$ & 19.5 & $\mathrm{Cr}_{2} \mathrm{O}_{3} / \mathrm{CaTiSiO}_{5}$ \\
\hline 60 & 0.0 & 0.0 & -- & 0.0 & -- \\
\hline 61 & 0.0 & 0.0 & - & 21.0 & $\mathrm{NaAlSiO}_{4} / \mathrm{CaAl}_{2} \mathrm{SiO}_{6}$ \\
\hline 62 & 0.0 & 16.5 & Unidentifiable & 16.0 & $\mathrm{Fe}_{2} \mathrm{TiO}_{5} / \mathrm{ZnAl}_{2} \mathrm{O}_{4}$ \\
\hline 63 & 0.0 & 0.0 & - & 30.0 & $(\mathrm{Ca}, \mathrm{Fe}, \mathrm{Mg}) \mathrm{SiO}_{3} / \mathrm{NiFe}_{2} \mathrm{O}_{4}$ \\
\hline$[64]$ & 1.0 & 0.0 & - & 76.5 & $\mathrm{NaA} 1 \mathrm{SiO}_{4} / \mathrm{Ca}_{2} \mathrm{Al}_{2} \mathrm{SiO}_{7}$ \\
\hline 65 & 0.0 & 0.0 & -- & 76.0 & $\mathrm{NaA} 1 \mathrm{SiO}_{4} / \mathrm{Ca}_{2} \mathrm{Al}_{2} \mathrm{SiO}_{7}$ \\
\hline L66. & 0.0 & 0.0 & -- & 78.0 & $\mathrm{NaAlSiO}_{4} / \mathrm{Ca}_{2} \mathrm{Al}_{2} \mathrm{SiO}_{7}$ \\
\hline 67 & 8.0 & 18.5 & $(\mathrm{Mg}, \mathrm{Ni})(\mathrm{Al}, \mathrm{Cr}) \mathrm{CrO}_{4}$ & 18.0 & $(\mathrm{Mg}, \mathrm{Ni})(\mathrm{Al}, \mathrm{Cr}) \mathrm{CrO}_{4}$ \\
\hline 68 & 11.0 & 12.5 & $\mathrm{Cr}_{2} \mathrm{O}_{3} / \mathrm{NiCr}_{2} \mathrm{O}_{4}$ & 16.5 & $\mathrm{NaAlSiO}_{4} / \mathrm{Cr}_{2} \mathrm{O}_{3}$ \\
\hline 69 & 14.0 & 14.0 & $(\mathrm{Ni}, \mathrm{Zn}) \mathrm{Cr}_{2} \mathrm{O}_{4}$ & 26.0 & $(\mathrm{Ni}, \mathrm{Zn}) \mathrm{Cr}_{2} \mathrm{O}_{4} / \mathrm{TiO}_{2}$ \\
\hline
\end{tabular}

(a) Not included in modeling.

(b) Replicate melts are bracketed. 
TABLE B.7. Group D Crystallinity Data

\begin{tabular}{|c|c|c|}
\hline Melt & \multicolumn{2}{|c|}{ Air-Quenched Crystallinity by XRD } \\
\hline Number & Total wt\% & Principal Phases \\
\hline 70 & 14.0 & Spine $1(a)$ \\
\hline 71 & 5.9 & Spinel \\
\hline 72 & 13.0 & Spine 1 \\
\hline 73 & 9.4 & Spinel \\
\hline 74 & 9.9 & Spine 1 \\
\hline 75 & 13.9 & Spinel \\
\hline 76 & 19.5 & Spine 1 \\
\hline 77 & 7.2 & Spinel \\
\hline 78 & 12.6 & Spine 1 \\
\hline 79 & 11.3 & Spinel \\
\hline 80 & 13.3 & Spine 1 \\
\hline 81 & 7.0 & Spinel \\
\hline 82 & 9.4 & Spine 1 \\
\hline 83 & 12.9 & Spinel \\
\hline 84 & 12.7 & Spine 1 \\
\hline 85 & 10.2 & Spinel \\
\hline 86 & 0.0 & Vitreous \\
\hline 87 & 18.8 & Spinel \\
\hline 88 & 10.7 & Spine 1 \\
\hline 89 & 12.8 & Spinel \\
\hline 90 & 10.1 & Spine 1 \\
\hline 91 & 15.5 & Spinel \\
\hline 92 & 4.3 & Unknown \\
\hline 93 & 0.0 & Vitreous \\
\hline 94 & 10.7 & $\mathrm{FeNiBO}_{4}$ \\
\hline 95 & 2.0 & Unknown \\
\hline 96 & 18.4 & Spinel \\
\hline 97 & 0.0 & Vitreous \\
\hline 98 & 10.9 & $\mathrm{Cr}_{2} \mathrm{O}_{3}$ \\
\hline 99 & 13.4 & Spine 1 \\
\hline 100 & 0.0 & Vitreous \\
\hline 101 & 0.0 & Vitreous \\
\hline 102 & 0.0 & Vitreous \\
\hline
\end{tabular}

(a) Spinel of general composition $(\mathrm{Ni}, \mathrm{Fe})(\mathrm{Fe}, \mathrm{Cr}) \mathrm{CrO}_{4}$. 
TABLE B.8. Group A Melt Properties

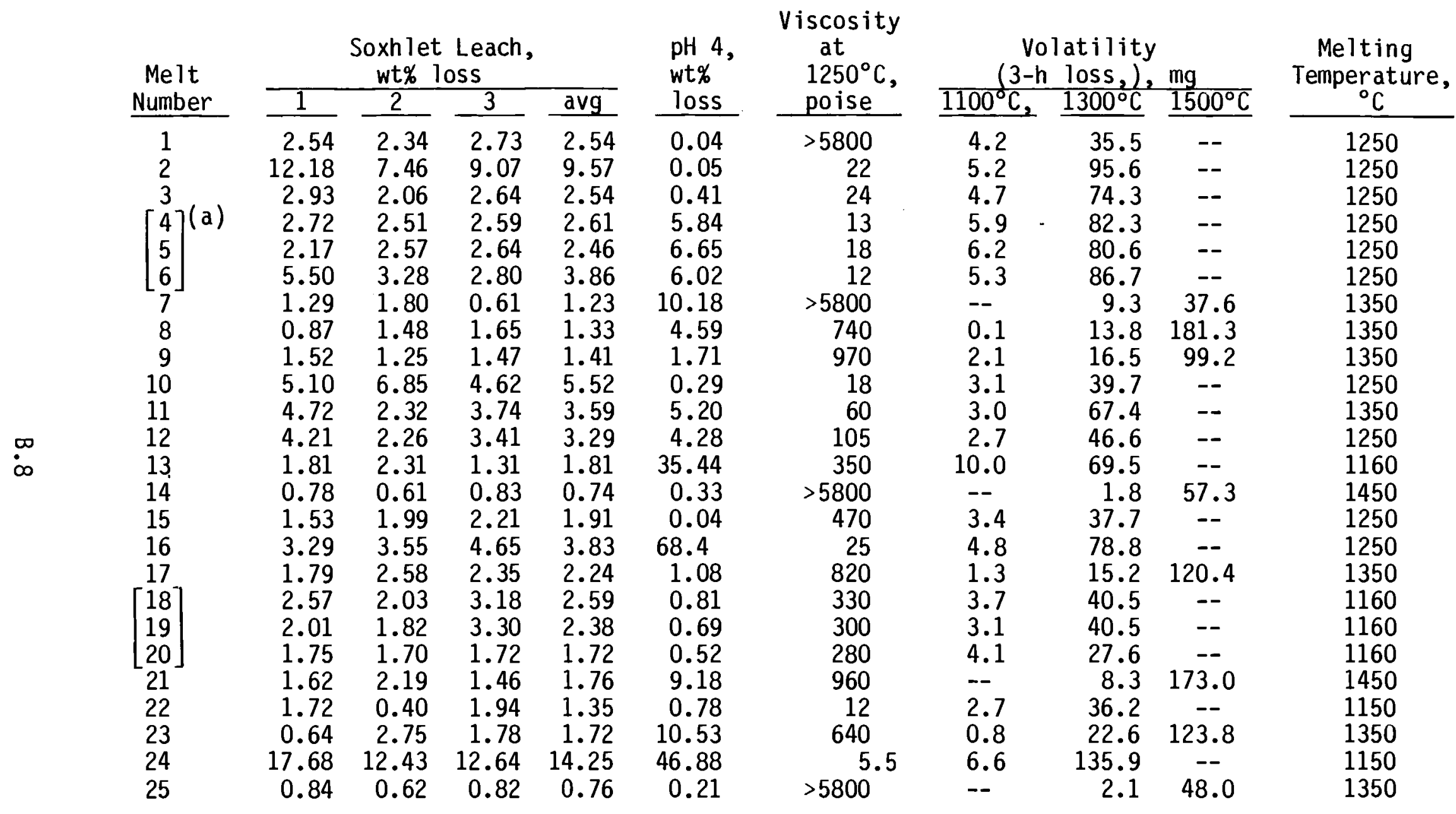

(a) Replicate melts are bracketed. 
TABLE B.9. Group B Me1t Properties

\begin{tabular}{|c|c|c|c|c|c|}
\hline $\begin{array}{l}\text { Melt } \\
\text { Number }\end{array}$ & $\begin{array}{c}\text { Melting } \\
\text { Temperature, } \\
{ }^{\circ} \mathrm{C}\end{array}$ & $\begin{array}{c}\text { Viscosity } \\
\text { at } \\
1250^{\circ} \mathrm{C} \text {, } \\
\text { poise }\end{array}$ & \multicolumn{3}{|c|}{$\begin{array}{c}\text { Volatility } \\
(3-\mathrm{h} \mathrm{loss}), \mathrm{mg} \\
\end{array}$} \\
\hline 26 & 1350 & $>5800^{(a)}$ & 1.7 & 11.9 & -- \\
\hline 27 & 1250 & 44 & 9.9 & 89.2 & -- \\
\hline 28 & 1250 & 83 & 12.0 & 112.0 & -- \\
\hline 29 & 1250 & 77 & 1.7 & 28.0 & -- \\
\hline 30 & 1150 & 1.3 & 7.4 & . $\quad 151.1$ & 408.4 \\
\hline 31 & 1150 & 66 & 11.3 & 78.7 & -- \\
\hline 32 & 1400 & 82 & 2.0 & 38.4 & -- \\
\hline 33 & 1380 & 84 & 2.7 & 41.6 & -- \\
\hline 34 & 1150 & 6.2 & 4.3 & 66.3 & -- \\
\hline$[35]^{(b)}$ & 1320 & $>5800^{(a)}$ & 2.0 & 15.2 & - \\
\hline$[36$ & 1320 & $>5800$ & 2.0 & 14.8 & -- \\
\hline 37 & 1400 & 1400 & -- & 4.2 & 42.5 \\
\hline 38 & 1450 & 495 & 1.3 & 14.6 & -- \\
\hline$[39]$ & 1150 & 34 & 5.4 & 94.0 & -- \\
\hline 40 & 1150 & 33 & 4.7 & 97.4 & -- \\
\hline 41 & 1250 & 68 & 4.4 & 49.9 & -- \\
\hline 42 & 1550 & $>5800^{(a)}$ & 2.0 & 9.8 & - \\
\hline$[437$ & 1250 & 220 & 4.4 & 44.7 & -- \\
\hline 44 & 1250 & 175 & 3.7 & 38.7 & -- \\
\hline [45] & 1250 & $243^{(a)}$ & 3.9 & 39.9 & -- \\
\hline
\end{tabular}

(a) Not included in modeling.

(b) Replicate melts are bracketed. 
TABLE B.10. Group C Melt Properties

\begin{tabular}{|c|c|c|c|c|c|}
\hline \multirow{2}{*}{$\begin{array}{l}\text { Melt } \\
\text { Number }\end{array}$} & \multirow{2}{*}{$\begin{array}{c}\text { Melting } \\
\text { Temperature, } \\
{ }^{\circ} \mathrm{C} \\
\end{array}$} & \multirow{2}{*}{$\begin{array}{c}V \text { iscosity } \\
\text { at } \\
1250^{\circ} \mathrm{C}, \\
\text { poise } \\
\end{array}$} & \multicolumn{3}{|c|}{$\begin{array}{c}\text { Volatility } \\
(3-h \text { loss })_{2} \mathrm{mg}\end{array}$} \\
\hline & & & $1100^{\circ} \mathrm{C}$ & $1300^{\circ} \mathrm{C}$ & $1500^{\circ} \mathrm{C}$ \\
\hline 46 & 1250 & 150 & 7.6 & 79.4 & -- \\
\hline 47 & 1250 & 18 & 1.3 & 26.3 & -- \\
\hline 48 & 1300 & 800 & 2.7 & 14.0 & -- \\
\hline 49 & 1200 & 23 & 6.8 & 113.0 & -- \\
\hline$[50]^{(a)}$ & 1200 & 523 & 4.3 & 20.1 & -- \\
\hline 51 & 1200 & 600 & 4.1 & 22.5 & -- \\
\hline L2. & 1200 & 350 & 4.0 & 27.8 & -- \\
\hline 53 & 1200 & 13 & 3.1 & 53.0 & -- \\
\hline 54 & 1250 & $>5800^{(b)}$ & -- & 4.8 & 59.2 \\
\hline 55 & 1250 & 585 & 2.7 & 31.0 & -- \\
\hline 56 & 1050 & 3.9 & 6.8 & 111.6 & -- \\
\hline 57 & 1150 & $>5800^{(b)}$ & -- & 10.9 & 49.7 \\
\hline 58 & 1150 & 74 & 3.1 & 49.9 & -- \\
\hline 59 & 1300 & 293 & 4.4 & 29.1 & -- \\
\hline 60 & 1050 & 37 & 4.9 & 66.9 & -- \\
\hline 61 & 1250 & 130 & 1.9 & 21.4 & -- \\
\hline 62 & 1300 & 90 & 1.0 & 35.2 & -- \\
\hline 63 & 1150 & 9.0 & 4.1 & 94.3 & -- \\
\hline$[64]$ & 1200 & 51 & 2.8 & 47.7 & -- \\
\hline 65 & 1200 & 68 & 2.5 & 45.0 & -- \\
\hline [66] & 1200 & 57 & 2.1 & 39.1 & -- \\
\hline 67 & 1150 & $680^{(b)}$ & 3.3 & 27.6 & 137.5 \\
\hline 68 & 1400 & 520 & 2.6 & 25.3 & -- \\
\hline 69 & 1400 & 150 & 8.7 & 28.8 & 132.2 \\
\hline
\end{tabular}

(a) Replicate melts are bracketed.

(b) Not included in modeling. 
TABLE B.11. Group D Melt Properties

\begin{tabular}{|c|c|c|c|}
\hline $\begin{array}{c}\text { Melt } \\
\text { Number } \\
\end{array}$ & $\begin{array}{c}\text { Melting } \\
\text { Temperature, }{ }^{\circ} \mathrm{C} \\
\end{array}$ & $\begin{array}{l}\text { Viscosity at } \\
1250^{\circ} \mathrm{C} \text {, poise } \\
\end{array}$ & $\begin{array}{c}\text { Volatility (3-h loss), } \\
\text { at } 1300^{\circ} \mathrm{C}, \mathrm{mg}\end{array}$ \\
\hline 70 & 1280 & 115 & 47 \\
\hline 71 & 1570 & 230 & 29 \\
\hline 72 & 1350 & 250 & 22 \\
\hline 73 & 1250 & 61 & 59 \\
\hline 74 & 1150 & 46 & 75 \\
\hline 75 & 1600 & 590 & 9.6 \\
\hline 76 & 1450 & 720 & 20 \\
\hline 77 & 1150 & 28 & 55 \\
\hline 78 & 1350 & 180 & 32 \\
\hline 79 & 1250 & 130 & 35 \\
\hline 80 & 1450 & 350 & 19 \\
\hline 81 & 1210 & 70 & 79 \\
\hline 82 & 1250 & 100 & 40 \\
\hline 83 & 1250 & 140 & 33 \\
\hline 84 & 1250 & 150 & 47 \\
\hline 85 & 1350 & 82 & 33 \\
\hline 86 & 1250 & 27 & 47 \\
\hline 87 & 1550 & 430 & 69 \\
\hline 88 & 1350 & 86 & 35 \\
\hline 89 & 1300 & 210 & 31 \\
\hline 90 & 1410 & - & 39 \\
\hline 91 & 1250 & 61 & 32 \\
\hline 92 & 1610 & 640 & -- \\
\hline 93 & 1600 & 1800 & 6.2 \\
\hline 94 & 1720 & -- & 1.9 \\
\hline 95 & 1600 & 2300 & 6.2 \\
\hline 96 & 1450 & 190 & 65 \\
\hline 97 & 1050 & 1.3 & 200 \\
\hline 98 & 1350 & 40 & 75 \\
\hline 99 & 1450 & 110 & 200 \\
\hline 100 & 1400 & 160 & 40 \\
\hline 101 & 1250 & 16 & 80 \\
\hline 102 & 1200 & 4.5 & 71 \\
\hline
\end{tabular}


TABLE B.12. Group B Weight Loss Leaching Data

\begin{tabular}{|c|c|c|c|c|c|c|c|}
\hline Melt & Soxh 1 & Leach & $w t \%$ & & & 4, wt? & loss \\
\hline Number & 7 & 2 & 3 & avg & 1 & 2 & avg \\
\hline 26 & 0.82 & 0.85 & 0.71 & 0.79 & 8.1 & 8.0 & 8.10 \\
\hline 27 & 4.1 & 4.0 & 3.8 & 3.97 & 0.10 & 0.18 & 0.14 \\
\hline 28 & $0.88^{(a)}$ & 2.1 & 2.1 & 2.10 & 0.00 & 0.00 & $0.01^{(b)}$ \\
\hline 29 & $2.6^{(a)}$ & 0.82 & 0.80 & 0.81 & 0.00 & 0.00 & $0.01^{(b)}$ \\
\hline 30 & 1.1 & 2.0 & 3.0 & 2.03 & 6.2 & 8.6 & 7.40 \\
\hline 31 & 2.0 & 3.0 & 1.0 & 2.00 & 4.7 & 3.0 & 3.90 \\
\hline 32 & 1.4 & 1.2 & 1.2 & 1.27 & 92.3 & 90.5 & 91.4 \\
\hline 33 & 2.1 & 1.1 & 1.0 & 1.40 & 47.0 & 51.0 & 49.0 \\
\hline 34 & 1.5 & 1.3 & 1.4 & 1.40 & 0.10 & 0.12 & 0.11 \\
\hline$[35]^{(c)}$ & 1.2 & 1.0 & 1.0 & 1.07 & 31.4 & 35.4 & 33.4 \\
\hline 36 & 1.2 & 1.4 & 1.1 & 1.23 & 41.5 & 37.5 & 39.5 \\
\hline 37 & 0.37 & 0.39 & 0.37 & 0.38 & 0.62 & 0.21 & 0.42 \\
\hline 38 & 1.1 & 1.2 & 1.0 & 1.10 & 9.3 & 9.8 & 9.60 \\
\hline$[39]$ & 4.9 & 4.6 & 4.0 & 4.50 & 0.18 & 0.22 & 0.20 \\
\hline 40 & 4.7 & 4.5 & 5.2 & 4.80 & 0.12 & 0.35 & 0.24 \\
\hline 41 & 3.2 & 4.2 & 2.9 & 3.43 & 8.3 & 4.1 & 6.20 \\
\hline 42 & 0.53 & 0.54 & 0.58 & 0.55 & 2.2 & 2.1 & 2.20 \\
\hline$[43]$ & 1.1 & 1.2 & 1.1 & 1.13 & 0.89 & 0.82 & 0.86 \\
\hline 44 & 1.1 & 1.0 & 1.1 & 1.07 & 0.75 & 0.85 & 0.80 \\
\hline [45] & 1.2 & 1.3 & 1.0 & 1.17 & 0.95 & 0.76 & 0.86 \\
\hline
\end{tabular}

(a) Not included in modeling.

(b) Small, nonzero number assigned for logarithm modeling purposes.

(c) Replicate melts are bracketed. 
TABLE B.13. Group C Weight Loss Leaching Data

\begin{tabular}{|c|c|c|c|c|c|c|c|}
\hline \multirow{2}{*}{$\begin{array}{c}\text { Melt } \\
\text { Number }\end{array}$} & \multicolumn{4}{|c|}{ Soxh let, wt\% loss } & \multicolumn{3}{|c|}{$\mathrm{pH} 4$, wt\% loss } \\
\hline & 1 & 2 & 3 & avg & 1 & 2 & avg \\
\hline 46 & 5.43 & 5.00 & 4.90 & 5.11 & 0.28 & 0.11 & 0.20 \\
\hline 47 & 1.08 & 1.12 & 1.12 & 1.11 & 0.03 & 2.91 & 1.47 \\
\hline 48 & 0.77 & 0.85 & 0.74 & 0.79 & 15.9 & 16.8 & 16.4 \\
\hline 49 & 1.97 & 1.90 & 1.97 & 1.95 & 0.18 & 0.11 & 0.15 \\
\hline$[50]^{(a)}$ & 0.88 & 0.80 & 0.78 & 0.82 & 0.14 & 0.16 & 0.15 \\
\hline 51 & 0.81 & 0.79 & 0.85 & 0.82 & 0.08 & 0.07 & 0.08 \\
\hline [52] & 0.61 & 0.83 & 0.80 & 0.75 & 0.15 & 0.15 & 0.15 \\
\hline 53 & 1.52 & 1.79 & 1.70 & 1.67 & 0.19 & 0.16 & 0.18 \\
\hline 54 & 0.58 & 0.64 & 0.66 & 0.63 & 1.88 & 2.20 & 2.04 \\
\hline 55 & 0.99 & 0.91 & 1.11 & 1.00 & 49.3 & 54.2 & 51.8 \\
\hline 56 & 1.51 & 1.68 & 2.11 & 1.77 & 9.46 & 8.61 & 9.04 \\
\hline 57 & 0.58 & 0.86 & 0.47 & 0.64 & 2.19 & 1.98 & 2.09 \\
\hline 58 & 0.94 & 0.98 & 0.96 & 0.96 & 24.6 & 24.8 & 24.7 \\
\hline 59 & 3.64 & 3.48 & 3.51 & 3.54 & 0.02 & 0.01 & 0.02 \\
\hline 60 & 1.35 & 1.30 & 1.35 & 1.33 & 0.06 & 0.10 & 0.08 \\
\hline 61 & 1.33 & 1.17 & 1.36 & 1.29 & 39.5 & 34.9 & 37.2 \\
\hline 62 & 0.85 & 0.92 & 0.83 & 0.87 & 6.83 & 7.94 & 7.39 \\
\hline 63 & 1.88 & 1.91 & 1.84 & 1.88 & 98.1 & 95.0 & 96.6 \\
\hline$[64]$ & 1.05 & 0.99 & 1.14 & 1.06 & 77.8 & 77.7 & 77.8 \\
\hline 65 & 1.08 & 0.96 & 0.92 & 0.99 & 76.8 & 74.3 & 75.6 \\
\hline$[66]$ & 1.11 & 1.30 & 0.95 & 1.12 & 80.7 & 72.0 & 76.4 \\
\hline 67 & 1.16 & 1.08 & 1.11 & 1.12 & 44.5 & 42.0 & 43.3 \\
\hline 68 & 1.35 & 1.57 & 1.49 & 1.47 & 23.5 & 27.3 & 25.4 \\
\hline 69 & 2.65 & 2.67 & 2.53 & 2.62 & 0.09 & 0.04 & 0.07 \\
\hline
\end{tabular}

(a) Replicate melts are bracketed. 
TABLE B.14. Group D Weight Loss Leaching Data

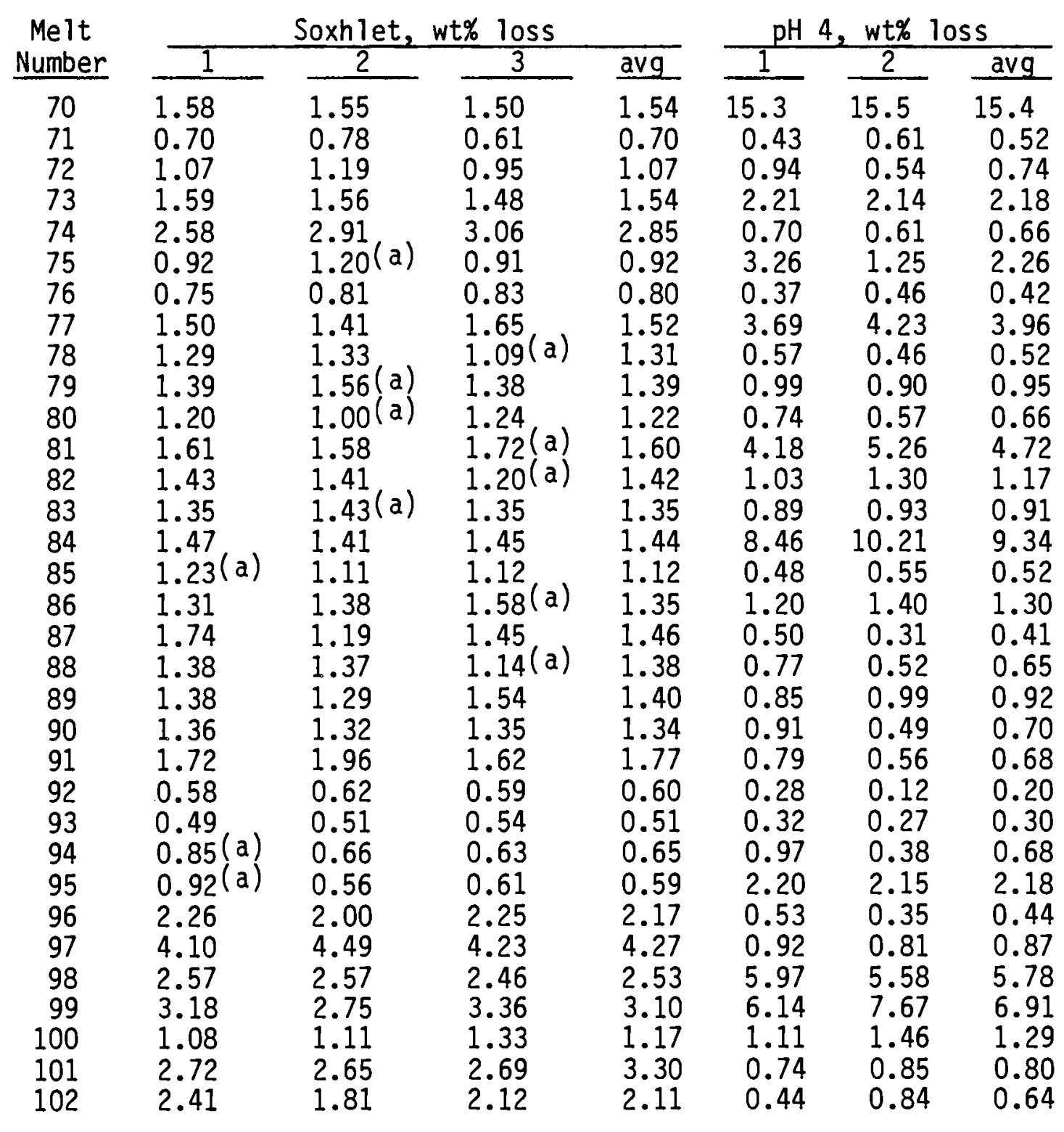

(a) Not used in computation of average. 
TABLE B.15. Group B Static Solution Analysis Leaching Data(a)

\begin{tabular}{|c|c|c|c|c|c|c|c|c|}
\hline \multirow{2}{*}{$\begin{array}{c}\text { Melt } \\
\text { Number }\end{array}$} & \multicolumn{8}{|c|}{ Elemental Release, normalized $\mathrm{g} / \mathrm{m}^{2}$} \\
\hline & $\overline{\mathrm{pH}}$ & $5 i$ & B & $\mathrm{Na}$ & $\mathrm{Mg}$ & $\mathrm{Ca}$ & $A T$ & $\mathrm{Cr}$ \\
\hline 26 & 7.8 & 6.1 & 9.7 & 7.7 & $--(b)$ & -- & 1.4 & -- \\
\hline & 8.9 & 55 & 86 & 110 & -- & 5.6 & -- & 21 \\
\hline $27 A(c)$ & 9.3 & 47 & 59 & 66 & -- & 8.6 & -- & 14 \\
\hline $27 B$ & 9.3 & 52 & 65 & 72 & -- & 6.5 & -- & 16 \\
\hline 28 & 8.5 & 33 & 36 & 40 & -- & -- & -- & 4.3 \\
\hline $28 \mathrm{~A}$ & 8.4 & 45 & 39 & 39 & -- & -- & -- & 5.4 \\
\hline $28 \mathrm{~B}$ & 8.6 & 46 & 39 & 40 & -- & -- & - & 5.6 \\
\hline 29 & 7.3 & 8.6 & 9.3 & 9.2 & 9.8 & -- & $0(d)$ & -- \\
\hline 30 & 8.9 & 18 & 96 & 114 & 0.7 & 6.2 & -- & -- \\
\hline 31 & 8.9 & 43 & 65 & 78 & -- & 8.2 & -- & 11 \\
\hline 32 & 7.5 & 5.0 & 6.2 & 9.6 & 4.3 & 7.2 & 3.3 & - \\
\hline 33 & 7.7 & 5.5 & 4.3 & 7.0 & - & 7.4 & 2.3 & -- \\
\hline & 8.3 & 16 & 35 & 38 & 4.0 & 15 & -- & -- \\
\hline $357^{(e)}$ & 7.5 & 3.2 & 7.1 & 5.1 & 2.5 & 0 & 0 & 0 \\
\hline $35 A$ & 4.3 & 3.2 & 2.9 & 1.9 & 1.1 & 0 & 0 & 0 \\
\hline $35 B$ & 4.1 & 3.1 & 6.7 & 5.5 & 2.5 & 0 & 0 & 0 \\
\hline 36 & 7.3 & 3.6 & 3.3 & 1.7 & 1.1 & 0 & 0 & 0 \\
\hline 37 & 6.0 & 1.3 & 1.0 & $>0.1$ & 0.7 & -- & 0 & -- \\
\hline 38 & 7.9 & 4.8 & 13 & 1.2 & -- & 13 & 1.4 & 0 \\
\hline 397 & 8.8 & 49 & 83 & 70 & -- & 10 & -- & -- \\
\hline 40$]$ & 8.9 & 37 & 58 & 55 & -- & 7.0 & -- & -- \\
\hline 41 & 9.2 & 46 & 81 & 84 & 0 & 7.2 & -- & 8.2 \\
\hline 42 & 5.4 & 1.4 & 1.4 & 0.8 & 0 & -- & 0 & \\
\hline $42 A$ & 3.8 & 2.5 & 3.4 & 3.7 & 2.1 & -- & 0.2 & 0.02 \\
\hline $42 B$ & 3.8 & 2.3 & 3.3 & 4.1 & 2.4 & -- & 0.2 & \\
\hline [43] & 7.6 & 4.6 & 4.8 & 8.2 & 5.8 & 6.1 & 1.6 & 0 \\
\hline 44 & 7 & 5. & 6.2 & 9.1 & 7.2 & 7.9 & 1.4 & 0 \\
\hline 45 & & 5.6 & 6.2 & 9.3 & 6.5 & 7.6 & 1.9 & 0 \\
\hline
\end{tabular}
(a) Conditions for all tests: $90^{\circ} \mathrm{C}$, static, deionized water; $\mathrm{SA} / \mathrm{SV}=10 \mathrm{~m}^{-1} ; 28$ days.
(b) Blank (-) denotes element not present in sample.
(c) Samples marked A or B are recent repeats using original sample bars, not remelts.
(d) Zero $(0)$ denotes element present in sample but not detected in leach solution.
(e) Replicate melts are bracketed. 
TABLE B.16. Group C Static Solution Analysis Leaching Data(a)

\begin{tabular}{|c|c|c|c|c|c|c|c|c|}
\hline \multirow{2}{*}{$\begin{array}{r}\text { Me } 1 t \\
\text { Number } \\
\end{array}$} & & \multicolumn{7}{|c|}{ Elemental Release, normalized $\mathrm{g} / \mathrm{m}^{2}$} \\
\hline & $\mathrm{pH}$ & $\mathrm{Si}$ & $B$ & $\mathrm{Na}$ & $\mathrm{Mg}$ & $\mathrm{Ca}$ & A] & $\mathrm{Cr}$ \\
\hline 46 & 7.8 & 12 & 11 & 14 & 9.1 & 7.0 & $--(b)$ & 1.7 \\
\hline 47 & 7.7 & 6.1 & 7.3 & 11 & 5.5 & 4.9 & 3.5 & - \\
\hline 48 & 7.8 & 5.6 & 5.9 & 9.1 & -- & 6.0 & 2.2 & $0^{(c)}$ \\
\hline 49 & 8.7 & 26 & 24 & 31 & -- & -- & -- & -- \\
\hline 53 & 8.8 & 16 & 26 & 38 & 1.8 & -- & -- & -- \\
\hline 55 & 7.3 & 4.9 & 6.0 & 7.5 & 5.1 & 9.0 & 1.4 & 0 \\
\hline 56 & 8.2 & 14 & 19 & 28 & -- & 11 & 1.6 & -- \\
\hline 58 & 7.7 & 6.2 & 7.0 & 4.1 & 4.6 & -- & 2.3 & -- \\
\hline 59 & 8.4 & 24 & 42 & 57 & -- & 2.6 & -- & 7.7 \\
\hline 61 & 7.7 & 4.0 & 4.5 & 6.0 & 5.9 & 6.4 & 2.2 & -- \\
\hline 62 & 6.7 & 3.3 & 3.5 & 7.0 & -- & 5.3 & 0.2 & -- \\
\hline 63 & 8.5 & 15 & 50 & 75 & 0.6 & 22 & 0 & -- \\
\hline $647^{(6}$ & 7.8 & 5.7 & 6.9 & 11 & -- & 8.1 & 2.6 & -- \\
\hline 66 & 7.7 & 5.5 & 7.5 & 11 & -- & 5.9 & 2.6 & -- \\
\hline 67 & 7.5 & 5.0 & 5.8 & 7.3 & 5.1 & 7.0 & 1.6 & 0 \\
\hline
\end{tabular}

(a) Conditions for all tests: $90^{\circ} \mathrm{C}$, static, deionized water; $\mathrm{SA} / \mathrm{SV}=10 \mathrm{~m}^{-1} ; 28$ days.

(b) Blank $(-)$ denotes element not present in sample.

(c) Zero (0) denotes element present in sample but not detected in leach solution.

(d) Replicate melts are bracketed. 
TABLE B.17. Group D Static Solution Analysis Leaching Data(a)

Melt

Number

70

71

72

73

74

75
76

77

78

79

80

81

82

83

84

85

86

87

88

89

90

91

92

93

94

95

96

97

98

99

100

101

102
Elemental Release, normalized $\mathrm{g} / \mathrm{m}^{2}$

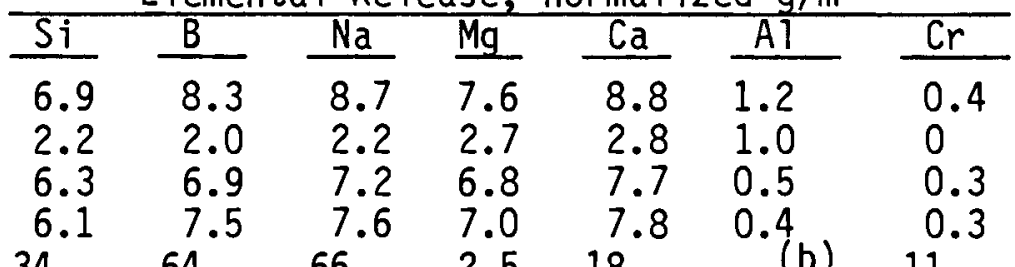
$34 \quad 6$

6.6

64 66

6.8

2.5

6.2

18

$8.1 \quad 1.4$

$-1.0$

$7.7 \quad 1.6$

7.81 .4

6.60

$7.6 \quad 0.9$

$\begin{array}{ll}7.8 & 0.3\end{array}$

6.91 .6

$11 \quad 1.4$

6.92 .6

8.10 .8

8.31 .8

$6.4 \quad 0.6$

$7.4 \quad 1.6$

$7.8 \quad 2.4$

$7.1 \quad 2.3$

9.13 .5

5.30

$5.7 \quad Q$

4.80

-- 0

31

1.5
5.0

5.0
3.8

5.5

37

19
$-$

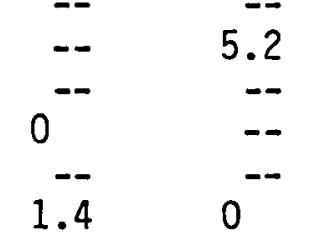

(a) Conditions for all tests: $90^{\circ} \mathrm{C}$, static, deionized water, $\mathrm{SA} / \mathrm{SV}=10 \mathrm{~m}^{-1}, 28$ days.

(b) Blank (-) denotes element not present in sample.

(c) Zero (0) denotes element present in sample but not detected in leach solution. 


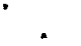

•

-

$+$ 


\section{APPENDIX C}

ANALYSIS OF VARIANCE TABLES AND PSEUDO-COEFFICIENTS FOR MODELS 
TABLE C.1. Analysis of Variance (AOV) and Pseudo-Coefficients for Log Soxhlet

Analysis of Variance (a)

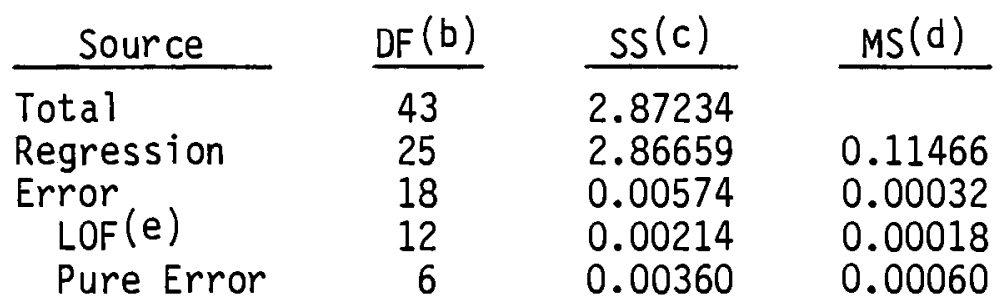

Adjusted R-Squared $=0.9952$

Lack of Fit-F $=0.30$ versus $F_{0.95}(12,6)=4.00$

\begin{tabular}{|c|c|c|}
\hline Component & $\begin{array}{c}\text { Pseudo- } \\
\text { Coefficient }\end{array}$ & $\begin{array}{l}\text { Standard } \\
\text { Error }\end{array}$ \\
\hline 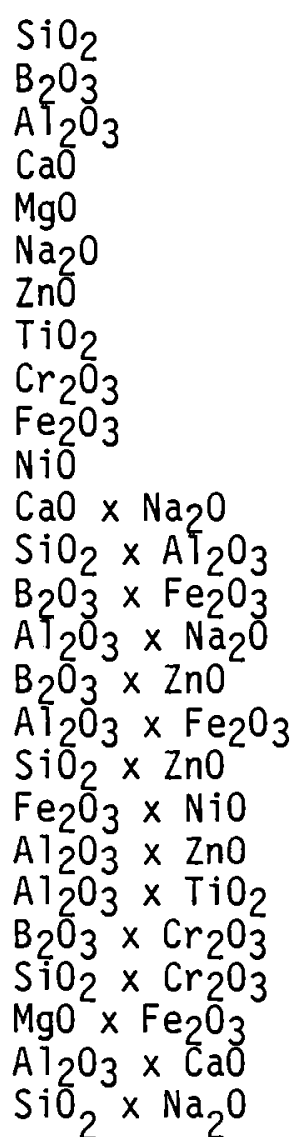 & $\begin{array}{r}1.081 \\
1.007 \\
-0.056 \\
0.591 \\
0.298 \\
0.727 \\
2.948 \\
0.388 \\
2.628 \\
-7.146 \\
-1.513 \\
-4.945 \\
-6.248 \\
18.501 \\
-3.783 \\
-15.469 \\
17.378 \\
-9.222 \\
73.993 \\
-4.178 \\
-4.111 \\
-16.033 \\
-5.959 \\
-6.651 \\
0.964 \\
1.962\end{array}$ & $\begin{array}{l}0.088 \\
0.203 \\
0.113 \\
0.125 \\
0.090 \\
0.443 \\
0.248 \\
0.115 \\
0.412 \\
0.436 \\
0.191 \\
0.929 \\
0.321 \\
2.130 \\
0.953 \\
1.090 \\
1.429 \\
0.832 \\
6.800 \\
0.614 \\
0.528 \\
2.834 \\
1.187 \\
1.687 \\
0.316 \\
0.996\end{array}$ \\
\hline
\end{tabular}

(a) AOV entries computed according to Marquardt and Snee (1974).

(b) $D F=$ degrees of freedom.

(c) $\mathrm{SS}=$ sum of squares.

(d) $M S=$ mean square.

(e) LOF = lack of fit. 
TABLE C.2. Analysis of Variance (AOV) and Pseudo-Coefficients for Log $\mathrm{pH} 4$

\begin{tabular}{|c|c|c|c|}
\hline Source & $\begin{array}{l}\text { sis of } \\
\text { DF (b) }\end{array}$ & $\begin{array}{c}\text { iance (a) } \\
\text { SS (c) }\end{array}$ & $\operatorname{MS}(d)$ \\
\hline $\begin{array}{l}\text { Total } \\
\text { Regression } \\
\text { Error } \\
\text { LOF(e) } \\
\text { Pure Error }\end{array}$ & $\begin{array}{r}43 \\
24 \\
19 \\
13 \\
6\end{array}$ & $\begin{array}{r}61.26104 \\
61.16660 \\
0.09448 \\
0.04098 \\
0.05350\end{array}$ & $\begin{array}{l}2.54861 \\
0.00497 \\
0.00315 \\
0.00892\end{array}$ \\
\hline
\end{tabular}

Adjusted R-Squared $=0.9965$

Lack of $F$ it- $F=0.35$ versus $F_{0.95}(13,6)=3.98$

\begin{tabular}{|c|c|c|}
\hline Component & $\begin{array}{c}\text { Pseudo- } \\
\text { Coefficient }\end{array}$ & $\begin{array}{l}\text { Standard } \\
\text { Error }\end{array}$ \\
\hline 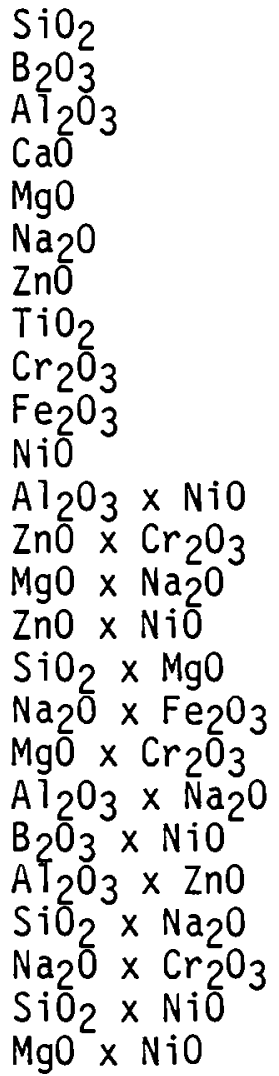 & $\begin{array}{r}-4.922 \\
2.726 \\
6.980 \\
-0.846 \\
1.829 \\
11.843 \\
-3.043 \\
-2.200 \\
-7.828 \\
-6.852 \\
19.356 \\
-134.669 \\
-92.624 \\
-91.931 \\
126.414 \\
14.941 \\
-35.770 \\
55.711 \\
-7.535 \\
40.752 \\
-8.985 \\
-10.426 \\
43.812 \\
-18.426 \\
15.572\end{array}$ & $\begin{array}{r}0.378 \\
0.373 \\
0.268 \\
0.243 \\
0.691 \\
1.343 \\
0.473 \\
0.335 \\
1.362 \\
1.263 \\
2.408 \\
5.887 \\
7.802 \\
6.330 \\
10.705 \\
1.533 \\
11.554 \\
7.107 \\
3.199 \\
8.616 \\
1.688 \\
3.005 \\
8.877 \\
5.544 \\
7.344\end{array}$ \\
\hline
\end{tabular}

(a) AOV entries computed according to Marquardt and Snee (1974).

(b) $D F=$ degrees of freedom.

(c) $\mathrm{SS}=$ sum of squares.

(d) $M S=$ mean square.

(e) LOF $=$ lack of fit. 
TABLE C.3. Analysis of Variance (AOV) and Pseudo-Coefficients for Log Viscosity Analysis of Variance (a)

\begin{tabular}{|c|c|c|c|}
\hline Source & $D F(b)$ & $S S(c)$ & $M S(d)$ \\
\hline Tota & 36 & 16.40221 & \\
\hline Regression & 14 & 16.04646 & 1.14618 \\
\hline Error & 22 & 0.35574 & 0.01617 \\
\hline LOF $(e)$ & 15 & 0.30744 & 0.02050 \\
\hline Pure Error & 7 & 0.04830 & 0.00690 \\
\hline
\end{tabular}

Adjusted R-Squared $=0.9645$

Lack of Fit-F $=2.97$ versus $F_{0.95}(15,7)=3.51$

\begin{tabular}{|c|c|c|}
\hline Component & $\begin{array}{c}\text { Pseudo- } \\
\text { Coefficient } \\
\end{array}$ & $\begin{array}{l}\text { Standard } \\
\text { Error }\end{array}$ \\
\hline $\begin{array}{l}\mathrm{SiO}_{2} \\
\mathrm{~B}_{2} \mathrm{O}_{3} \\
\mathrm{AT}_{2} \mathrm{O}_{3} \\
\mathrm{CaO} \\
\mathrm{MgO} \\
\mathrm{Na}_{2} \mathrm{O} \\
\mathrm{ZnO} \\
\mathrm{TiO}_{2} \\
\mathrm{Cr}_{2} \mathrm{O}_{3} \\
\mathrm{Fe}_{2} \mathrm{O}_{3} \\
\mathrm{NiO} \\
\mathrm{CaO} \mathrm{ZnO} \\
\mathrm{Al}_{2} \mathrm{O}_{3} \times \mathrm{MgO} \\
\mathrm{SiO}_{2} \times \mathrm{NiO} \\
\mathrm{MgO} \times \mathrm{NiO}\end{array}$ & $\begin{array}{r}4.202 \\
0.430 \\
4.865 \\
-0.855 \\
0.117 \\
-2.049 \\
-1.840 \\
1.003 \\
12.626 \\
3.693 \\
5.110 \\
16.732 \\
6.248 \\
-12.048 \\
-17.525\end{array}$ & $\begin{array}{l}0.305 \\
0.302 \\
0.219 \\
0.277 \\
0.522 \\
0.458 \\
0.757 \\
0.308 \\
0.771 \\
0.896 \\
1.667 \\
3.578 \\
2.360 \\
6.179 \\
9.135\end{array}$ \\
\hline
\end{tabular}

(a) AOV entries computed according to Marquardt and Snee (1974).

(b) $\mathrm{DF}=$ degrees of freedom.

(c) $\mathrm{SS}=$ sum of squares.

(d) $M S=$ mean square.

(e) LOF $=1$ ack of fit. 
TABLE C.4. Analysis of Variance (AOV) and Pseudo-Coefficients for Log Volatility Analysis of Variance (a)

\begin{tabular}{|c|c|c|c|}
\hline Source & $D F(b)$ & $S S(c)$ & $\operatorname{MS}(d)$ \\
\hline Tota & 43 & 5.61624 & \\
\hline Regression & 14 & 5.40037 & 0.38574 \\
\hline Error & 29 & 0.21587 & 0.00744 \\
\hline $\operatorname{LOF}(e)$ & 23 & 0.20267 & 0.00881 \\
\hline Pure Error & 6 & 0.01320 & 0.00220 \\
\hline
\end{tabular}

Adjusted R-Squared $=0.9430$

Lack of $F i t-F=4.01$ versus $F_{0.95}(23,6)=3.85$

Component

$\mathrm{SiO}_{2}$

$\mathrm{B}_{2} \mathrm{O}_{3}$

$\mathrm{CaO}$

$\mathrm{MgO}$

$\mathrm{Na} 2 \mathrm{O}$

ZnO

$\mathrm{TiO}_{2}$

$\mathrm{Cr}_{2} \mathrm{O}_{3}$

$\mathrm{Fe}_{2} \mathrm{O}_{3}$

$\mathrm{NiO}$

$\mathrm{SiO}_{2} \times \mathrm{Al}_{2} \mathrm{O}_{3}$

$\mathrm{Na}_{2} \mathrm{O} \times \mathrm{Fe}_{2} \mathrm{O}_{3}$

$\mathrm{Al}_{2} \mathrm{O}_{3} \times \mathrm{TiO}_{2}$

$\mathrm{Al}_{2} \mathrm{O}_{3} \times \mathrm{Na}_{2} \mathrm{O}$
Pseudo-

Coefficient

1.351

2.893

0.243

2.257

1.403

5.379

1.697

0.425

$-0.722$

3.377

0.443

$-4.022$

$-36.263$

3.295

$-4.444$
Standard Error

0.130

0.220

0.253

0.118

0.169

0.472

0.195

0.303

0.442

0.927

0.496

1.003

9.115

1.379

1.863

(a) AOV entries computed according to Marquardt and Snee (1974).

(b) $D F=$ degrees of freedom.

(c) $\mathrm{SS}=$ sum of squares.

(d) $M S=$ mean square.

(e) $\mathrm{LOF}=1$ ack of fit. 
TABLE C.5. Analysis of Variance (AOV) and Pseudo-Coefficients for Air-Quenched Crystallinity Analysis of Variance (a)

\begin{tabular}{|c|c|c|c|}
\hline Source & $\mathrm{DF}(\mathrm{b})$ & $S S(c)$ & $\operatorname{MS}(d)$ \\
\hline $\begin{array}{l}\text { Total } \\
\text { Regression } \\
\text { Error } \\
\text { LOF (e) } \\
\text { Pure Error }\end{array}$ & $\begin{array}{r}43 \\
22 \\
21 \\
15 \\
6\end{array}$ & $\begin{array}{r}3230.41040 \\
3218.99438 \\
11.41590 \\
9.24590 \\
2.17000\end{array}$ & $\begin{array}{r}146.31793 \\
0.54361 \\
0.61639 \\
0.36167\end{array}$ \\
\hline
\end{tabular}

Adjusted R-Squared $=0.9928$

Lack of Fit-F $=1.70$ versus $F_{0.95}(15,6)=3.94$

\begin{tabular}{|c|c|c|}
\hline Component & $\begin{array}{c}\text { Pseudo- } \\
\text { Coefficient } \\
\end{array}$ & $\begin{array}{l}\text { Standar } \\
\text { Error }\end{array}$ \\
\hline 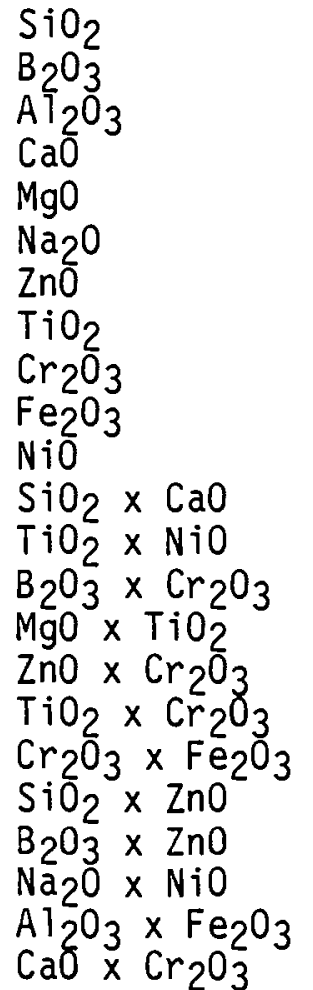 & $\begin{array}{r}-6.059 \\
-1.680 \\
14.043 \\
-24.864 \\
9.039 \\
-19.325 \\
44.198 \\
37.189 \\
66.719 \\
65.042 \\
-34.914 \\
71.982 \\
637.508 \\
830.650 \\
-276.028 \\
938.812 \\
-438.378 \\
-1252.518 \\
-139.252 \\
-122.522 \\
344.701 \\
121.324 \\
101.894\end{array}$ & $\begin{array}{r}2.106 \\
4.044 \\
1.245 \\
1.848 \\
2.468 \\
3.767 \\
5.140 \\
5.779 \\
19.244 \\
10.799 \\
11.278 \\
12.617 \\
72.314 \\
98.034 \\
32.838 \\
75.996 \\
81.100 \\
238.196 \\
21.345 \\
40.389 \\
89.512 \\
47.219 \\
45.913\end{array}$ \\
\hline
\end{tabular}

\footnotetext{
(a) AOV entries computed according to Marquardt and Snee (1974).

(b) $D F=$ degrees of freedom.

(c) $\mathrm{SS}=$ sum of squares.

(d) $M S=$ mean square.

(e) LOF = lack of fit.
} 


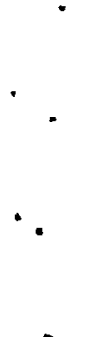




\section{DISTRIBUTION}

No. of

Copies

OFFSITE

A. A. Churm

DOE Patent Division

9800 S. Cass Avenue

Argonne, IL 60439

13 DOE Nuclear Waste Management Programs

NE30, B-107, HQ

Washington, DC 20545

ATTN: C. R. Cooley

G. H. Daly

J. E. Dieckhoner

C. H. George

C. A. Heath

M. L. Lawrence

D. J. McGoff

S. Meyers/R. Romatowski

G. Oertel

A. F. Perge

R. W. Ramsey, Jr.

D. L. Vieth

R. D. Walton

R. E. Cunningham

Office of Nuclear Safety

Materials and Safeguards

Room 562

Nuclear Regulatory Commission 7915 Eastern Avenue

Silver Springs, MD 20910

3 Division of Waste Management Nuclear Regulatory Commission Washington, DC 20555

ATTN: J. B. Martin

D. M. Rohrer

R. Dale Smith

W. E. Mott

DOE Division of Environmental Control Technology

Washington, DC 20545
No. of

Copies

S. A. Mann

DOE Chicago Operations and Region Office

Argonne, IL 60439

J. Neff

DOE Columbus Program Office

505 King Avenue

Columbus, $\mathrm{OH} 43201$

4 DOE Idaho Operations Office

550 2nd St.

Idaho Falls, ID 83401

ATTN: K. A. Carlson

J. P. Hamric

J. W. Peel

J. B. Whitsett

2 DOE Oak Ridge Operations Office

P.0. Box E

Oak Ridge, TN 37830

ATTN: S. W. Ahrends

D. Large

3 DOE Savannah River Operations Office

P.0. Box A

Aiken, SC 29801

ATTN: E. S. Goldberg

T. B. Hindman

R. P. Whitfield

S. G. Harbinson

DOE San Francisco Operations

1333 Broadway

Oakland, CA 94612

2 DOE Albuquerque Operations Office

P.0. Box 5400

Albuquerque, NM 87185

ATTN: R. Y. Lowrey

A. L. Taboas 
No. of

Copies

27 DOE Technical Information Center

Oak Ridge National Laboratory

ATTN: R. E. Blanco

P.0. BoX Y

Oak Ridge, TN 37830

Los Alamos Scientific Laboratory

P.0. Box 1663

Los Alamos, NM 87544

Exxon Nuclear Idaho

ATTN: G. L. Ritter

P.0. Box 2800

Idaho Falls, ID 83401

Allied-General Nuclear Services

P.0. Box 847

Barnwe 11, SC 29812

ATTN: J. A. Buckham

2 Argonne National Laboratory

9700 South Cass Avenue

Argonne, IL 60439

ATTN: J. H. Kittel

M. J. Steindler/

L. E. Trevorrow

3 Battelle Memorial Institute

Office of Nuclear Waste

Isolation

505 King Avenue

Columbus, $\mathrm{OH} 43201$

ATTN: A. Brandstetter

N. E. Carter

Beverly Rawles

3 Rockwell International

Rocky Flats Plant

P.0. Box 464

Golden, CO 80401

ATTN: W. S. Bennett

Lawrence J. Smith

E. Vejvoda
No. of

Copies

A. B. Martin

Rockwell International

8900 DeSoto Avenue

Canoga Park, CA 91304

8 E. I. du Pont de Nemours and Co. Savannah River Laboratory

Aiken, SC 29801

ATTN: M. D. Boersma

J. L. Crandall

R. G. Garvin

D. E. Gordon

J. A. Kelley

G. Wicks

A. S. Jennings

M. J. Plodinec

R. Williams

Electric Power Research

Institute

3412 Hillview Avenue

P.0. Box 10412

Palo Alto, CA 94304

Environmental Protection Agency

Technological Assessment Division (AW-559)

Office of Radiation Programs

U.S. Environmental Protection Agency

Washington, DC 20460

C. J. Kershner

Monsanto Research Corporation

Mound Laboratory

P.0. Box 32

Miamisburg, OH 45342

J. P. Duckworth

Plant Manager

Nuclear Fuels Services, Inc.

P.0. Box 124

West Valley, NY 14171 
No. of

Copies

S. Lane

Brookhaven National Laboratory

B 1dg. 830

Upton, NY 11973

J. D. Tewhey

Lawrence Livermore Laboratory

P.0. Box 808

Livermore, CA 94550

3 Sandia Laboratories

Albuquerque, NM 87185

ATTN: D. R. Anderson

0 . E. Jones

R. G. Kepler

J. W. Bartlett

The Analytical Sciences Corp.

6 Jacob Way

Reading, MA 01867

R. G. Post

College of Engineering

University of Arizona

Tucson, $A Z 85721$

L. L. Hench

Dept. of Materials Science and Engineering

University of Florida

Gainesville, FL 32611

H. Palmour, III

2140 Burlington Engineering Laboratories

North Carolina State University Raleigh, NC 27607

W. Tope

Westinghouse Electric Corporation

Penn Center, Bldg. 2

Box 355

Pittsburgh, PA 15230
No. of

Copies

R. Roy

202 Materials Research Laboratory

University Park, PA 16802

John Pomeroy

Technical Secretary

National Academy of Sciences

Committee of Radioactive Waste

Management

National Research Council

2101 Constitution Avenue

Washington, DC 20418

J. R. Berreth

Allied Chemical Corporation

550 Second Street

Idaho Falls, ID 83401

Rod Ewing

University of New Mexico

Albuquerque, NM 87131

D. J. Hotaling

Penberthy Electromelt International, Inc.

631 South 96 Street

Seattle, WA 98108

L. Penberthy

Penberthy Electromelt Internationa 1, Inc.

631 South 96 Street

Seattle, WA 98108

ONSITE

8 DOE Richland Operations Office

E. A. Bracken

P. A. Craig

0. J. Elgert

R. E. Gerton

H. E. Ransom

J. J. Schreiber

M. W. Shupe

M. J. Zamorski 
No. of

Copies

8 Rockwe 11 Hanford Operations

L. C. Brown

R. A. Deju

D. R. Gustavson

B. A. Higley

M. J. Kupfer

I. E. Reep

D. D. Wodrich

United Nuclear Industries

T. E. Dabrowski

Westinghouse Hanford Company

A. G. Blasewitz

78 Pacific Northwest Laboratory

W. J. Bjork lund

H. T. Blair

W. F. Bonner

C. Q. Buckwalter

L. A. Chick (20)

T. D. Chikalla

S. K. Edler
No. of

Copies

W. J. Gray (5)

D. L. Hall

C. R. Hann

M. S. Hanson

O. F. Hill

J. H. Jarrett

D. E. Knowlton

L. T. Lakey

D. E. Larson

J. A. Mahaffey

R. P. Marsha 11

R. P. May (5)

J. L. MCE lroy

G. L. McVay

G. B. Mellinger

J. E. Mendel

R. D. Nelson

R. E. Nightingale

G. F. Piepel (10)

A. M. Platt

W. A. Ross

J. M. Rusin

R. J. Serne

R. P. Turcotte

Technical Information (5)

Publishing Coordination yo(2) 